NBER WORKING PAPER SERIES

\title{
SAVING TEENS: USING A POLICY DISCONTINUITY TO ESTIMATE THE EFFECTS OF MEDICAID ELIGIBILITY
}

\author{
Bruce D. Meyer \\ Laura R. Wherry \\ Working Paper 18309 \\ http://www.nber.org/papers/w18309 \\ NATIONAL BUREAU OF ECONOMIC RESEARCH \\ 1050 Massachusetts Avenue \\ Cambridge, MA 02138
}

August 2012

This work was supported by the National Institute for Child Health and Human Development. We would like to thank Andrew Goodman-Bacon, Miriam Kalichman, Genevieve Kenney, Lindsey Leininger, Tony Lo Sasso, Karin Rhodes and participants at seminars at the Georgia Institute of Technology, the 2011 Census Research Data Center Conference, Purdue University, Syracuse University, University of Michigan and the Midwest Health Economics Conference for their comments and Negasi Beyene, Clint Carter, Karen Davis and Frank Limehouse for their assistance in accessing the restricted data used in this project at the Chicago and Michigan Census Research Data Centers. Laura Wherry acknowledges funding support from the Agency for Health Care Research and Quality National Training Fellowship in Health Services Research and the Robert Wood Johnson Foundation Health \& Society Scholars program. The views expressed herein are those of the authors and do not necessarily reflect the views of the National Bureau of Economic Research.

NBER working papers are circulated for discussion and comment purposes. They have not been peerreviewed or been subject to the review by the NBER Board of Directors that accompanies official NBER publications.

(C) 2012 by Bruce D. Meyer and Laura R. Wherry. All rights reserved. Short sections of text, not to exceed two paragraphs, may be quoted without explicit permission provided that full credit, including (C) notice, is given to the source. 
Saving Teens: Using a Policy Discontinuity to Estimate the Effects of Medicaid Eligibility Bruce D. Meyer and Laura R. Wherry

NBER Working Paper No. 18309

August 2012, Revised January 2013

JEL No. I13,I14

\begin{abstract}
$\underline{\text { ABSTRACT }}$
This paper uses a policy discontinuity to identify the immediate and long-term effects of public health insurance coverage during childhood. Our identification strategy exploits a unique feature of several early Medicaid expansions that extended eligibility only to children born after September 30, 1983. This feature resulted in a large discontinuity in the lifetime years of Medicaid eligibility of children at this birthdate cutoff. Those with family incomes at or just below the poverty line had close to five more years of eligibility if they were born just after the cutoff than if they were born just before. We use this discontinuity in eligibility to measure the impact of public health insurance on mortality by following cohorts of children born on either side of this cutoff from childhood through early adulthood. We examine changes in rates of mortality by the underlying causes of death, distinguishing between deaths due to internal and external causes. We also examine outcomes separately for black and white children. Our analysis shows that black children were more likely to be affected by the Medicaid expansions and gained twice the amount of eligibility as white children. We find a substantial effect of public eligibility during childhood on the later life mortality of black children at ages 15-18. The estimates indicate a 13-20 percent decrease in the internal mortality rate of black teens born after September 30, 1983. We find no evidence of an improvement in the mortality of white children under the expansions.
\end{abstract}

Bruce D. Meyer

Harris School of Public Policy

University of Chicago

1155 E. 60th Street

Chicago, IL 60637

and NBER

bdmeyer@uchicago.edu

Laura R. Wherry

Harris School of Public Policy

University of Chicago

1155 E. 60th Street

Chicago, IL 60637

1wherry@uchicago.edu 


\section{Introduction}

Interest in public health insurance in the U.S. is motivated by the relatively poor health of children in families with low incomes. Not only are children from poorer families more likely to be born in poor health, but the relative health of these children worsens with age (Case, et al. 2002). To address this disparity in child health, U.S. policy has largely focused on increasing access to medical care for children through expansions in publicly provided health insurance. ${ }^{1}$ These expansions aim to promote health among children by providing timely access to child health services that meet national standards for pediatric care. A major focus is preventive care and the early diagnosis and treatment of the physical and mental health needs of low-income children.

There is strong evidence that public coverage improves utilization of medical care for children. Several papers have documented an increase in preventive care for children under public health insurance expansions in the form of an annual doctor visit, including Card and Shore-Sheppard (2004), Currie and Gruber (1996a), and Currie, et al. (2008). In addition, other papers have found an increase in hospital use (see Currie and Gruber 1996a, Dafny and Gruber 2005).

There is also some evidence that this increase in utilization translates into improved immediate health outcomes for children, but as Howell and Kenney (2012) emphasize the evidence is much more limited. ${ }^{2}$ In a widely cited paper, Currie and Gruber (1996a) find that increased Medicaid eligibility is correlated with a decline in

\footnotetext{
${ }^{1}$ A series of expansions of the Medicaid program beginning in 1984, and later expansions under the State Children's Health Insurance Program (SCHIP), are estimated to have more than doubled the share of children eligible for public health insurance from 17.8 percent in 1987 (Cutler and Gruber 1996) to 41.7 percent in 2000 (Lo Sasso and Buchmueller 2004).

${ }^{2}$ Although not discussed here, improvements in birth outcomes under expansions in pregnancy-related coverage have also been documented (see Currie and Gruber 1996b).
} 
child deaths where the underlying cause of death reflects disease, or other conditions likely to be influenced by medical care. Finding no effect on deaths due to other (external) causes, such as accidents or homicides, their results suggest an improvement in child health achieved through improved access to care. ${ }^{3}$ A recent paper by Howell et al. (2010) finds additional evidence of a decline in child mortality associated with expanded public insurance, although their findings indicate a decline in external-cause mortality. The authors cite anticipatory guidance, improved access to mental health services, and timely medical care in the incidence of accident or injury as potential mechanisms behind this improvement.

There is little evidence regarding the effect of public health insurance during childhood on later life health. From a program evaluation standpoint, the effect of public coverage on the long-term health of children is an important component of program benefits. Many preventive services are designed to protect healthy children from future disease or risks, such as immunizations and health education. Physician monitoring and screenings during childhood may identify and target precursors for later health problems such as cardiovascular disease. The payoffs from these types of interventions might not be evident until later in life. For those children with mental and physical disabilities or chronic illness, early diagnosis and treatment may help the management of these conditions or limit their persistence into adulthood. Medical care may also have a

\footnotetext{
${ }^{3}$ A number of studies using more subjective health measures, including parental reports of child health status and restricted activity days, find little effect of improvement under public health insurance (Currie and Gruber 1995, Racine, et al. 2001, Currie, et al. 2008).
} 
positive impact through counseling regarding behavior risks and linking children to helpful social services. ${ }^{4}$

This paper provides new evidence on the role of public health insurance coverage during childhood on both immediate and long-term health. Our identification strategy exploits a unique feature of several early Medicaid expansions that extended eligibility only to children born after September 30, 1983. A path-breaking study by Card and Shore-Sheppard (2004) identified and used this policy discontinuity to examine the takeup of public health insurance and the crowdout of private insurance under these expansions. The authors estimate an 8 percent Medicaid takeup rate among newly eligible children born after this birthdate cutoff. They find that the expansions resulted in an overall increase in health insurance coverage with little evidence of crowd-out. The authors also provide evidence that this new Medicaid coverage led to a large increase in the utilization of medical care. Their estimates suggest that children with new coverage were 60 percent more likely to have at least one doctor visit within the last year.

Building on this earlier work, we show that the early Medicaid expansion rules led to a large cumulative difference in public eligibility for children born before and after September 30, 1983. Children in families with incomes at or just below the poverty line gained close to five additional years of eligibility if they were born in October 1983 rather than just one month before. We use regression discontinuity and difference in difference methods to examine outcomes for cohorts of children born just before and after the birthdate cutoff to identify the impact of this additional public coverage during childhood.

\footnotetext{
${ }^{4}$ The standard economic argument is also applicable that providing free medical care may free up resources for making other investments with long term impacts.
} 
Importantly, this research design allows us to examine the impact of childhood coverage later in life by following these cohorts of children into early adulthood. The discontinuity in insurance coverage under the expansions occurred between the ages of 8 and 14. In addition to studying the immediate impact of coverage at these ages, we follow these cohorts through age 18 to observe any long-term impacts on health. We also provide some early evidence on impacts through age 22. Most previous studies of the Medicaid expansions have only considered contemporaneous impacts on child health.

Two existing studies have considered the long-term effect of public health insurance for children. Using variation in eligibility across states, Currie et al. (2008) find some evidence to suggest improvements in adolescent health resulting from past eligibility. The authors regress parent-reported health status for children of ages 9 to 17 on the fraction of children who were eligible in the child's birth cohort and current state of residence for a given year of age between 0 and $8 .{ }^{5}$ They find that more generous coverage at ages 2, 3, and 4 is associated with better health status for older children.

De la Mata (2012) also examines longer-term effects of public eligibility using a regression discontinuity design that compares children in families with incomes just above and below the income eligibility thresholds for public health insurance. In addition to looking at changes in contemporaneous health, she examines whether eligibility for a child age 5-18 in a given year leads to health improvements after 1 or 5 years have passed. Using health status, obesity, and the number of school days missed due to illness as outcome measures, she finds no evidence of significant effects on health in the immediate or longer-term.

\footnotetext{
${ }^{5}$ Citing collinearity between eligibility at various ages, they run a separate regression with eligibility at each age. In general, regressions of outcomes on eligibility at a single year of age will give coefficient estimates that reflect the correlation of eligibility at other ages with eligibility in that given year of age.
} 
In general, very little is known about the potential long-term effects of health insurance coverage on health (Cutler and Zeckhauser 2000). The RAND Health Insurance Experiment examined the health of children at entry and exit during its 3- and 5-year periods of study. Researchers found no significant differences in health measures for children in families randomly assigned to health insurance plans providing medical care free of charge and those requiring some form of co-payment, despite reduced demand for ambulatory care for children in families enrolled in the cost-sharing plans (Valdez et al. 1985). ${ }^{6}$

The main focus of this paper is measuring the effects of childhood Medicaid eligibility on immediate and long-term mortality. We focus on mortality as our health measure because it is accurately measured and higher values are unambiguously bad. We considered other outcomes such as doctor visits and hospitalizations, but power calculations suggested that the effects would need to be quite large to be detectible with available data. In addition, the direction of any changes in these outcomes is not as clearly predicted a priori and not obviously good or bad for health.

Following Currie and Gruber (1996a), we examine rates of mortality by the underlying causes of death distinguishing between deaths due to internal and external causes. Because we are using national-level data in our analysis, we also examine outcomes for subsamples that are more likely to be affected by the change in Medicaid policy. We estimate models separately for black and white children, and also split our sample into states with a high or low gain in years of public eligibility for children at the September 30, 1983 cutoff.

\footnotetext{
${ }^{6}$ Some gains in health were observed among poor adults with existing chronic health problems, while individuals between the ages 12 and 35 on the free-care plan showed some improvement in dental health (Manning et al. 1987).
} 
This paper is structured as follows: Section II provides some background on the Medicaid expansions used in our estimation and the resulting discontinuity in childhood eligibility for children born around the September 30, 1983 birthdate cutoff. Section III reviews our research design and empirical specifications. Section IV describes the data we use in our analysis while Section V presents our mortality results. Section VI compares our results to past work and estimates the cost per life saved. Section VII concludes with a summary of our findings and their applicability to public policy.

\section{The Discontinuity in Eligibility}

Medicaid is a joint federal-state program that provides health services to certain low-income beneficiaries. Since 1967, the program has included a special benefit package for children designed to provide comprehensive health coverage including preventive care. This benefit package provides all Medicaid children with early and periodic screenings for physical, mental and developmental health; vision, dental and hearing examinations and follow-up care; and all health services they are found to need.

Historically not all children in poor families were eligible for Medicaid coverage. Eligibility for non-disabled children was previously linked to participation in the Aid to Families with Dependent Children (AFDC) program. Beginning in 1984, a series of Congressional acts expanded eligibility for Medicaid to children who were not traditionally eligible for AFDC, often with income levels above AFDC cutoffs. To phase in the Medicaid expansions, many of the legislative changes were applied only to children born after September 30, 1983 (see Table 1). This legislative provision meant that children born in October 1983 faced more generous eligibility criteria for the 
Medicaid program than children born just one month earlier in September 1983. The result of this provision was a large discontinuity in the number of childhood years of Medicaid eligibility for children born around this birthdate cutoff.

To illustrate the discontinuity, we model childhood public eligibility for cohorts born between 1980 and 1987. Using detailed federal and state eligibility rules for the years 1980 to 2005, our simulation program uses information on state of residence, family structure and size, parent employment, and family income to calculate monthly public eligibility status through age $17 .^{7}$ To obtain a nationally representative sample of these characteristics of children and families, we employ data from the March Supplements to the Current Population Survey (CPS). We use a random sample of 500 children of ages 0-17 from each year of the 1981-1988 CPS and estimate the childhood eligibility for this pooled sample for each birth month between January 1980 and December $1987 .{ }^{8}$ This simulation holds family characteristics constant over the child's lifetime. $^{9}$

Figure 1 shows the results of our simulation for children in families with income below 150 percent of poverty, those most likely to be affected by the change in Medicaid eligibility rules. This graph depicts the average total number of years of public eligibility during childhood by birth month cohort. Each line on the graph represents an income bracket. For all income brackets, we see a gradual increase in childhood eligibility across

\footnotetext{
${ }^{7}$ For the years prior to welfare reform, we estimate eligibility for Medicaid under AFDC, state Ribicoff rules, and federal and state Medicaid expansions. For 1997 forward, eligibility is estimated under the postwelfare reform eligibility rules for Medicaid, as well as under continuing state Medicaid expansions and new separate state programs funded by SCHIP.

${ }^{8}$ We use the 1981-1988 CPS surveys because the information collected on income is for the previous calendar year.

${ }^{9}$ This convention may understate eligibility during early childhood and overstate eligibility during the later years of childhood if family income grows with child age and is not counterbalanced by changes in family size that alter the poverty thresholds to which income is compared.
} 
birth cohorts prior to a jump in years of eligibility for children born in October 1983.

Children born in October 1983 are the first cohort of children to be eligible for the Medicaid expansions with the September 30, 1983 birthdate cutoff. Following this jump, we again see a gradual increase in childhood eligibility for the remaining birth cohorts. ${ }^{10}$

The magnitude of the discontinuity in childhood eligibility at the September 30, 1983 cutoff varies by family income. Figure 2 presents the size of the discontinuity as captured by the average difference in years of eligibility for a child born in October versus September 1983 by income group. The largest jump in years of eligibility occurs among children with family incomes above AFDC eligibility levels but below poverty. Children in families with incomes just below poverty see the largest gain with an additional 4.7 years of eligibility during childhood, while those with incomes between 50 to 74 percent of poverty see a gain of 3.9 years. We see a smaller discontinuity in childhood eligibility among children in families with incomes at or below AFDC levels, around 50 percent of poverty. This is unsurprising since many of these children were already eligible for Medicaid under AFDC before the expansions. Finally, we also see a very small discontinuity among children in families with incomes above poverty.

Across all family income groups, the main legislative source behind the jump in eligibility is the implementation of the Omnibus Reconciliation Act of 1990 (OBRA90). ${ }^{11}$ Effective July 1, 1991, OBRA90 mandated state coverage to children under age 19 born after September 30, 1983 with family incomes below poverty. Children born in October 1983 were almost 8 years of age when this change was implemented. To illustrate the

\footnotetext{
${ }^{10}$ Much of this gradual increase is due to a larger share of each successive cohort's life occurring when younger children were Medicaid eligible under various age cutoffs rather than a gradual change in rules.

${ }^{11}$ We estimate that OBRA accounts for 92 percent of the 4.7 year gain in eligibility for children with incomes between 75 and 100 percent of poverty and 89 percent of the 3.9 year gain for children with incomes between 50 and 75 percent of poverty. See Appendix Table 1.
} 
timing of the gain in eligibility, Figure 3 compares the share of children eligible for public health insurance if born in October versus September 1983 by each year of age. Corresponding to the introduction of OBRA90, we see a sizeable jump in the share of October-born children with eligibility at age 8 . Faced with new and more generous eligibility criteria, this cohort remains more likely to be eligible for public health insurance until the introduction of the State Children's Health Insurance Program (SCHIP) in August 1997. Authorized by the Balanced Budget Act, SCHIP allowed states to expand eligibility for public health insurance to children of higher incomes, regardless of the child's month of birth, under existing state Medicaid programs or new state programs. These expansions were quickly adopted by states and served to close any discontinuity in eligibility by age 15 .

We distinguish between three different age ranges in our analysis. Ages 4 to 7 captures a period prior to the implementation of OBRA90 where differences in eligibility at the birthdate threshold are small. Our analysis of this period serves to establish a baseline difference in health for children at the cutoff. We do not expect to find any discontinuity in health for this age group.

Next we examine children at ages 8 to 14 . Children who benefitted from the expansions primarily gained eligibility during this age range, as shown in Figure 3. We interpret any discontinuity in health observed during this period as an immediate effect of public health insurance coverage, similar to the existing estimates using cross-sectional data in the literature (e.g., Currie and Gruber 1996a). However, any difference in health observed in our estimates may also be due to a cumulative gain in exposure to health insurance coverage over the period. For instance, a child at age 14 born in October 1983 
may have gained Medicaid coverage for the five years prior, beginning at age 8 . There is little research that has examined the effect of multi-year coverage on health care access or outcomes for children. $^{12}$

Finally, we examine children at ages 15 to 18, the period following the gain in public eligibility. Although equally as likely to have public eligibility during this age range, children born in October 1983 received an average of 0.43 years of additional health insurance during their 8-14 years when compared to children born one month earlier (see Table 3). We already showed that for children with incomes just below poverty, the average difference in eligibility was 4.7 years. By examining this older age group, we are able to consider the longer-term effects of childhood coverage as these cohorts enter adulthood.

We also examine differential effects of the expansions by the race and state of residence of the child. Black children in the U.S. are more likely to be in low-income families and without health insurance than white children. At the time of the Medicaid expansions, black children were nearly three times as likely to be in poverty as white children. Therefore, we may see a larger impact of the expansions among black children. The gain in Medicaid eligibility for children born after September 30, 1983 will also vary across states due to differences in Medicaid policies before and after the expansions. States had different eligibility criteria in place prior to the expansions depending on statedetermined AFDC program rules and optional eligibility programs. In addition, state decisions regarding optional Medicaid and SCHIP expansions varied in terms of timing

\footnotetext{
${ }^{12}$ One exception, Cassedy, et al. (2008) show that children with any gap in insurance coverage over a twoyear period have higher odds of lacking a usual source of care and not having well-care visits than those with continuous insurance coverage, regardless of whether that continuous coverage was public or private. This is also a substantial literature finding that continuous coverage during a year is associated with better access to care (see Leininger 2009 for evidence and cites to the literature).
} 
and child age and family incomes covered. We should emphasize that this source of variation in Medicaid eligibility across states is not as clearly exogenous as birthdate. States with improving child mortality may be less likely to expand coverage, for example. However, this type of variation is the main source of identifying variation that has been used in the literature on Medicaid expansions.

To compare the eligibility gains by child race and state of residence, we use a sample that draws a maximum of 500 children ages 0-17 from each race (black, white, other) and state cell from the pooled 1981-1988 CPS years, giving us 50,874 child observations. Holding family characteristics constant, we estimate eligibility for each child for each year during childhood by calculating eligibility in July of the appropriate calendar year. We use these estimates to calculate the average gain in years of eligibility at the September 30, 1983 cutoff by child race. ${ }^{13}$

To estimate the eligibility gain for each state that resulted from legislative variation in Medicaid policy, we follow the literature and use a simulated eligibility measure constructed using the national sample of children. We estimate the average eligibility gain for the national sample given the rules in each state and, in this way, capture variation due to legislative differences rather than demographic differences across states. Ranking the state average estimates, we divide states into a "high" eligibility and a "low" eligibility group that each represent approximately half of the total child population. The high eligibility group includes the states with the largest average gain in years of eligibility while the low eligibility group includes the states with the smallest

\footnotetext{
${ }^{13}$ In calculating all averages that we report in the text and in tables, we multiply the CPS-provided survey weights by an adjustment factor specific to each cell in order to account for the manner in which we constructed our sample. This factor is calculated as the inverse of the ratio of the sum of the survey weights of individuals in the cell in our sample and the sum of the survey weights of individuals in the cell in the CPS.
} 
average gain in years of eligibility. We use this method to identify the high and low eligibility gain states for children of each race, in addition to the identification for all children. Table 2 gives the ranking of states by their gain in eligibility for all children. ${ }^{14}$ Table 3 presents summary characteristics for children in each of the state groups in 1983 prior to the first Medicaid eligibility expansions. Children in the high eligibility gain states were less likely to be eligible for AFDC or Medicaid than children in the low eligibility gain states, despite similar shares of children with family incomes below the poverty level. This indicates that more children stood to gain from the Medicaid eligibility expansions in the high eligibility gain states because pre-expansion eligibility levels for Medicaid were lower.

Table 4 reports the estimated discontinuity in childhood eligibility at the September 30, 1983 cutoff separately by race and state group. Looking across all states, black children, on average, gain 2 times the average years of eligibility gained by white children. Figure 4 gives additional insight into the nature of the gain in eligibility specific to each racial group. Although the gain is concentrated during the 8 to 14 -age range, a much larger share of black children are affected by the expansion in eligibility. Meanwhile, Table 3 shows that children residing in high eligibility gain states receive 5 times the average number of additional years of coverage of those in low eligibility gain states.

\footnotetext{
${ }^{14}$ Appendix Table 2 reports the state groupings for each racial group.
} 


\section{The Research Designs}

\section{Regression Discontinuity Methods}

Our research design uses comparisons across the September 30, 1983 birthdate cutoff to measure the impact of Medicaid eligibility on health outcomes. Since factors other than date of birth determine childhood eligibility for public health insurance, such as childhood family income, this is an example of a "fuzzy" RD design. Birth cohort is defined in our sample using the month and year of birth for cohorts born between 1980 and 1987. We denote birth cohorts using the integer values $c \in[-45,50]$, where $c=0$ for the birth cohort October 1983, the first cohort born after the cutoff date September 30, 1983. Our main analysis is based on a regression discontinuity (RD) model of the form

$$
\text { (1) } y_{c a}=\alpha+f(\gamma ; c)+\beta 1(c \geq 0)+\delta_{a} A_{a}+\delta_{m} M_{c}+\delta_{t} Y_{t}+\varepsilon_{c a}
$$

where $y_{c a}$ represents mortality or another health-related outcome for cohort $c$ at age $a$, $f(\cdot)$ is a smooth function of birth month cohort with parameter vector $\gamma$, and $1(c \geq 0)$ is an indicator for whether the cohort was born after September 30, 1983. Control variables included in our regression are age dummies $A_{a}$, calendar year dummies $Y_{t}$ (where $\mathrm{t}$ is a function of $\mathrm{c}$ and a), and month of birth dummies $M_{c}$. We may interpret $\beta$ as the effect of the eligibility expansions averaged across the full sample of children at the cutoff. ${ }^{15}$

The central question for implementation is how to model the function of birth month cohort $f(\cdot)$. We present estimates of the treatment effect $\beta$ using both linear and quadratic specifications of the regression function. We also report estimates where we allow the parameter vector $\gamma$ of these specifications to differ on both sides of the

\footnotetext{
${ }^{15}$ In other words, we estimate the proportion eligible times an intent-to-treat parameter.
} 
birthdate cutoff (i.e. linear and quadratic splines). All regressions are estimated using OLS.

As described above, we estimate equation (1) separately for each of the following three age groups: 4-7, 8-14, and 15-18. All graphical representations plot the means of the outcome variable for each birth cohort at each of the three age groups. The lines are fitted values from a regression that includes a second-order polynomial in birth cohort and a dummy variable for children born after September 30, 1983. In our regression results, heteroskedasticity-robust standard errors are clustered by birth month cohort to account for our grouping of narrow age ranges into broader ones as we describe below. ${ }^{16}$

\section{Differences, and Differences in Differences}

The regression discontinuity approach allows us to examine how mortality changes precisely at the date of the eligibility discontinuity. As a consequence it puts a great deal of weight on a small number of data points. As a check on the results, we also present simple differences that compare the mortality of children born over the twelve months prior to the September 30, 1983 cutoff to that of children born over the following twelve months. Particularly when we examine rare outcomes such as narrow causes of death, the reliance on data for the full year before seems to be a better balancing of bias and precision. Finally, when the underlying trends in mortality are similar across race groups, we sometimes compare the magnitude of the estimated differences for the twelve month before and after the cutoff for black and white children.

\footnotetext{
${ }^{16}$ Clustering on each value of the discrete assignment variable can also account for uncertainty in the choice of the functional form, as shown by Lee and Card (2008). Their model of deviations from the true regression function (i.e. "specification errors") introduces a common component to the variance term for each value of the assignment variable provided that the specification errors on either side of the discontinuity are the same.
} 


\section{Outcomes and Data}

Our empirical analysis requires data on child health or the utilization of medical care with information on child birthdate. The main focus of this paper is measuring the effects of childhood Medicaid eligibility on immediate and long-term mortality. We initially considered using a broader range of outcome measures in our analysis. These measures included doctor visits, hospitalizations, and the incidence of certain reportable diseases. We considered the presence of at least an annual visit to the doctor as reported in the National Health Interview Survey. We also considered the incidence of hospitalizations, particularly avoidable hospitalizations, sometimes referred to as those due to ambulatory care sensitive (ACS) conditions, as reported in the National Hospital Discharge Survey.

Two issues, however, pointed us toward a focus on mortality. First, we conducted extensive power analyses that suggested that reasonably large effects of Medicaid eligibility on other outcomes might be hard to detect with the available data sources. Second, for some of these outcomes such as hospitalizations, the interpretation of changes in rates is unclear. Higher rates of contact with a medical provider do not unambiguously mean that children are healthier. The availability of public health insurance may lead to an increase in access that could even increase the rate of hospitalizations that are commonly classified as avoidable. ${ }^{17}$

Our analysis uses mortality data records for all deaths in the United States. We focus on this measure of the success of health insurance because mortality is precisely

\footnotetext{
${ }^{17}$ In their analysis of expansions in public health insurance on child hospitalizations, Dafny and Gruber (2005) find an increase in avoidable hospitalizations but it is not statistically significant. They find a larger and significant increase in unavoidable hospitalizations under the expansions.
} 
measured, it is very likely to be recorded even for those without access to health care, and higher values are unambiguously bad. Previous path-breaking research has found an impact of public eligibility on child mortality at young ages (Currie and Gruber 1996a).

Mortality is also an outcome for which we might potentially see long-term impacts of health insurance coverage for children. Figure 5 shows the age profile of rates of mortality due to internal and external underlying causes for children in their first year of life through age 19 in the year preceding the Medicaid expansions. For both types of death, the relationship with child age takes on a U-shape, though it is much less pronounced for internal causes. Children face lower mortality rates during the middle childhood years and higher rates of death in early and late childhood. Given this relationship, the gain in health insurance coverage during the middle childhood years and its impact on health might be more apparent during the later childhood years when mortality is higher.

We construct aggregate mortality outcomes using information from the National Vital Statistics System (NVSS) Multiple Cause of Death files for the years 1980 to 2006 and NVSS Birth Data files for the years 1980 to 1987. To take maximum advantage of the discontinuity in childhood eligibility by birth cohort, we construct cohort-specific death rates, where cohort is defined as the month and year of birth. While the date of birth of the decedent is excluded from the publicly available mortality files, we are able to access this restricted information at the Chicago Census Research Data Center. Necessarily, we drop all observations from the mortality data with missing information on child birthdate. The average share of child observations with missing birthdate information for each year of mortality data is about 2 percent. We also exclude those 
observations where the birth year information contradicts the reported age of the child. ${ }^{18}$ In addition, we use only those observations of children born in the U.S. with residence in the 50 U.S. states and the District of Columbia, excluding any residents of U.S. territories or foreign residents. ${ }^{19}$

For our outcome measure, we construct the rate of death $R_{c a}$ for each of the 96 monthly birth cohorts in our sample for the following age groupings: 4-5, 6-7, 8-10, 11 $12,13-14,15-16$, and $17-18$. We tally the total number of deaths $D_{c a}$ for each birth cohort $c$ at specified years of age $a$. We then divide this number by the total population at risk, calculated as the total population of births for each birth cohort $N_{c}$ minus the total number of deaths for all ages prior to age $a .^{20}$ We express all final rates as the number of deaths per 10,000 children in each birth cohort.

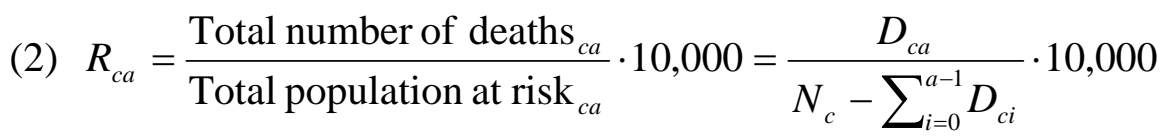

In addition to examining mortality among all children, we also focus our analysis on subpopulations that were more likely to benefit from the Medicaid expansions. Specifically, we examine outcomes by child race and state of residence. As shown earlier, black children gained on average twice the length of coverage as white children. Meanwhile, children in states with a "high eligibility gain” saw an increase in coverage that averaged six times that of children in low eligibility gain states.

\footnotetext{
${ }^{18}$ The average share of child observations with conflicting responses for birth year and age for each year of mortality data is approximately 0.09 percent.

19 The exclusion of foreign-born observations reduces our sample of mortality records by 10,232 out of 157,244 cases, or 7 percent. This count includes observations for whom place of birth was reported to be unknown.

${ }^{20}$ The NVSS Birth Data files for 1980-1984 offer only a 50\% random sample of births for a handful of states, stratified by month of birth and county of occurrence. For each of these states and years, we double the number of births for each birth cohort to approximate the universe. We make this adjustment for the following states and years: AZ, CA, DE, GA, and DC in 1980-1984, ND in 1980-1982, and NM in 19801981.
} 
We also examine the underlying cause of death for children and distinguish between internal and external causes of death, which we classify according to the medical code reported on the death certificate. For the years 1999-2006, the cause of death is reported according to the Tenth Revision of the International Classification of Diseases (ICD-10), while the Ninth Revision (ICD-9) is used for the 1980-1998 years. We follow the definition of external causes of mortality presented under both classifications, and classify all other causes of death as internal. ${ }^{21}$

Table 5 presents the average rates of death for cohorts born prior to September 30, 1983 in our sample by race, age and state group. Mortality is much higher among older children across all groups with mortality rates for 15-18 year-olds more than twice as high as those of children of ages 4-7. Although deaths due to internal causes are more common among older children, it is the frequency of deaths due to external causes that drives most of the increase in total mortality for this age group. Black children have higher rates of mortality than white children across all age and state groups. For the most part, mortality rates are higher in the high eligibility gain states compared to the low eligibility gain states. This suggests that the largest Medicaid expansions occurred in the states that had children with poorer baseline health.

Finally, we examine more narrow classifications of the underlying causes of death. For internal causes, we code subcategories following the chapter structure of the ICD-10. ${ }^{22}$ We code subcategories for external causes following the groupings in a

\footnotetext{
${ }^{21}$ The ICD-10 and ICD-9 differ in several respects including in the classification structures and rules for coding of deaths. These changes may result in a slight definitional change between the revisions but the inclusion of year dummies in our regression specifications should control for this change.

${ }^{22}$ There are 18 chapters of internal causes in the ICD-10. Since deaths falling under a handful of chapters are extremely rare among children, we chose the 11 chapters with the highest number of deaths in our sample and grouped the remaining 7 chapters into an "other" category for a total of 12 categories.
} 
tabulation list developed by the National Center for Health Statistics for use with mortality data classified by ICD-10. ${ }^{23}$ To aid in constructing comparable measures over time, we draw on the assignment of ICD-9 codes to the ICD-10 tabulation list presented in Anderson et al. (2001). ${ }^{24}$

Table 6 gives the average rates of death under each subcategory for cohorts born prior to September 30, 1983 by race and age group. Among all children, the most common causes of internal death are neoplasms (tumors), diseases of the nervous system (which include meningitis, epilepsy, and cerebral palsy), cardiovascular diseases, respiratory diseases, and congenital malformations and chromosomal abnormalities. With the exception of neoplasms, deaths from these causes are more frequent among black children than white children. Additionally, infectious and parasitic diseases are also a major cause of death among black children.

A common cause of deaths due to external causes is transport-related accidents, particularly among older children. Accidental drowning and submersion is also a frequent cause of death. Among older children, deaths due to suicide and homicide are prevalent with suicide almost twice as likely among white children than black children and homicide over six times more likely among black children.

\footnotetext{
${ }^{23}$ We follow the List of 113 Selected Causes of Death (113-cause list) to create our subcategories for external causes. We have omitted deaths due to "Operations of war and their sequelae" since there were no deaths in our sample falling under this subcategory.

${ }^{24}$ Anderson et al. (2001) provide detailed information on the classification and rule changes between the ICD-9 and ICD-10 revisions and construct comparability ratios by case of death. They find substantial discontinuities in mortality trends resulting from implementing the ICD-10. Again, the inclusion of year dummies in our regression specification should serve to control for this change.
} 


\section{Mortality Results}

Table 7 presents estimates of the effect of the eligibility expansions on rates of mortality by age and race. Each cell reports the estimated discontinuity for children at the September 30, 1983 birthdate cutoff, or coefficient $\beta$ in equation (1), from a regression for the specified sample. The first set of rows in the table present our estimates for all children. Our results, and the visual evidence presented in Figures 6 and 7, show no evidence of an improvement in mortality under the eligibility expansions. In fact, we see a slight jump in the rate of deaths due to external causes for children at 15-18 years of age. The coefficient estimates indicate an increase of 0.26 to 0.27 deaths per 10,000 children in the first three specifications, but the effect is not significantly different from zero in the quadratic spline specification. This increase represents approximately a 5 percent change over the baseline rate of 5.16 external-cause deaths per 10,000 children.

Next we examine mortality separately for black and white children. Figures 8-10 accompany the estimates presented in the bottom two panels of Table 7 for these groups. For black children, there is evidence of a decline in mortality at the September 30, 1983 cutoff during the period of extended Medicaid coverage (ages 8 to 14). With a baseline rate of 3.31 deaths per 10,000, the coefficient estimates for the first three specifications suggest approximately a 7-8 percent decline in the total mortality rate for black children at these ages. However, the estimate under the quadratic spline specification is not statistically significant. The coefficient estimates for internal and external mortality suggest that declines in deaths due to both types of causes are behind any change in mortality, although these results are not significant. The visual evidence of a discontinuity in either measure of mortality for black children ages 8-14 is not obvious. 
When we examine the long-term impact of the expansions on black children at ages 15-18, we find evidence of a substantial decline in deaths due to internal causes. Our estimates show a 13-20 percent decrease in the internal mortality rate for black children at these ages. The coefficient estimates indicating a discontinuous fall in mortality are significantly different from zero in all four specifications. Figure 8 gives strong visual evidence to support this decline in internal mortality for older black children. With no evidence of a baseline discontinuity at ages 4 to 7, these findings indicate improvement in the health of black children under expanded Medicaid eligibility.

For white children, we find no evidence of improvements in mortality. Surprisingly, we find some indication of an increase in external mortality beginning at ages 8-14. Our estimates suggest up to a 5-8 percent increase in external mortality over the baseline of 1.22 deaths per 10,000 children but are not consistently significant. At ages 15-18, we find evidence of an increase of approximately 5 percent under the first three specifications. The estimate under the quadratic spline is smaller and not statistically significant. The visual evidence is presented in Figure 10. Presumably, this change for white children is driving the increase in external mortality we saw among all children of ages 15-18.

Table 8 provides additional evidence by examining differences in mortality rates for children born just one year before and after the birthdate cutoff. Again, we find strong evidence of a decline in internal-cause deaths for black children at ages 15-18. Using a simple difference-in-difference estimate that compares this change to that experienced by white children, we estimate a decline of 0.37 deaths per 10,000 black children. This estimate is within the range of our earlier RD regression results. It is also worth noting 
that the comparison of the external mortality rate of older white children born before and after the birthdate cutoff reveals no significant difference. This last finding suggests the absence of a robust relationship between Medicaid eligibility and white external mortality.

\section{State Eligibility Groups}

We next examine changes in mortality by state eligibility group. ${ }^{25}$ The results of our earlier simulation indicated that children residing in high eligibility gain states on average received 5 times the number of additional years of coverage of those in low eligibility gain states. We showed that the high eligibility gain states had less generous AFDC and Medicaid eligibility rules prior to the expansions and fewer children eligible for these programs. This meant that a larger share of children stood to gain coverage in these states under the federally-mandated OBRA90 expansion.

Table 9 presents the estimation results for children residing in the high eligibility gain states. Looking at all children, we find no evidence of improvements in internal mortality and an increase in external mortality among older children. This increase appears to be driving an increase in the total mortality rate for children residing in these states. When we examine the results separately by race, we find that evidence of an increase in external mortality at ages $15-18$ is particularly strong for white children, although there is some suggestion of an increase among black children as well. There also appears to be some indication of an increase in total mortality for white children at ages 8-14. Among black children, there is some evidence of decreases in internal and

\footnotetext{
${ }^{25}$ The RD graphs for each of the state eligibility groups are included in the Appendix.
} 
external mortality at ages 8-14 and a decrease in internal mortality at ages 15-18 but the estimates are not statistically significant.

Table 10 presents the estimation results for the low eligibility gain states. There is no evidence of a change in mortality in either direction for the children residing in these states. It appears that the increase in external mortality was confined to the high eligibility gain states only. When we examine the results by race group, there is again some evidence of an improvement in mortality for black children at ages 8-14 but the estimates are not statistically significant. There is a modestly significant decline in internal mortality for black children at ages 15-18. The evidence of any change in mortality for whites is not strong.

It is somewhat surprising that we do not see major differences in the mortality trends across state groups. Specifically, we find no significant evidence that children residing in the high eligibility gain states saw greater improvements in health. If anything, our results are more indicative of an improvement in black mortality in the low eligibility gain states. Furthermore, the increase in external mortality for white teens appears to be confined to the high eligibility gain states.

One potential explanation for not finding stronger improvements in health in the high eligibility gain states is that larger expansions in eligibility do not directly translate into higher levels of enrollment or improvements in access to medical care for children. Increases in enrollment require outreach by states and the dissemination of eligibility information to parents. In addition, larger numbers of new beneficiaries may strain limited supply-side resources, particularly if physicians opt not to accept Medicaid clients due to low reimbursement rates or slow payment. Finally, we should emphasize that this 
source of identification is not sharp and not clearly exogenous like the variation due to birthdate.

\section{Specific Causes of Death}

Our results indicate changes in the mortality rates of black and white children born after September 30, 1983 at older ages. We find strong evidence of a 13-20 percent decrease in the internal mortality rate among black children. We also find some evidence of a 5 percent increase in the external mortality rate among white children at ages 15-18, but this increase is not robust to specification choice nor is it apparent in the differences for children born the year before and after the discontinuity. To better understand the potential role of expanded Medicaid eligibility in these changes, we study the more specific underlying causes of death for each racial group using the classification described earlier.

Specific cause mortality is often very low, leading to little information being available in the months that are relied upon by the regression discontinuity method, those that immediately surrounding the September 1983 cutoff. The paucity of the data encouraged us to focus on differences in mortality between those born the year before and after the discontinuity. Comparisons of internal-cause deaths of children born one year before and after the September 30, 1983 cutoff reveal no significant differences in the rates of death due to any of these causes among black or white children (see Table 11). There are moderate sized but statistically insignificant declines for black children spread across many causes. In the aggregate, however, these estimates still support a large decline in the total number of internal-cause deaths occurring among older black 
children. Thus, although we provide evidence of a decline in deaths related to disease, we are unable to definitively say what were the underlying causes for which health insurance coverage mattered most. This is an important question and area for future work. With access to Medicaid claims data from this period, researchers might be able to learn more regarding the nature of health care and services accessed by children benefiting from the eligibility expansions. This information would provide valuable insight into the role of public health insurance in preventing child mortality.

Estimates comparing mortality from external causes for white children born one year before and after the birthdate cutoff provide no support for a change at the birthdate cutoff (Table 12). This agrees with our earlier result indicating that the discontinuity in external mortality is not present among older white children born closest to the cutoff. The estimates for black children in Table 12 do, however, suggest the presence of changes in several external causes at the birthdate cutoff at different ages. However, when compared to similar estimates for white children, they are not statistically significant. We should also note, as can be seen in Figure 10, that external mortality for each of the age and race groups has a pronounced trend decline over time. The presence of such a trend makes the year-to-year differences over time in external mortality less sensible as a summary measure because they at least partly reflect that trend.

\section{Robustness and Additional Results}

Earlier we show that the decline in internal mortality for black teens born after the September 30, 1983 cutoff is largely robust to the choice of functional form of the regression discontinuity specification. In addition, we also test the sensitivity of this 
result to the use of narrower windows of observations around the birthdate cutoff. When we restrict the sample to children born within 36 of the cutoff date, the estimated decline in internal mortality for black teens remains strong under the first three specifications (Appendix Table 3). In addition, the evidence of an increase in external mortality for white teens at ages 15-18 is no longer significant, although there remains some evidence of an increase at ages 8-14. When further limiting the sample to children born within 24 months of the cutoff date, the coefficient estimates mostly indicate a decline in internal mortality for black teens but they are no longer statistically significant (Appendix Table 4). Surprisingly, there is a significant decline in internal mortality for black children ages 4-7 in most specifications.

We also expand our analysis to examine the impact of the Medicaid expansions at older ages to the extent possible. Not enough time has passed for us to observe mortality for our entire RD sample at early adult ages but we are able to construct simple differences that compare mortality at ages 19-22 of children born 12 months before and after the birthdate cutoff. These results do not indicate any change (increase or decrease) in internal mortality for blacks at these later ages (Appendix Table 5). This result suggests that the improvement in internal mortality observed at ages 15-18 for black children is not reversed during the early adult years. Our results for ages 19-22 also suggest a decline in deaths due to external causes among black children, primarily from a reduction in accidents (Appendix Table 6). However, a visual examination of the data suggests that these declines are the result of preexisting trends. 


\section{Interpreting the Estimates: Comparisons to Past Work and Cost per Life Saved}

In this paper, we our point estimates suggest a 13-20 percent decrease in the internal mortality rate of older black teens as a result of increased childhood eligibility for Medicaid. We find no evidence of a similar effect among white children, although the implied 95 percent confidence intervals for three of our four estimates allow us only to rule out a decline greater than 3.1 percent over the baseline for white teens. This finding is supported by previous work examining the Medicaid expansions of 1984-1992. In their working paper, Currie and Gruber (1995) estimate that an increase in the fraction of children eligible for Medicaid at the state-level had a much larger impact on mortality for blacks (more than four times as big) than for whites, although neither estimate is significantly different from zero and they are not significantly different from each other. ${ }^{26}$ The authors explain that black children are poorer and more likely to be affected by Medicaid expansions. In the first stage of our analysis, we estimated that black children born at the September 30, 1983 cutoff on average gained 2 times the total years of public health insurance eligibility as white children. Currie and Gruber also provide suggestive evidence that newly covered black children under the Medicaid expansions used more health care than their white counterparts.

Using back-of-the-envelope calculations, we can further interpret the magnitude of our estimates. In our regression analysis, we estimate a decline in the annual internal mortality rate of older black children ages $15-18$ of between 0.30 deaths and 0.47 deaths per 10,000 children. Meanwhile, we estimated an average gain in years of eligibility of

\footnotetext{
${ }^{26}$ Howell, et al. (2010) report testing for whether black and white children were differentially affected by the public expansions with the use of an interaction term and finding a nonsignificant coefficient. However, the estimates are not reported in the paper so we are unable to determine if they are small and precisely estimated or imprecise and potentially large.
} 
0.8 for black children. When we consider the more conservative estimate of a decline of 0.30 deaths among all black teens, it suggests that 0.30 times four (for the four years between ages 15 -18) divided by $0.8=1.5$ deaths were avoided for each 10,000 black children made newly Medicaid eligible for a year. Furthermore, with black children representing approximately 15.6 percent of all children and our calculation of 0.43 years of eligibility gain on average for all children, our estimates imply an overall decline of $(0.30 \times 4 \times 0.156) \div 0.43=0.435$ deaths per 10,000 children of all races made eligible. ${ }^{27}$

This mortality derivative with respect to eligibility can be compared to that found by Currie and Gruber (1996a) for children 1-14. They found that 1.277 deaths in a year were avoided for every 10,000 children of all races made eligible for that year. While our estimate is somewhat lower than that found by Currie and Gruber, we should emphasize that their estimate is for children 1-14, while ours is for children ages 15-18. Maybe more importantly, their estimate is based on variation in eligibility from one year to the next and is for contemporaneous mortality, while our estimate is for eligibility that likely lasts for several years and is for mortality during the years following the change in eligibility.

To further interpret our results, we estimate the approximate cost to the Medicaid program of each child life saved. By its nature, this calculation ignores any effects of the expansions on morbidity or quality of life. To calculate the cost of provision of Medicaid services for every 10,000 children, we use the 8 percent take-up rate among newly eligible children under the OBRA90 expansion estimated by Card and Shore-Sheppard (2004). With the average gain in eligibility of 0.43 years among all children, this rate

\footnotetext{
${ }^{27}$ We consider only the reduction to black mortality observed at ages 15-18 in our calculation and assume that the expansions had no effect on mortality at other ages or for other race groups. In 2000, 15.6 percent of all children in the U.S. were black.
} 
implies an increase in Medicaid coverage of $0.43 \times .08=0.034$ years per child. We estimate the average cost of Medicaid coverage per child during this time period at approximately $\$ 891$ (in 1992 dollars). ${ }^{28}$ Thus, the Medicaid program pays $\$ 891$ x 0.034 x $10,000=\$ 302,940$ for every 10,000 children.

With our estimate that $0.30 \times 4 \times 0.156=0.187$ deaths per 10,000 children were prevented by the expansions, this implies that it cost $\$ 302,940 \div 0.187=\$ 1.62$ million (in 1992 dollars) to save one life. This estimate is extremely similar to the $\$ 1.61$ million cost per child life saved calculated by Currie and Gruber (1996) under the Medicaid expansions in 1984-1992. Both estimates are much lower than the Environmental Protection Agency statistical value of life of \$7.9 million (1996 dollars).

These calculations rely on the large decline in black internal mortality observed at ages 15-18. Once we take into consideration the potentially low takeup rate of Medicaid coverage, the plausibility of our estimates requires that pre-OBRA internal-cause deaths among black children be highly concentrated among those groups gaining coverage. Using information on deaths for children ages 15-18 prior to the expansions available in the 1993 National Mortality Followback Study, we estimate that 64 percent of the deaths occurring among black children at these ages were to decedents with household incomes below the poverty line. Combining this estimate with our measured 13-20 percent decline in internal mortality among blacks under the expansions, this implies a 20-31 percent (1320 divided by 0.64 ) decline in the internal mortality rate for poor blacks. ${ }^{29}$ This is not implausible given that our first stage estimates indicate that 31 percent of poor black

\footnotetext{
${ }^{28}$ The per capita Medicaid payment for categorically needy AFDC children in FY 1992 was $\$ 891$ (Source: 1996 Green Book).

${ }^{29}$ This assumes that the share of internal-cause deaths for black children aged 15-18 with incomes under poverty is similar to the share for all deaths.
} 
children at the birthdate cutoff gained eligibility under the expansions. Furthermore, it is reasonable to hypothesize that the children who do takeup Medicaid coverage are most in need of medical care. In their study of takeup and the utilization of health care under OBRA90, Card and Shore-Sheppard (2004) estimate that children with new Medicaid coverage are 60 percent more likely to have an annual doctor visit. It is worth also noting that even if the typical newly eligible child is not enrolled in Medicaid, upon commencing any costly hospital or physician care it is likely that an eligible child would be enrolled.

\section{Conclusions}

This paper provides new evidence on the mortality effects of expansions in public health insurance eligibility for children in the mid 1980s to early 1990s. Our identification strategy exploits a unique feature of several early Medicaid expansions that extended eligibility only to children born after September 30, 1983. This feature led to a large cumulative difference in public health insurance eligibility for children born on either side of this birthdate cutoff. Children in families with incomes at or just below the poverty line gained close to five additional years of eligibility if they were born in October 1983 rather than just one month before. Black children were more likely to be affected by the Medicaid expansions and gained twice the years of eligibility on average as white children at this birthdate cutoff. The average gain in eligibility also varied by state of residence due to differences in state Medicaid eligibility rules prior to and during the expansions, as well as differences in the demographic characteristics of state residents. 
Using a regression discontinuity design, we examine the impact of public health insurance eligibility during childhood on mortality by comparing outcomes for cohorts of children born just before and after the September 30, 1983 cutoff. The discontinuity in public health insurance eligibility under the expansions occurred between the ages of 8 and 14 . We measure mortality outcomes for this period as well as through age 18 to gauge any longer-term impacts. We also examine differential effects of the expansions by the race and state of residence of the child.

The results provide strong evidence of an improvement in mortality for black children under the Medicaid expansions. Although there is some evidence of a decline in mortality rates during the period of coverage (ages 8-14), we find a substantial decline in the later life mortality of black children at ages 15-18. The regression estimates indicate a 13-20 percent decrease in the internal mortality rate of black teens born after September 30, 1983. Because deaths due to internal causes are more likely to be influenced by access to medical care, this result supports an improvement in the underlying health of black children under the eligibility expansions. Early evidence indicates that this gain in health is not reversed during the early adult years. We find no evidence of an improvement in the mortality of white children under the expansions. Furthermore, we are unable to detect mortality improvements among children residing in those states with the largest gains in public health insurance eligibility under the expansions.

The effectiveness of public health insurance in the long-term improvement of the health of children has important policy implications. Despite drastic expansions in public health insurance over the last thirty years, the evidence connecting this expanded coverage to improved child health remains hard to come by. However, the payoffs from 
health insurance coverage during childhood might not be fully evident until later in life. A major focus of pediatric care is prevention and the early diagnosis and treatment of health conditions. Without considering the long-term effects of these types of interventions, we may be missing an important component of program benefits. Even in our study, one limitation is that not enough time has passed to look at longer-term adult outcomes for the cohorts of children affected by the change in Medicaid policy. With time (and further study), we may be able to evaluate both the persistence of the mortality improvements for black children and whether there are additional gains to childhood coverage. 


\section{References}

American Academy of Pediatrics. 2008. "Recommendations for Pediatric Preventive Health Care.” American Academy of Pediatrics Policy Statement.

Anderson, Robert N., Arialdi M. Minino, Donna L. Hoyert, and Harry M. Rosenberg. 2001. "Comparability of Cause of Death Between ICD-9 and ICD-10: Preliminary Estimates.” National Vital Statistics Reports 49(2): 1-32, May 18.

Becker, Gary. 2007. "Health as human capital: synthesis and extensions.” Oxford Economic Papers 59(3): 379-410.

Buckles, Kasey and Daniel M. Hungerman, 2008. "Season of Birth and Later Outcomes: Old Questions, New Answers," National Bureau of Economic Research Working Paper Series No. 14573.

Card, David, C. Dobkin, and N. Maestas. 2009. “Does Medicare Save Lives?,” Quarterly Journal of Economics 124, no. 2: 597-636.

Card, David, and Lara Shore-Sheppard. 2004. "Using Discontinuous Eligibility Rules to Identify the Effects of the Federal Medicaid Expansions.” Review of Economics and Statistics, 86.

Case, Anne, Darren Lubotsky, and Christina Paxson. 2002. "Economic status and health in childhood: The origins of the gradient.” The American Economic Review 92(5): 13081334.

Case, Anne, Angela Fertig, and Christina Paxson. 2005. "The lasting impact of childhood health and circumstance.” Journal of Health Economics 24: 365-389.

Cassedy, Amy, Gerry Fairbrother and Paul W Newacheck. 2008. “The impact of insurance instability on children's access, utilization, and satisfaction with health care.” Ambulatory Pediatrics 8(5): 321-328.

Currie, Janet, Sandra Decker, and Wanchuan Lin. 2008. "Has public health insurance for older children reduced disparities in access to care and health outcomes?” Journal of Health Economics 27: 1567-1581.

Currie, Janet and Jonathan Gruber. 1995. "Health insurance eligibility, utilization of medical care, and child health.” NBER Working Paper No. 5052.

Currie, Janet and Jonathan Gruber. 1996a. "Health insurance eligibility, utilization of medical care, and child health.” The Quarterly Journal of Economics 111(2): 431-466. 
Currie, Janet and Jonathan Gruber. 1996b. "Saving babies: the efficacy and cost of recent changes in the Medicaid eligibility of pregnant women.” The Journal of Political Economy 104(6): 1263-1296.

Currie, Janet and Mark Stabile. 2003. "Socioeconomic status and child health: Why is the relationship stronger for children?” The American Economic Review 93(5): 1813-1823.

Cutler, David M. and Jonathan Gruber. 1996. "Does public insurance crowd out private insurance.” The Quarterly Journal of Economics 111(2): 391-430.

Cutler, D.M., and R. J. Zeckhauser. 2000. The Anatomy of Health Insurance. In Handbook of Health Economics, ed. Anthony J. Culyer and Joseph P. Newhouse. Vol. 1. North Holland: Elsevier.

Dafny, Leemore and Jonathan Gruber. 2005. "Public insurance and child hospitalizations: access and efficiency effects.” Journal of Public Economics 89: 109-129.

De la Mata, Dolores. 2012. "The effect of Medicaid eligibility on coverage, utilization, and children's health.” Health Economics, published online July 16.

Franks, Paul W., Robert L. Hanson, William C. Knowler, Maurice L. Sievers, Peter H. Bennett, and Helen C. Looker. 2010. "Childhood obesity, other cardiovascular risk factors, and premature death.” The New England Journal of Medicine 362(6): 485-493.

Grossman, Michael. 1972. "On the concept of health capital and the demand for health." The Journal of Political Economy 80(2): 223-255.

Grossman, Michael. 2000. “The human capital model.” Handbook of Health Economics, vol. 1. Edited by A.J. Cuyler and J.P. Newhouse.

Howell, Embry, Sandra Decker, Sara Hogan, Alshadye Yemane and Jonay Foster. 2010. "Declining child mortality and continuing racial disparities in the era of the Medicaid and SCHIP insurance coverage expansions.” American Journal of Public Health 100(12): 2500-2506.

Howell, Embry M. and Genevieve M. Kenney. 2012. "The Impact of the Medicaid/CHIP expansions on children: A synthesis of the evidence.” Medical Care Research and Review 20(10): 1-25.

Joyce, Ted and Andrew Racine. 2005. "CHIP shots: Association between the State Children's Health Insurance Programs and immunization rates.” Pediatrics 115: e26e534.

Kaestner, Robert, Ted Joyce, and Andrew Racine. 2001. "Medicaid eligibility and the incidence of ambulatory care sensitive hospitalizations for children." Social Science and Medicine 52: 305-313. 
Lee, David S., and David Card. 2008. "Regression discontinuity inference with specification error.” Journal of Econometrics 142 (2) (February): 655-674.

Leininger, Lindsey. 2009. "Partial-year insurance coverage and the health care utilization of children.” Medical Care Research and Review 66(1): 49-67.

Lo Sasso, Anthony T. and Thomas C. Buchmueller. 2004. "The effect of the state children's health insurance program on health insurance coverage.” Journal of Health Economics 23(5): 1059-1082.

Manning, Willard G., Joseph P. Newhouse, Naihua Duan, Emmett B. Keeler, and Arleen Leibowitz. 1987. "Health Insurance and the Demand for Medical Care: Evidence from a Randomized Experiment.” The American Economic Review 77 (3) (June 1): 251-277.

Minino, Arialdi M., Jiaquan Xu, and Kenneth D. Kochanek. 2010. "Deaths: Preliminary Data for 2008.” National Vital Statistics Reports 59(2): 1-71.

Racine, Andrew D., Robert Kaestner, Theodore J. Joyce and Gregory J. Colman. 2001 "Differential impact of recent Medicaid expansions by race and ethnicity." Pediatrics 108: $1135-1142$.

Shi, Lei Yu, Michael E. Samuels, Mary Pease, Walter P. Bailey and Elizabeth H. Corley. 1999. "Patient Characteristics Associated with Hospitalizations for Ambulatory Care Sensitive Conditions in South Carolina.” Southern Medical Journal 92(10): 989-998.

Valdez, R. Burciaga, Robert H. Brook, William H. Rogers, John E. Ware, Emmett B. Keeler, Cathy A. Sherbourne, Kathleen N. Lohr, George A. Goldberg, Patricia Camp, and Joseph Newhouse. 1985. "Consequences for Cost-Sharing for Children's Health.” Pediatrics 75(5): 952-961. 
Table 1. Federal Legislation Expanding Medicaid Eligibility for Children Using September 30, 1983 Birthdate Cutoff

\begin{tabular}{|c|c|c|c|}
\hline Legislation & $\begin{array}{c}\text { Date } \\
\text { Effective }\end{array}$ & Mandatory Expansion & State Option \\
\hline Deficit Reduction Act, 1984 (DEFRA) & Oct. 1,1984 & $\begin{array}{l}\text { Made eligible children under age } 5 \text { born after } \\
\text { September 30, } 1983 \text { whose families were income } \\
\text { and resource eligible for AFDC }\end{array}$ & \\
\hline \multirow[t]{2}{*}{$\begin{array}{l}\text { Omnibus Budget Reconciliation Act, } 1987 \\
\text { (OBRA87) }\end{array}$} & Jul. 1, 1988 & & $\begin{array}{l}\text { Gave states the option of making eligible } \\
\text { children under age 2, 3, 4, or } 5 \text { and born after } \\
\text { September 30, } 1983 \text { in families with incomes } \\
\text { below } 100 \% \text { FPL }\end{array}$ \\
\hline & Oct. 1,1988 & $\begin{array}{l}\text { Made eligible children under age } 7 \text { born after } \\
\text { September 30, } 1983 \text { whose families were income } \\
\text { and resource eligible for AFDC }\end{array}$ & $\begin{array}{l}\text { Gave states the option of making eligible } \\
\text { children under age } 8 \text { born after September } 30 \text {, } \\
1983 \text { with incomes below 100\% FPL } \\
\text { Gave states the option of making eligible } \\
\text { children under age } 8 \text { born after September 30, } \\
1983 \text { whose families were income and resource } \\
\text { eligible for AFDC }\end{array}$ \\
\hline $\begin{array}{l}\text { Omnibus Budget Reconciliation Act, } 1990 \\
\text { (OBRA90) }\end{array}$ & Jul. 1, 1991 & $\begin{array}{l}\text { Made eligible children under age } 19 \text { born after } \\
\text { September 30, } 1983 \text { with incomes below } 100 \% \\
\text { FPL }\end{array}$ & \\
\hline
\end{tabular}

Sources: Congressional Research Service (1988) and Kaiser Family Foundation (2010). 
Table 2. Ranking of States by Gain in Eligibility at September 30, 1983

\begin{tabular}{|c|c|c|}
\hline Rank & State & $\begin{array}{c}\text { Average Difference in Years of Eligibility } \\
\text { Child Born in Oct. vs. Sept. } 1983\end{array}$ \\
\hline 1 & Maryland & 1.68 \\
\hline 2 & Louisiana & 0.91 \\
\hline 3 & Nevada & 0.84 \\
\hline 4 & Arkansas & 0.82 \\
\hline 5 & Colorado & 0.82 \\
\hline 6 & Alabama & 0.79 \\
\hline 7 & Texas & 0.79 \\
\hline 8 & Indiana & 0.78 \\
\hline 9 & Montana & 0.69 \\
\hline 10 & Wyoming & 0.69 \\
\hline 11 & Idaho & 0.68 \\
\hline 12 & Connecticut & 0.65 \\
\hline 13 & Arizona & 0.64 \\
\hline 14 & Florida & 0.63 \\
\hline 15 & Ohio & 0.63 \\
\hline 16 & District of Columbia & 0.61 \\
\hline 17 & Nebraska & 0.57 \\
\hline 18 & South Dakota & 0.53 \\
\hline 19 & Mississippi & 0.51 \\
\hline 20 & Illinois & 0.50 \\
\hline 21 & Rhode Island & 0.49 \\
\hline 22 & Oklahoma & 0.47 \\
\hline 23 & New Hampshire & 0.46 \\
\hline 24 & South Carolina & 0.45 \\
\hline 25 & Kentucky & 0.43 \\
\hline 26 & New Mexico & 0.42 \\
\hline 27 & Iowa & 0.40 \\
\hline 28 & Wisconsin & 0.39 \\
\hline 29 & West Virginia & 0.39 \\
\hline 30 & New Jersey & 0.37 \\
\hline 31 & Oregon & 0.35 \\
\hline 32 & Tennessee & 0.32 \\
\hline 33 & Virginia & 0.31 \\
\hline 34 & Pennsylvania & 0.31 \\
\hline 35 & Kansas & 0.29 \\
\hline 36 & Michigan & 0.26 \\
\hline 37 & Hawaii & 0.26 \\
\hline 38 & Missouri & 0.23 \\
\hline 39 & Washington & 0.19 \\
\hline 40 & North Dakota & 0.18 \\
\hline 41 & Minnesota & 0.16 \\
\hline 42 & Alaska & 0.16 \\
\hline 43 & New York & 0.13 \\
\hline 44 & North Carolina & 0.13 \\
\hline 45 & Utah & 0.13 \\
\hline 46 & Delaware & 0.13 \\
\hline 47 & Massachussetts & 0.11 \\
\hline 48 & Georgia & 0.10 \\
\hline 49 & Vermont & 0.03 \\
\hline 50 & California & 0.03 \\
\hline 51 & Maine & 0.02 \\
\hline
\end{tabular}

Notes: Horizontal line separates the high and low eligibility gain states. Average difference in years of eligibility is calculated usinga fixed sample of children of ages 0-17 in the 1981-1988 March CPS. See text for more information. 
Table 3. Characteristics of Children in State Eligibility Groups, 1983

\begin{tabular}{lccc}
\hline \hline & $\begin{array}{c}\text { Low eligibility } \\
\text { gain }\end{array}$ & $\begin{array}{c}\text { High eligibility } \\
\text { gain }\end{array}$ & Difference \\
\hline Nonwhite & 0.186 & 0.186 & 0.000 \\
Married family & 0.761 & 0.757 & -0.004 \\
Family size & 4.363 & 4.356 & -0.007 \\
At least one employed parent & 0.880 & 0.897 & $0.017 * * *$ \\
Family with income below 100\% FPL & 0.203 & 0.201 & -0.002 \\
Eligible for AFDC & 0.151 & 0.111 & $-0.040 * * *$ \\
Eligible for Medicaid & 0.151 & 0.112 & $-0.039 * * *$ \\
$N$ & 21,113 & 22,762 & \\
\hline
\end{tabular}

Notes: Weighted means are calculated for children ages 0-17 using the 1984 March Current

Population Survey. Asterisks denote p-value for difference, ${ }^{* * *} \mathrm{p}<0.01, * * \mathrm{p}<0.05,{ }^{*} \mathrm{p}<0.1$. 
Table 4. Difference in Years of Eligibility by Race and State Group for a Child Born in October vs. September 1983

\begin{tabular}{lccc}
\hline \hline & All children & Black children & White children \\
\hline All states & 0.43 & 0.80 & 0.37 \\
States with high eligibility gain & 0.71 & 1.33 & 0.59 \\
States with low eligibility gain & 0.14 & 0.24 & 0.13 \\
\hline
\end{tabular}

Notes: Weighted average calculated using the characteristics and state of residence of a sample of children of ages 0-17 in the 1981-1988 March CPS. See text for more information. Family income is indexed using the CPI-U and assumed to be constant over the child's lifetime. For each race category, states are classified as having a high eligibility gain by first ranking state-level estimates of the difference in years of eligibility for a child of that race born in October versus September 1983 and then selecting the number of states with the largest average gain in eligibility that comprises $50 \%$ of the national population of children of that race. See Appendix Table 2 for the ranking of states by eligibility gain for all children. 
Table 5. Average Rate of Death for Children Born Before September 30, 1983 By Race, Age and State Group

\begin{tabular}{|c|c|c|c|c|c|c|c|c|c|c|}
\hline & \multicolumn{3}{|c|}{ All states } & \multicolumn{3}{|c|}{ Low eligibility gain states } & \multicolumn{3}{|c|}{ High eligibility gain states } & \multirow[t]{2}{*}{$N$} \\
\hline & $\begin{array}{c}\text { All } \\
\text { causes }\end{array}$ & $\begin{array}{c}\text { Internal } \\
\text { causes }\end{array}$ & $\begin{array}{c}\text { External } \\
\text { causes }\end{array}$ & $\begin{array}{c}\text { All } \\
\text { causes }\end{array}$ & $\begin{array}{c}\text { Internal } \\
\text { causes }\end{array}$ & $\begin{array}{c}\text { External } \\
\text { causes }\end{array}$ & $\begin{array}{c}\text { All } \\
\text { causes }\end{array}$ & $\begin{array}{c}\text { Internal } \\
\text { causes }\end{array}$ & $\begin{array}{c}\text { External } \\
\text { causes }\end{array}$ & \\
\hline \multicolumn{11}{|l|}{ All children } \\
\hline Age 4-7 & 2.58 & 1.24 & 1.34 & 2.50 & 1.21 & 1.29 & 2.66 & 1.27 & 1.38 & 90 \\
\hline Age 8-14 & 2.37 & 1.06 & 1.32 & 2.25 & 1.03 & 1.22 & 2.49 & 1.09 & 1.41 & 135 \\
\hline Age $15-18$ & 6.70 & 1.54 & 5.16 & 6.19 & 1.47 & 4.72 & 7.18 & 1.60 & 5.58 & 90 \\
\hline \multicolumn{11}{|l|}{ Black children } \\
\hline Age 4-7 & 3.62 & 1.53 & 2.09 & 3.64 & 1.53 & 2.11 & 3.61 & 1.53 & 2.08 & 90 \\
\hline Age 8-14 & 3.31 & 1.47 & 1.85 & 3.20 & 1.46 & 1.74 & 3.44 & 1.47 & 1.96 & 135 \\
\hline Age $15-18$ & 8.90 & 2.35 & 6.55 & 8.50 & 2.30 & 6.21 & 9.34 & 2.40 & 6.94 & 90 \\
\hline \multicolumn{11}{|l|}{ White children } \\
\hline Age 4-7 & 2.39 & 1.20 & 1.19 & 2.33 & 1.17 & 1.16 & 2.44 & 1.22 & 1.22 & 90 \\
\hline Age 8-14 & 2.21 & 0.99 & 1.22 & 2.10 & 0.97 & 1.14 & 2.30 & 1.00 & 1.30 & 135 \\
\hline Age $15-18$ & 6.31 & 1.39 & 4.92 & 5.83 & 1.34 & 4.49 & 6.74 & 1.44 & 5.31 & 90 \\
\hline
\end{tabular}

Notes: Average of annual rates of death per 10,000 children calculated for each birth month cohort between January 1980 and September 1983. Mortality rates constructed using National Vital Statistics System Multiple Cause of Death files for the years 1980 to 2007 and NVSS Birth Date files for the years 1980 to 1987. 
Table 6. Average Rate of Death for Children Born Before September 30, 1983 By Underlying Cause of Death By Race and Age

\begin{tabular}{|c|c|c|c|c|c|c|c|c|c|}
\hline & \multicolumn{3}{|c|}{ All children } & \multicolumn{3}{|c|}{ Black children } & \multicolumn{3}{|c|}{ White children } \\
\hline & $4-7$ & $8-14$ & $15-18$ & $4-7$ & $8-14$ & $15-18$ & $4-7$ & 8-14 & $15-18$ \\
\hline Deaths from all causes & 2.58 & 2.37 & 6.70 & 3.62 & 3.31 & 8.90 & 2.39 & 2.21 & 6.31 \\
\hline Deaths due to internal causes & 1.24 & 1.06 & 1.54 & 1.53 & 1.47 & 2.35 & 1.20 & 0.99 & 1.39 \\
\hline Infectious and parasitic diseases & 0.09 & 0.08 & 0.09 & 0.15 & 0.15 & 0.17 & 0.08 & 0.06 & 0.07 \\
\hline Neoplasms (malignant and nonmalignant) & 0.37 & 0.29 & 0.38 & 0.31 & 0.29 & 0.43 & 0.39 & 0.29 & 0.38 \\
\hline Diseases of blood, blood-forming organs, immune forming & 0.03 & 0.02 & 0.03 & 0.08 & 0.06 & 0.08 & 0.02 & 0.02 & 0.02 \\
\hline Endocrine, nutritional, and metabolic diseases & 0.06 & 0.06 & 0.10 & 0.05 & 0.05 & 0.10 & 0.07 & 0.07 & 0.10 \\
\hline Mental and behavioral disorders & 0.02 & 0.01 & 0.03 & 0.02 & 0.01 & 0.03 & 0.02 & 0.01 & 0.03 \\
\hline Diseases of the nervous system & 0.16 & 0.15 & 0.20 & 0.21 & 0.21 & 0.27 & 0.15 & 0.14 & 0.19 \\
\hline Cardiovascular and circulatory system diseases & 0.10 & 0.12 & 0.25 & 0.15 & 0.19 & 0.48 & 0.10 & 0.11 & 0.21 \\
\hline Respiratory system diseases & 0.10 & 0.10 & 0.13 & 0.16 & 0.21 & 0.24 & 0.09 & 0.08 & 0.10 \\
\hline Digestive system diseases & 0.04 & 0.03 & 0.04 & 0.06 & 0.04 & 0.08 & 0.04 & 0.03 & 0.03 \\
\hline Congenital and chromosomal abnormalities & 0.19 & 0.11 & 0.11 & 0.22 & 0.12 & 0.17 & 0.19 & 0.11 & 0.10 \\
\hline Symptoms and signs not elsewhere classified & 0.05 & 0.05 & 0.12 & 0.09 & 0.08 & 0.18 & 0.04 & 0.04 & 0.11 \\
\hline All other diseases & 0.03 & 0.03 & 0.06 & 0.04 & 0.05 & 0.14 & 0.03 & 0.02 & 0.04 \\
\hline Deaths due to external causes & 1.34 & 1.32 & 5.16 & 2.09 & 1.85 & 6.55 & 1.19 & 1.22 & 4.92 \\
\hline Accidents (unintentional injuries) & 1.22 & 0.98 & 3.31 & 1.81 & 1.24 & 2.50 & 1.10 & 0.93 & 3.50 \\
\hline Transport accidents & 0.66 & 0.62 & 2.70 & 0.84 & 0.63 & 1.79 & 0.62 & 0.63 & 2.91 \\
\hline Nontransport accidents & 0.56 & 0.35 & 0.60 & 0.97 & 0.61 & 0.71 & 0.48 & 0.31 & 0.59 \\
\hline Falls & 0.02 & 0.01 & 0.04 & 0.02 & 0.01 & 0.02 & 0.02 & 0.01 & 0.05 \\
\hline Accidental discharge of firearms & 0.03 & 0.06 & 0.08 & 0.05 & 0.07 & 0.15 & 0.02 & 0.06 & 0.07 \\
\hline Accidental drowning and submersion & 0.17 & 0.11 & 0.18 & 0.26 & 0.29 & 0.31 & 0.15 & 0.07 & 0.15 \\
\hline Accidental exposure to smoke, fire and flames & 0.21 & 0.06 & 0.04 & 0.51 & 0.14 & 0.07 & 0.15 & 0.05 & 0.04 \\
\hline Accidental poisoning and exposure to noxious substances & 0.01 & 0.01 & 0.12 & 0.02 & 0.01 & 0.05 & 0.01 & 0.01 & 0.14 \\
\hline Other and unspecified nontransport accidents & 0.12 & 0.09 & 0.14 & 0.12 & 0.07 & 0.11 & 0.12 & 0.10 & 0.15 \\
\hline Intentional self-harm (suicide) & 0.02 & 0.01 & 0.04 & 0.00 & 0.09 & 0.52 & 0.00 & 0.15 & 0.88 \\
\hline Assault (homicide) & 0.03 & 0.06 & 0.08 & 0.23 & 0.48 & 3.40 & 0.07 & 0.11 & 0.47 \\
\hline Legal intervention & 0.17 & 0.11 & 0.18 & 0.00 & 0.00 & 0.03 & 0.00 & 0.00 & 0.01 \\
\hline Events of undetermined intent & 0.21 & 0.06 & 0.04 & 0.04 & 0.03 & 0.10 & 0.01 & 0.02 & 0.06 \\
\hline Operations of war and their sequelae & 0.01 & 0.01 & 0.12 & 0.00 & 0.00 & 0.00 & 0.00 & 0.00 & 0.00 \\
\hline Complications of medical and surgical care & 0.12 & 0.09 & 0.14 & 0.01 & 0.01 & 0.01 & 0.01 & 0.01 & 0.01 \\
\hline
\end{tabular}

Notes: Average of annual rates of death calculated for each birth month cohort between January 1980 and September 1983. Mortality rates constructed using National Vital Statistics System Multiple Cause of Death files for the years 1980 to 2007 and NVSS Birth Date files for the years 1980 to 1987. 
Table 7. Change in Annual Mortality Rate for Children Born after September 30, 1983 by Age and Race

\begin{tabular}{|c|c|c|c|c|c|c|c|c|c|}
\hline & \multicolumn{3}{|c|}{ Ages 4-7 } & \multicolumn{3}{|c|}{ Ages 8-14 } & \multicolumn{3}{|c|}{ Ages 15-18 } \\
\hline & $\begin{array}{c}\text { All } \\
\text { causes } \\
(1) \\
\end{array}$ & $\begin{array}{c}\text { Internal } \\
\text { causes } \\
(2)\end{array}$ & $\begin{array}{c}\text { External } \\
\text { causes } \\
(3)\end{array}$ & $\begin{array}{c}\text { All } \\
\text { causes } \\
(4) \\
\end{array}$ & $\begin{array}{c}\text { Internal } \\
\text { causes } \\
(5)\end{array}$ & $\begin{array}{c}\text { External } \\
\text { causes } \\
(6)\end{array}$ & $\begin{array}{c}\text { All } \\
\text { causes } \\
(7) \\
\end{array}$ & $\begin{array}{c}\text { Internal } \\
\text { causes } \\
(8)\end{array}$ & $\begin{array}{c}\text { External } \\
\text { causes } \\
(9) \\
\end{array}$ \\
\hline \multicolumn{10}{|l|}{ All children } \\
\hline Linear & $\begin{array}{c}0.050 \\
(0.057)\end{array}$ & $\begin{array}{c}0.056 \\
(0.043)\end{array}$ & $\begin{array}{l}-0.006 \\
(0.052)\end{array}$ & $\begin{array}{c}0.025 \\
(0.042)\end{array}$ & $\begin{array}{c}-0.001 \\
(0.030)\end{array}$ & $\begin{array}{c}0.026 \\
(0.029)\end{array}$ & $\begin{array}{c}0.268 * * \\
(0.106)\end{array}$ & $\begin{array}{c}0.008 \\
(0.049)\end{array}$ & $\begin{array}{c}0.260 * * * * \\
(0.095)\end{array}$ \\
\hline Linear spline & $\begin{array}{c}0.036 \\
(0.058)\end{array}$ & $\begin{array}{c}0.048 \\
(0.044)\end{array}$ & $\begin{array}{l}-0.012 \\
(0.052)\end{array}$ & $\begin{array}{c}0.065 \\
(0.042)\end{array}$ & $\begin{array}{c}0.000 \\
(0.031)\end{array}$ & $\begin{array}{c}0.064 * * \\
(0.031)\end{array}$ & $\begin{array}{c}0.269 * * \\
(0.104)\end{array}$ & $\begin{array}{c}0.000 \\
(0.051)\end{array}$ & $\begin{array}{c}0.269 * * * \\
(0.093)\end{array}$ \\
\hline Quadratic & $\begin{array}{c}0.034 \\
(0.057)\end{array}$ & $\begin{array}{c}0.047 \\
(0.044)\end{array}$ & $\begin{array}{l}-0.014 \\
(0.052)\end{array}$ & $\begin{array}{c}0.062 \\
(0.040)\end{array}$ & $\begin{array}{c}0.001 \\
(0.030)\end{array}$ & $\begin{array}{c}0.061 * * \\
(0.028)\end{array}$ & $\begin{array}{c}0.268^{* *} \\
(0.105)\end{array}$ & $\begin{array}{l}-0.001 \\
(0.050)\end{array}$ & $\begin{array}{c}0.269 * * * \\
(0.094)\end{array}$ \\
\hline Quadratic spline & $\begin{array}{c}0.060 \\
(0.075)\end{array}$ & $\begin{array}{c}0.001 \\
(0.066)\end{array}$ & $\begin{array}{c}0.059 \\
(0.080)\end{array}$ & $\begin{array}{c}0.023 \\
(0.059)\end{array}$ & $\begin{array}{l}-0.010 \\
(0.040)\end{array}$ & $\begin{array}{c}0.033 \\
(0.048)\end{array}$ & $\begin{array}{c}0.039 \\
(0.182)\end{array}$ & $\begin{array}{l}-0.070 \\
(0.088)\end{array}$ & $\begin{array}{c}0.109 \\
(0.154)\end{array}$ \\
\hline Baseline mean & 2.580 & 1.241 & 1.339 & 2.373 & 1.057 & 1.316 & 6.697 & 1.537 & 5.160 \\
\hline \multicolumn{10}{|l|}{ Black children } \\
\hline Linear & $\begin{array}{c}0.034 \\
(0.163)\end{array}$ & $\begin{array}{c}0.085 \\
(0.098)\end{array}$ & $\begin{array}{l}-0.051 \\
(0.155)\end{array}$ & $\begin{array}{c}-0.275^{* *} \\
(0.128)\end{array}$ & $\begin{array}{c}-0.113 \\
(0.090)\end{array}$ & $\begin{array}{c}-0.162^{*} \\
(0.091)\end{array}$ & $\begin{array}{l}-0.179 \\
(0.287)\end{array}$ & $\begin{array}{c}-0.296 * * \\
(0.140)\end{array}$ & $\begin{array}{c}0.116 \\
(0.273)\end{array}$ \\
\hline Linear spline & $\begin{array}{l}-0.018 \\
(0.160)\end{array}$ & $\begin{array}{c}0.076 \\
(0.100)\end{array}$ & $\begin{array}{l}-0.094 \\
(0.145)\end{array}$ & $\begin{array}{c}-0.237^{*} \\
(0.131)\end{array}$ & $\begin{array}{c}-0.124 \\
(0.091)\end{array}$ & $\begin{array}{c}-0.113 \\
(0.095)\end{array}$ & $\begin{array}{l}-0.110 \\
(0.276)\end{array}$ & $\begin{array}{c}-0.303 * * \\
(0.145)\end{array}$ & $\begin{array}{c}0.193 \\
(0.254)\end{array}$ \\
\hline Quadratic & $\begin{array}{l}-0.020 \\
(0.158)\end{array}$ & $\begin{array}{c}0.068 \\
(0.099)\end{array}$ & $\begin{array}{l}-0.088 \\
(0.150)\end{array}$ & $\begin{array}{c}-0.237^{*} \\
(0.128)\end{array}$ & $\begin{array}{c}-0.118 \\
(0.090)\end{array}$ & $\begin{array}{l}-0.119 \\
(0.093)\end{array}$ & $\begin{array}{l}-0.120 \\
(0.284)\end{array}$ & $\begin{array}{c}-0.309 * * \\
(0.142)\end{array}$ & $\begin{array}{c}0.190 \\
(0.262)\end{array}$ \\
\hline Quadratic spline & $\begin{array}{l}-0.258 \\
(0.195)\end{array}$ & $\begin{array}{c}0.034 \\
(0.132)\end{array}$ & $\begin{array}{l}-0.292 \\
(0.181)\end{array}$ & $\begin{array}{l}-0.286 \\
(0.188)\end{array}$ & $\begin{array}{l}-0.158 \\
(0.132)\end{array}$ & $\begin{array}{c}-0.128 \\
(0.164)\end{array}$ & $\begin{array}{l}-0.630 \\
(0.402)\end{array}$ & $\begin{array}{c}-0.467 * * \\
(0.230)\end{array}$ & $\begin{array}{l}-0.164 \\
(0.352)\end{array}$ \\
\hline Baseline mean & 3.624 & 1.532 & 2.092 & 3.313 & 1.466 & 1.847 & 8.903 & 2.349 & 6.554 \\
\hline \multicolumn{10}{|l|}{ White children } \\
\hline Linear & $\begin{array}{c}0.054 \\
(0.060)\end{array}$ & $\begin{array}{c}0.050 \\
(0.047)\end{array}$ & $\begin{array}{c}0.004 \\
(0.050)\end{array}$ & $\begin{array}{l}0.080 * \\
(0.045)\end{array}$ & $\begin{array}{c}0.021 \\
(0.029)\end{array}$ & $\begin{array}{l}0.058^{*} \\
(0.035)\end{array}$ & $\begin{array}{c}0.325 * * * \\
(0.116)\end{array}$ & $\begin{array}{c}0.058 \\
(0.046)\end{array}$ & $\begin{array}{c}0.267 * * \\
(0.101)\end{array}$ \\
\hline Linear spline & $\begin{array}{c}0.046 \\
(0.062)\end{array}$ & $\begin{array}{c}0.041 \\
(0.048)\end{array}$ & $\begin{array}{c}0.005 \\
(0.052)\end{array}$ & $\begin{array}{c}0.118 * * \\
(0.047)\end{array}$ & $\begin{array}{c}0.024 \\
(0.030)\end{array}$ & $\begin{array}{c}0.093 * * \\
(0.038)\end{array}$ & $\begin{array}{c}0.313 * * * \\
(0.116)\end{array}$ & $\begin{array}{c}0.051 \\
(0.048)\end{array}$ & $\begin{array}{c}0.262 * * \\
(0.101)\end{array}$ \\
\hline Quadratic & $\begin{array}{c}0.044 \\
(0.062)\end{array}$ & $\begin{array}{c}0.042 \\
(0.047)\end{array}$ & $\begin{array}{c}0.002 \\
(0.051)\end{array}$ & $\begin{array}{c}0.115^{* *} \\
(0.044)\end{array}$ & $\begin{array}{c}0.025 \\
(0.030)\end{array}$ & $\begin{array}{c}0.090^{* *} \\
(0.035)\end{array}$ & $\begin{array}{c}0.314 * * * \\
(0.117)\end{array}$ & $\begin{array}{c}0.051 \\
(0.048)\end{array}$ & $\begin{array}{c}0.263^{* *} \\
(0.102)\end{array}$ \\
\hline Quadratic spline & $\begin{array}{c}0.097 \\
(0.079)\end{array}$ & $\begin{array}{c}-0.030 \\
(0.070)\end{array}$ & $\begin{array}{c}0.126 \\
(0.079)\end{array}$ & $\begin{array}{c}0.076 \\
(0.068)\end{array}$ & $\begin{array}{c}0.019 \\
(0.039)\end{array}$ & $\begin{array}{c}0.057 \\
(0.060)\end{array}$ & $\begin{array}{c}0.135 \\
(0.192)\end{array}$ & $\begin{array}{c}0.003 \\
(0.083)\end{array}$ & $\begin{array}{c}0.132 \\
(0.166)\end{array}$ \\
\hline Baseline mean & 2.390 & 1.197 & 1.193 & 2.207 & 0.987 & 1.220 & 6.308 & 1.392 & 4.916 \\
\hline
\end{tabular}

Notes: Coefficients from OLS regressions with the specified function in birth cohort, which also includes age, month, and year dummies. Standard errors reported in parentheses are robust and clustered by birth month cohort, $* * * \mathrm{p}<0.01, * * \mathrm{p}<0.05, * \mathrm{p}<0.1$ 
Table 8. Comparison of Annual Mortality Rates for Children Born One Year Before and After Cutoff

\begin{tabular}{|c|c|c|c|c|c|}
\hline & \multicolumn{2}{|c|}{ 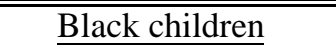 } & \multicolumn{2}{|c|}{ White children } & \multirow{2}{*}{$\begin{array}{c}\text { Diff-in-Diff } \\
\text { (Black Post-Pre) } \\
\text { (White Post-Pre) } \\
\end{array}$} \\
\hline & Pre & Post-Pre & Pre & Post-Pre & \\
\hline \multicolumn{6}{|c|}{ Total Mortality } \\
\hline Age 4-7 & $\begin{array}{c}3.888 \\
(0.130)\end{array}$ & $\begin{array}{l}-0.216 \\
(0.181)\end{array}$ & $\begin{array}{c}2.323 \\
(0.045)\end{array}$ & $\begin{array}{l}-0.085 \\
(0.063)\end{array}$ & $\begin{array}{l}-0.132 \\
(0.230)\end{array}$ \\
\hline Age 8-14 & $\begin{array}{c}3.180 \\
(0.118)\end{array}$ & $\begin{array}{c}-0.293^{*} \\
(0.163)\end{array}$ & $\begin{array}{c}2.021 \\
(0.042)\end{array}$ & $\begin{array}{c}0.006 \\
(0.059)\end{array}$ & $\begin{array}{l}-0.299 \\
(0.210)\end{array}$ \\
\hline Age $15-18$ & $\begin{array}{c}8.254 \\
(0.190)\end{array}$ & $\begin{array}{c}-0.480^{*} \\
(0.264)\end{array}$ & $\begin{array}{c}6.014 \\
(0.072)\end{array}$ & $\begin{array}{c}0.065 \\
(0.102)\end{array}$ & $\begin{array}{l}-0.546 \\
(0.350)\end{array}$ \\
\hline \multicolumn{6}{|c|}{ Internal Mortality } \\
\hline Age 4-7 & $\begin{array}{c}1.572 \\
(0.083)\end{array}$ & $\begin{array}{c}0.049 \\
(0.118)\end{array}$ & $\begin{array}{c}1.191 \\
(0.032)\end{array}$ & $\begin{array}{l}-0.027 \\
(0.045)\end{array}$ & $\begin{array}{c}0.076 \\
(0.155)\end{array}$ \\
\hline Age 8-14 & $\begin{array}{c}1.476 \\
(0.080)\end{array}$ & $\begin{array}{l}-0.099 \\
(0.111)\end{array}$ & $\begin{array}{c}0.952 \\
(0.029)\end{array}$ & $\begin{array}{l}-0.011 \\
(0.041)\end{array}$ & $\begin{array}{l}-0.089 \\
(0.144)\end{array}$ \\
\hline Age $15-18$ & $\begin{array}{c}2.461 \\
(0.104)\end{array}$ & $\begin{array}{c}-0.363 * * \\
(0.141)\end{array}$ & $\begin{array}{c}1.384 \\
(0.035)\end{array}$ & $\begin{array}{c}0.007 \\
(0.049)\end{array}$ & $\begin{array}{c}-0.370 * * \\
(0.179)\end{array}$ \\
\hline \multicolumn{6}{|c|}{ External Mortality } \\
\hline Age 4-7 & $\begin{array}{c}2.316 \\
(0.100)\end{array}$ & $\begin{array}{c}-0.265^{*} \\
(0.138)\end{array}$ & $\begin{array}{c}1.133 \\
(0.031)\end{array}$ & $\begin{array}{l}-0.057 \\
(0.044)\end{array}$ & $\begin{array}{l}-0.208 \\
(0.169)\end{array}$ \\
\hline Age 8-14 & $\begin{array}{l}1.705 \\
(0.086)\end{array}$ & $\begin{array}{l}-0.194 \\
(0.118)\end{array}$ & $\begin{array}{c}1.069 \\
(0.030)\end{array}$ & $\begin{array}{c}0.016 \\
(0.043)\end{array}$ & $\begin{array}{l}-0.210 \\
(0.153)\end{array}$ \\
\hline Age $15-18$ & $\begin{array}{c}5.793 \\
(0.159)\end{array}$ & $\begin{array}{l}-0.118 \\
(0.223)\end{array}$ & $\begin{array}{c}4.630 \\
(0.063)\end{array}$ & $\begin{array}{c}0.058 \\
(0.090)\end{array}$ & $\begin{array}{l}-0.176 \\
(0.301)\end{array}$ \\
\hline
\end{tabular}

Notes: Mortality rates for each age group are calculated as the sum of the total number of deaths divided by the sum of the population at risk for those ages. Counts of deaths are from the NVSS Multiple Cause of Death files for the years 1980-2007. The population at risk for each age is calculated as the population at birth minus the number of deaths for all preceding ages. Population counts at birth are from the NVSS Birth Data files for the years 1980-2007. Standard errors are calculated based on the binomial distribution, $* * * \mathrm{p}<0.01, * * \mathrm{p}<0.05, *$ $\mathrm{p}<0.1$. 
Table 9. Change in Mortality in High Eligibility Gain States for Children Born after September 30, 1983

\begin{tabular}{|c|c|c|c|c|c|c|c|c|c|}
\hline & \multicolumn{3}{|c|}{ Ages 4-7 } & \multicolumn{3}{|c|}{ Ages 8-14 } & \multicolumn{3}{|c|}{ Ages 15-18 } \\
\hline & $\begin{array}{c}\text { All } \\
\text { causes } \\
(1) \\
\end{array}$ & $\begin{array}{c}\text { Internal } \\
\text { causes } \\
(2)\end{array}$ & $\begin{array}{c}\text { External } \\
\text { causes } \\
(3)\end{array}$ & $\begin{array}{c}\text { All } \\
\text { causes } \\
(4)\end{array}$ & $\begin{array}{c}\text { Internal } \\
\text { causes } \\
(5)\end{array}$ & $\begin{array}{c}\text { External } \\
\text { causes } \\
(6)\end{array}$ & $\begin{array}{c}\text { All } \\
\text { causes } \\
(7) \\
\end{array}$ & $\begin{array}{c}\text { Internal } \\
\text { causes } \\
(8)\end{array}$ & $\begin{array}{c}\text { External } \\
\text { causes } \\
(9)\end{array}$ \\
\hline \multicolumn{10}{|l|}{ All children } \\
\hline Linear & $\begin{array}{c}0.011 \\
(0.077)\end{array}$ & $\begin{array}{c}0.024 \\
(0.056)\end{array}$ & $\begin{array}{l}-0.013 \\
(0.065)\end{array}$ & $\begin{array}{c}0.033 \\
(0.058)\end{array}$ & $\begin{array}{c}0.010 \\
(0.040)\end{array}$ & $\begin{array}{c}0.023 \\
(0.040)\end{array}$ & $\begin{array}{c}0.464 * * * \\
(0.133)\end{array}$ & $\begin{array}{c}0.039 \\
(0.055)\end{array}$ & $\begin{array}{c}0.425^{* * * *} \\
(0.138)\end{array}$ \\
\hline Linear spline & $\begin{array}{l}-0.007 \\
(0.076)\end{array}$ & $\begin{array}{c}0.019 \\
(0.058)\end{array}$ & $\begin{array}{l}-0.026 \\
(0.064)\end{array}$ & $\begin{array}{l}0.095^{*} \\
(0.053)\end{array}$ & $\begin{array}{c}0.028 \\
(0.038)\end{array}$ & $\begin{array}{l}0.067 * \\
(0.037)\end{array}$ & $\begin{array}{c}0.483 * * * \\
(0.126)\end{array}$ & $\begin{array}{c}0.038 \\
(0.057)\end{array}$ & $\begin{array}{c}0.446 * * * \\
(0.133)\end{array}$ \\
\hline Quadratic & $\begin{array}{l}-0.006 \\
(0.076)\end{array}$ & $\begin{array}{c}0.021 \\
(0.057)\end{array}$ & $\begin{array}{l}-0.026 \\
(0.064)\end{array}$ & $\begin{array}{c}0.086 \\
(0.053)\end{array}$ & $\begin{array}{c}0.023 \\
(0.038)\end{array}$ & $\begin{array}{l}0.063^{*} \\
(0.036)\end{array}$ & $\begin{array}{c}0.486 * * * \\
(0.128)\end{array}$ & $\begin{array}{c}0.037 \\
(0.056)\end{array}$ & $\begin{array}{c}0.449 * * * \\
(0.134)\end{array}$ \\
\hline Quadratic spline & $\begin{array}{l}-0.164 \\
(0.109)\end{array}$ & $\begin{array}{l}-0.099 \\
(0.086)\end{array}$ & $\begin{array}{l}-0.065 \\
(0.103)\end{array}$ & $\begin{array}{c}0.022 \\
(0.072)\end{array}$ & $\begin{array}{c}-0.003 \\
(0.050)\end{array}$ & $\begin{array}{c}0.025 \\
(0.056)\end{array}$ & $\begin{array}{c}0.258 \\
(0.194)\end{array}$ & $\begin{array}{c}0.029 \\
(0.109)\end{array}$ & $\begin{array}{c}0.229 \\
(0.209)\end{array}$ \\
\hline Baseline mean & 2.656 & 1.271 & 1.384 & 2.491 & 1.086 & 1.405 & 7.185 & 1.603 & 5.582 \\
\hline \multicolumn{10}{|l|}{ Black children } \\
\hline Linear & $\begin{array}{c}0.227 \\
(0.241)\end{array}$ & $\begin{array}{l}-0.009 \\
(0.147)\end{array}$ & $\begin{array}{c}0.236 \\
(0.188)\end{array}$ & $\begin{array}{l}-0.294 \\
(0.192)\end{array}$ & $\begin{array}{l}-0.121 \\
(0.119)\end{array}$ & $\begin{array}{l}-0.172 \\
(0.143)\end{array}$ & $\begin{array}{c}0.264 \\
(0.405)\end{array}$ & $\begin{array}{l}-0.235 \\
(0.195)\end{array}$ & $\begin{array}{c}0.499 \\
(0.390)\end{array}$ \\
\hline Linear spline & $\begin{array}{c}0.181 \\
(0.246)\end{array}$ & $\begin{array}{l}-0.009 \\
(0.147)\end{array}$ & $\begin{array}{c}0.189 \\
(0.187)\end{array}$ & $\begin{array}{l}-0.249 \\
(0.195)\end{array}$ & $\begin{array}{c}-0.138 \\
(0.123)\end{array}$ & $\begin{array}{l}-0.111 \\
(0.144)\end{array}$ & $\begin{array}{c}0.405 \\
(0.373)\end{array}$ & $\begin{array}{l}-0.229 \\
(0.199)\end{array}$ & $\begin{array}{l}0.635^{*} \\
(0.365)\end{array}$ \\
\hline Quadratic & $\begin{array}{c}0.176 \\
(0.242)\end{array}$ & $\begin{array}{l}-0.013 \\
(0.147)\end{array}$ & $\begin{array}{c}0.190 \\
(0.185)\end{array}$ & $\begin{array}{l}-0.253 \\
(0.194)\end{array}$ & $\begin{array}{l}-0.132 \\
(0.122)\end{array}$ & $\begin{array}{l}-0.121 \\
(0.144)\end{array}$ & $\begin{array}{c}0.402 \\
(0.383)\end{array}$ & $\begin{array}{l}-0.233 \\
(0.198)\end{array}$ & $\begin{array}{l}0.635^{*} \\
(0.369)\end{array}$ \\
\hline Quadratic spline & $\begin{array}{l}-0.419 \\
(0.346)\end{array}$ & $\begin{array}{l}-0.189 \\
(0.216)\end{array}$ & $\begin{array}{l}-0.230 \\
(0.279)\end{array}$ & $\begin{array}{l}-0.146 \\
(0.258)\end{array}$ & $\begin{array}{l}-0.156 \\
(0.167)\end{array}$ & $\begin{array}{c}0.010 \\
(0.218)\end{array}$ & $\begin{array}{l}-0.742 \\
(0.449)\end{array}$ & $\begin{array}{l}-0.399 \\
(0.325)\end{array}$ & $\begin{array}{l}-0.343 \\
(0.466)\end{array}$ \\
\hline Baseline mean & 3.610 & 1.535 & 2.076 & 3.437 & 1.473 & 1.964 & 9.344 & 2.403 & 6.941 \\
\hline \multicolumn{10}{|l|}{ White children } \\
\hline Linear & $\begin{array}{c}0.016 \\
(0.082)\end{array}$ & $\begin{array}{c}0.032 \\
(0.061)\end{array}$ & $\begin{array}{l}-0.016 \\
(0.068)\end{array}$ & $\begin{array}{c}0.079 \\
(0.061)\end{array}$ & $\begin{array}{c}0.039 \\
(0.041)\end{array}$ & $\begin{array}{c}0.041 \\
(0.050)\end{array}$ & $\begin{array}{c}0.537 * * * \\
(0.162)\end{array}$ & $\begin{array}{l}0.112 * \\
(0.057)\end{array}$ & $\begin{array}{c}0.425 * * * \\
(0.151)\end{array}$ \\
\hline Linear spline & $\begin{array}{c}0.007 \\
(0.082)\end{array}$ & $\begin{array}{c}0.026 \\
(0.061)\end{array}$ & $\begin{array}{l}-0.019 \\
(0.069)\end{array}$ & $\begin{array}{c}0.137 * * \\
(0.061)\end{array}$ & $\begin{array}{c}0.058 \\
(0.040)\end{array}$ & $\begin{array}{c}0.079 \\
(0.051)\end{array}$ & $\begin{array}{c}0.539 * * * \\
(0.163)\end{array}$ & $\begin{array}{l}0.109^{*} \\
(0.058)\end{array}$ & $\begin{array}{c}0.430^{* * * *} \\
(0.151)\end{array}$ \\
\hline Quadratic & $\begin{array}{c}0.008 \\
(0.082)\end{array}$ & $\begin{array}{c}0.028 \\
(0.061)\end{array}$ & $\begin{array}{l}-0.020 \\
(0.069)\end{array}$ & $\begin{array}{c}0.128 * * \\
(0.060)\end{array}$ & $\begin{array}{c}0.053 \\
(0.041)\end{array}$ & $\begin{array}{c}0.075 \\
(0.049)\end{array}$ & $\begin{array}{c}0.543 * * * \\
(0.163)\end{array}$ & $\begin{array}{l}0.108^{*} \\
(0.057)\end{array}$ & $\begin{array}{c}0.434 * * * \\
(0.150)\end{array}$ \\
\hline Quadratic spline & $\begin{array}{l}-0.131 \\
(0.118)\end{array}$ & $\begin{array}{l}-0.130 \\
(0.085)\end{array}$ & $\begin{array}{l}-0.001 \\
(0.107)\end{array}$ & $\begin{array}{c}0.064 \\
(0.095)\end{array}$ & $\begin{array}{c}0.030 \\
(0.058)\end{array}$ & $\begin{array}{c}0.034 \\
(0.079)\end{array}$ & $\begin{array}{c}0.471 * * \\
(0.236)\end{array}$ & $\begin{array}{c}0.145 \\
(0.093)\end{array}$ & $\begin{array}{c}0.326 \\
(0.227)\end{array}$ \\
\hline Baseline mean & 2.441 & 1.217 & 1.224 & 2.301 & 1.004 & 1.296 & 6.744 & 1.438 & 5.306 \\
\hline
\end{tabular}

Notes: Coefficients from OLS regressions with the specified function in birth cohort, which also includes age, month, and year dummies. Standard errors reported in parentheses are robust and clustered by birth month cohort, *** $\mathrm{p}<0.01, * * \mathrm{p}<0.05, * \mathrm{p}<0.1$. 
Table 10. Change in Mortality in Low Eligibility Gain States for Children Born after September 30, 1983

\begin{tabular}{|c|c|c|c|c|c|c|c|c|c|}
\hline & \multicolumn{3}{|c|}{ Ages 4-7 } & \multicolumn{3}{|c|}{ Ages 8-14 } & \multicolumn{3}{|c|}{ Ages 15-18 } \\
\hline & $\begin{array}{c}\text { All } \\
\text { causes } \\
(1) \\
\end{array}$ & $\begin{array}{c}\text { Internal } \\
\text { causes } \\
(2)\end{array}$ & $\begin{array}{c}\text { External } \\
\text { causes } \\
(3)\end{array}$ & $\begin{array}{c}\text { All } \\
\text { causes } \\
(4)\end{array}$ & $\begin{array}{c}\text { Internal } \\
\text { causes } \\
(5)\end{array}$ & $\begin{array}{c}\text { External } \\
\text { causes } \\
(6)\end{array}$ & $\begin{array}{c}\text { All } \\
\text { causes } \\
(7) \\
\end{array}$ & $\begin{array}{c}\text { Internal } \\
\text { causes } \\
(8)\end{array}$ & $\begin{array}{c}\text { External } \\
\text { causes } \\
(9)\end{array}$ \\
\hline \multicolumn{10}{|l|}{ All children } \\
\hline Linear & $\begin{array}{c}0.090 \\
(0.090)\end{array}$ & $\begin{array}{c}0.088 \\
(0.057)\end{array}$ & $\begin{array}{c}0.002 \\
(0.072)\end{array}$ & $\begin{array}{c}0.017 \\
(0.055)\end{array}$ & $\begin{array}{c}-0.012 \\
(0.041)\end{array}$ & $\begin{array}{c}0.029 \\
(0.045)\end{array}$ & $\begin{array}{c}0.065 \\
(0.177)\end{array}$ & $\begin{array}{l}-0.026 \\
(0.079)\end{array}$ & $\begin{array}{c}0.091 \\
(0.145)\end{array}$ \\
\hline Linear spline & $\begin{array}{c}0.080 \\
(0.093)\end{array}$ & $\begin{array}{c}0.077 \\
(0.059)\end{array}$ & $\begin{array}{c}0.003 \\
(0.074)\end{array}$ & $\begin{array}{c}0.034 \\
(0.057)\end{array}$ & $\begin{array}{l}-0.028 \\
(0.043)\end{array}$ & $\begin{array}{c}0.062 \\
(0.048)\end{array}$ & $\begin{array}{c}0.048 \\
(0.174)\end{array}$ & $\begin{array}{l}-0.040 \\
(0.081)\end{array}$ & $\begin{array}{c}0.088 \\
(0.146)\end{array}$ \\
\hline Quadratic & $\begin{array}{c}0.074 \\
(0.092)\end{array}$ & $\begin{array}{c}0.074 \\
(0.058)\end{array}$ & $\begin{array}{c}0.000 \\
(0.074)\end{array}$ & $\begin{array}{c}0.038 \\
(0.056)\end{array}$ & $\begin{array}{l}-0.021 \\
(0.043)\end{array}$ & $\begin{array}{c}0.059 \\
(0.046)\end{array}$ & $\begin{array}{c}0.044 \\
(0.175)\end{array}$ & $\begin{array}{l}-0.041 \\
(0.080)\end{array}$ & $\begin{array}{c}0.085 \\
(0.147)\end{array}$ \\
\hline Quadratic spline & $\begin{array}{c}0.296 * * \\
(0.117)\end{array}$ & $\begin{array}{c}0.107 \\
(0.085)\end{array}$ & $\begin{array}{l}0.189 * \\
(0.107)\end{array}$ & $\begin{array}{c}0.025 \\
(0.080)\end{array}$ & $\begin{array}{c}-0.017 \\
(0.055)\end{array}$ & $\begin{array}{c}0.042 \\
(0.073)\end{array}$ & $\begin{array}{l}-0.185 \\
(0.280)\end{array}$ & $\begin{array}{c}-0.174 \\
(0.118)\end{array}$ & $\begin{array}{c}-0.011 \\
(0.224)\end{array}$ \\
\hline Baseline mean & 2.502 & 1.211 & 1.292 & 6.186 & 1.467 & 4.719 & 6.186 & 1.467 & 4.719 \\
\hline \multicolumn{10}{|l|}{ Black children } \\
\hline Linear & $\begin{array}{l}-0.131 \\
(0.261)\end{array}$ & $\begin{array}{c}0.167 \\
(0.154)\end{array}$ & $\begin{array}{l}-0.298 \\
(0.237)\end{array}$ & $\begin{array}{l}-0.259 \\
(0.185)\end{array}$ & $\begin{array}{l}-0.102 \\
(0.118)\end{array}$ & $\begin{array}{l}-0.157 \\
(0.141)\end{array}$ & $\begin{array}{l}-0.571 \\
(0.439)\end{array}$ & $\begin{array}{c}-0.352^{*} \\
(0.200)\end{array}$ & $\begin{array}{l}-0.219 \\
(0.359)\end{array}$ \\
\hline Linear spline & $\begin{array}{l}-0.190 \\
(0.258)\end{array}$ & $\begin{array}{c}0.148 \\
(0.159)\end{array}$ & $\begin{array}{l}-0.337 \\
(0.226)\end{array}$ & $\begin{array}{l}-0.228 \\
(0.192)\end{array}$ & $\begin{array}{l}-0.109 \\
(0.121)\end{array}$ & $\begin{array}{l}-0.119 \\
(0.148)\end{array}$ & $\begin{array}{l}-0.564 \\
(0.441)\end{array}$ & $\begin{array}{c}-0.372^{*} \\
(0.200)\end{array}$ & $\begin{array}{l}-0.193 \\
(0.356)\end{array}$ \\
\hline Quadratic & $\begin{array}{l}-0.190 \\
(0.257)\end{array}$ & $\begin{array}{c}0.137 \\
(0.156)\end{array}$ & $\begin{array}{l}-0.327 \\
(0.232)\end{array}$ & $\begin{array}{l}-0.224 \\
(0.189)\end{array}$ & $\begin{array}{l}-0.103 \\
(0.118)\end{array}$ & $\begin{array}{l}-0.121 \\
(0.147)\end{array}$ & $\begin{array}{l}-0.579 \\
(0.440)\end{array}$ & $\begin{array}{c}-0.379 * \\
(0.197)\end{array}$ & $\begin{array}{l}-0.199 \\
(0.359)\end{array}$ \\
\hline Quadratic spline & $\begin{array}{l}-0.119 \\
(0.384)\end{array}$ & $\begin{array}{c}0.230 \\
(0.235)\end{array}$ & $\begin{array}{l}-0.348 \\
(0.301)\end{array}$ & $\begin{array}{c}-0.413 \\
(0.267)\end{array}$ & $\begin{array}{l}-0.159 \\
(0.183)\end{array}$ & $\begin{array}{l}-0.255 \\
(0.232)\end{array}$ & $\begin{array}{l}-0.539 \\
(0.648)\end{array}$ & $\begin{array}{c}-0.528 * \\
(0.278)\end{array}$ & $\begin{array}{c}-0.011 \\
(0.531)\end{array}$ \\
\hline Baseline mean & 3.636 & 1.530 & 2.106 & 3.201 & 1.459 & 1.742 & 8.505 & 2.298 & 6.206 \\
\hline \multicolumn{10}{|l|}{ White children } \\
\hline Linear & $\begin{array}{c}0.094 \\
(0.100)\end{array}$ & $\begin{array}{c}0.068 \\
(0.064)\end{array}$ & $\begin{array}{c}0.026 \\
(0.074)\end{array}$ & $\begin{array}{c}0.082 \\
(0.059)\end{array}$ & $\begin{array}{c}0.003 \\
(0.044)\end{array}$ & $\begin{array}{c}0.079 \\
(0.048)\end{array}$ & $\begin{array}{c}0.094 \\
(0.163)\end{array}$ & $\begin{array}{l}-0.002 \\
(0.071)\end{array}$ & $\begin{array}{c}0.095 \\
(0.142)\end{array}$ \\
\hline Linear spline & $\begin{array}{c}0.088 \\
(0.104)\end{array}$ & $\begin{array}{c}0.058 \\
(0.065)\end{array}$ & $\begin{array}{c}0.030 \\
(0.076)\end{array}$ & $\begin{array}{c}0.098 \\
(0.062)\end{array}$ & $\begin{array}{l}-0.012 \\
(0.045)\end{array}$ & $\begin{array}{c}0.110 * * \\
(0.052)\end{array}$ & $\begin{array}{c}0.068 \\
(0.158)\end{array}$ & $\begin{array}{l}-0.014 \\
(0.073)\end{array}$ & $\begin{array}{c}0.082 \\
(0.140)\end{array}$ \\
\hline Quadratic & $\begin{array}{c}0.082 \\
(0.103)\end{array}$ & $\begin{array}{c}0.056 \\
(0.064)\end{array}$ & $\begin{array}{c}0.026 \\
(0.076)\end{array}$ & $\begin{array}{l}0.103^{*} \\
(0.059)\end{array}$ & $\begin{array}{l}-0.004 \\
(0.045)\end{array}$ & $\begin{array}{c}0.107^{* *} \\
(0.049)\end{array}$ & $\begin{array}{c}0.067 \\
(0.159)\end{array}$ & $\begin{array}{l}-0.013 \\
(0.072)\end{array}$ & $\begin{array}{c}0.079 \\
(0.142)\end{array}$ \\
\hline Quadratic spline & $\begin{array}{c}0.346^{* *} \\
(0.139)\end{array}$ & $\begin{array}{c}0.081 \\
(0.100)\end{array}$ & $\begin{array}{c}0.265^{* *} \\
(0.114)\end{array}$ & $\begin{array}{c}0.092 \\
(0.087)\end{array}$ & $\begin{array}{c}0.008 \\
(0.052)\end{array}$ & $\begin{array}{c}0.084 \\
(0.084)\end{array}$ & $\begin{array}{l}-0.228 \\
(0.266)\end{array}$ & $\begin{array}{c}-0.154 \\
(0.118)\end{array}$ & $\begin{array}{c}-0.074 \\
(0.231)\end{array}$ \\
\hline Baseline mean & 2.334 & 1.174 & 1.160 & 2.104 & 0.968 & 1.136 & 5.830 & 1.342 & 4.488 \\
\hline
\end{tabular}

Notes: Coefficients from OLS regressions with the specified function in birth cohort, which also includes age, month, and year dummies. Standard errors reported in parentheses are robust and clustered by birth month cohort, *** $\mathrm{p}<0.01, * * \mathrm{p}<0.05, * \mathrm{p}<0.1$. 
Table 11. Comparison of Annual Rates of Internal-Cause Death for Children Born One Year Before and After Cutoff for Black and White Children

\begin{tabular}{|c|c|c|c|c|c|c|c|c|c|}
\hline & \multicolumn{3}{|c|}{$\underline{\text { Black Children }}$} & \multicolumn{3}{|c|}{ White Children } & \multirow{2}{*}{\multicolumn{3}{|c|}{$\begin{array}{c}\text { Difference-in-Differences } \\
\text { (Black Post-Pre) - (White Post-Pre) }\end{array}$}} \\
\hline & \multicolumn{3}{|c|}{ (Post-Pre) } & \multicolumn{3}{|c|}{ (Post-Pre) } & & & \\
\hline & $4-7$ & $8-14$ & $15-18$ & $4-7$ & $8-14$ & $15-18$ & $4-7$ & $8-14$ & $15-18$ \\
\hline \multirow[t]{2}{*}{ Deaths due to internal causes } & 0.049 & -0.099 & $-0.363 * *$ & -0.027 & -0.011 & 0.007 & 0.076 & -0.089 & $-0.370 * *$ \\
\hline & $(0.118)$ & $(0.111)$ & $(0.141)$ & $(0.101)$ & $(0.091)$ & $(0.110)$ & $(0.155)$ & $(0.144)$ & $(0.179)$ \\
\hline \multirow[t]{2}{*}{ Infectious and parasitic diseases } & 0.044 & -0.037 & -0.052 & 0.011 & 0.000 & 0.002 & 0.033 & -0.037 & -0.054 \\
\hline & $(0.044)$ & $(0.039)$ & $(0.038)$ & $(0.026)$ & $(0.024)$ & $(0.024)$ & $(0.051)$ & $(0.046)$ & $(0.044)$ \\
\hline \multirow[t]{2}{*}{ Neoplasms (malignant and nonmalignant) } & 0.070 & -0.035 & -0.087 & 0.016 & -0.004 & -0.019 & 0.054 & -0.031 & -0.068 \\
\hline & $(0.054)$ & $(0.051)$ & $(0.060)$ & $(0.056)$ & $(0.050)$ & $(0.057)$ & $(0.078)$ & $(0.071)$ & $(0.083)$ \\
\hline \multirow[t]{2}{*}{ Diseases of blood, blood-forming organs, immune forming mechanisms } & 0.031 & -0.010 & 0.009 & -0.004 & 0.002 & -0.003 & 0.035 & -0.012 & 0.011 \\
\hline & $(0.024)$ & $(0.019)$ & $(0.025)$ & $(0.013)$ & $(0.011)$ & $(0.011)$ & $(0.027)$ & $(0.022)$ & $(0.027)$ \\
\hline \multirow[t]{2}{*}{ Endocrine, nutritional, and metabolic diseases } & $-0.039 * *$ & -0.012 & 0.018 & -0.002 & -0.006 & -0.010 & -0.037 & -0.006 & 0.028 \\
\hline & $(0.019)$ & $(0.020)$ & $(0.028)$ & $(0.025)$ & $(0.022)$ & $(0.028)$ & $(0.031)$ & $(0.030)$ & $(0.040)$ \\
\hline \multirow[t]{2}{*}{ Mental and behavioral disorders } & 0.017 & 0.007 & -0.026 & -0.003 & -0.002 & -0.003 & 0.020 & 0.009 & -0.024 \\
\hline & $(0.012)$ & $(0.010)$ & $(0.019)$ & $(0.012)$ & $(0.011)$ & $(0.015)$ & $(0.017)$ & $(0.015)$ & $(0.024)$ \\
\hline \multirow[t]{2}{*}{ Diseases of the nervous system } & -0.013 & -0.017 & -0.074 & 0.007 & -0.005 & -0.002 & -0.020 & -0.012 & -0.072 \\
\hline & $(0.045)$ & $(0.040)$ & $(0.050)$ & $(0.037)$ & $(0.034)$ & $(0.041)$ & $(0.058)$ & $(0.053)$ & $(0.064)$ \\
\hline \multirow[t]{2}{*}{ Cardiovascular and circulatory system diseases } & 0.026 & 0.018 & -0.022 & -0.023 & -0.009 & -0.002 & 0.049 & 0.027 & -0.020 \\
\hline & $(0.035)$ & $(0.039)$ & $(0.061)$ & $(0.029)$ & $(0.030)$ & $(0.042)$ & $(0.046)$ & $(0.049)$ & $(0.074)$ \\
\hline \multirow[t]{2}{*}{ Respiratory system diseases } & -0.030 & -0.040 & -0.057 & 0.006 & 0.013 & 0.002 & -0.037 & -0.053 & -0.059 \\
\hline & $(0.035)$ & $(0.043)$ & $(0.044)$ & $(0.028)$ & $(0.025)$ & $(0.030)$ & $(0.044)$ & $(0.050)$ & $(0.054)$ \\
\hline \multirow[t]{2}{*}{ Digestive system diseases } & -0.013 & 0.007 & -0.031 & -0.004 & 0.007 & 0.012 & -0.009 & 0.001 & -0.043 \\
\hline & $(0.025)$ & $(0.017)$ & $(0.023)$ & $(0.017)$ & $(0.016)$ & $(0.018)$ & $(0.030)$ & $(0.023)$ & $(0.029)$ \\
\hline \multirow[t]{2}{*}{ Congenital and chromosomal abnormalities } & -0.048 & 0.013 & -0.009 & -0.015 & 0.004 & 0.000 & -0.033 & 0.009 & -0.008 \\
\hline & $(0.045)$ & $(0.033)$ & $(0.039)$ & $(0.041)$ & $(0.030)$ & $(0.033)$ & $(0.061)$ & $(0.045)$ & $(0.051)$ \\
\hline \multirow[t]{2}{*}{ Symptoms and signs not elsewhere classified } & 0.013 & 0.003 & -0.017 & -0.011 & -0.004 & 0.017 & 0.024 & 0.006 & -0.035 \\
\hline & $(0.025)$ & $(0.023)$ & $(0.040)$ & $(0.017)$ & $(0.019)$ & $(0.033)$ & $(0.030)$ & $(0.030)$ & $(0.052)$ \\
\hline \multirow[t]{2}{*}{ All other diseases } & -0.009 & 0.005 & -0.013 & -0.005 & -0.005 & 0.012 & -0.004 & 0.010 & -0.025 \\
\hline & $(0.018)$ & $(0.023)$ & $(0.036)$ & $(0.015)$ & $(0.014)$ & $(0.018)$ & $(0.024)$ & $(0.027)$ & $(0.041)$ \\
\hline
\end{tabular}

Notes: Mortality rates for each age group are calculated as the sum of the total number of deaths divided by the sum of the population at risk for those ages. Counts of death are from the National Vital Statistics System Multiple Cause of Death files for the years 1980 to 2007. The population at risk for each age is calculated as the population at birth minus the number of deaths for all preceding ages. Population counts at birth are from the NVSS Birth Date files for the years 1980 to 2007 . Standard errors are calculated based on the binomial distribution, $* * *$ p $<0.01$, $* * \mathrm{p}<0.05, * \mathrm{p}<0.1$. 
Table 12. Comparison of Annual Rates of External-Cause Death for Children Born One Year Before and After Cutoff for Black and White Children

\begin{tabular}{|c|c|c|c|c|c|c|c|c|c|}
\hline & \multicolumn{3}{|c|}{$\frac{\text { Black Children }}{\text { (Post-Pre) }}$} & \multicolumn{3}{|c|}{$\frac{\text { White Children }}{\text { (Post-Pre) }}$} & \multicolumn{3}{|c|}{$\begin{array}{c}\text { Difference-in-Differences } \\
\text { (Black Post-Pre) - (White Post-Pre) }\end{array}$} \\
\hline & $4-7$ & $8-14$ & $15-18$ & $4-7$ & $8-14$ & $15-18$ & $4-7$ & $8-14$ & $15-18$ \\
\hline \multirow{2}{*}{ Deaths due to external causes } & $-0.265^{*}$ & -0.194 & -0.118 & -0.057 & 0.016 & 0.058 & -0.208 & -0.210 & -0.176 \\
\hline & $(0.138)$ & $(0.118)$ & $(0.223)$ & $(0.098)$ & $(0.097)$ & $(0.201)$ & $(0.169)$ & $(0.153)$ & $(0.301)$ \\
\hline \multirow[t]{2}{*}{ Accidents (unintentional injuries) } & $-0.234 *$ & -0.164 & -0.083 & -0.040 & 0.011 & 0.088 & -0.194 & -0.175 & -0.171 \\
\hline & $(0.128)$ & $(0.102)$ & $(0.142)$ & $(0.094)$ & $(0.086)$ & $(0.172)$ & $(0.159)$ & $(0.133)$ & $(0.223)$ \\
\hline \multirow[t]{2}{*}{ Transport accidents } & $-0.156^{*}$ & $-0.139 *$ & -0.065 & -0.003 & 0.003 & 0.044 & -0.154 & -0.142 & -0.110 \\
\hline & $(0.084)$ & $(0.072)$ & $(0.122)$ & $(0.070)$ & $(0.071)$ & $(0.157)$ & $(0.110)$ & $(0.101)$ & $(0.199)$ \\
\hline \multirow[t]{2}{*}{ Nontransport accidents } & -0.078 & -0.025 & -0.017 & -0.037 & 0.008 & 0.043 & -0.041 & -0.033 & -0.061 \\
\hline & $(0.096)$ & $(0.072)$ & $(0.073)$ & $(0.063)$ & $(0.048)$ & $(0.070)$ & $(0.115)$ & $(0.086)$ & $(0.101)$ \\
\hline \multirow[t]{2}{*}{ Falls } & -0.004 & 0.003 & $-0.022 *$ & -0.002 & 0.003 & -0.010 & -0.003 & 0.000 & -0.012 \\
\hline & $(0.014)$ & $(0.010)$ & $(0.013)$ & $(0.011)$ & $(0.011)$ & $(0.019)$ & $(0.018)$ & $(0.015)$ & $(0.023)$ \\
\hline \multirow[t]{2}{*}{ Accidental discharge of firearms } & -0.009 & -0.007 & 0.004 & -0.003 & -0.007 & -0.004 & -0.006 & -0.001 & 0.009 \\
\hline & $(0.022)$ & $(0.024)$ & $(0.028)$ & $(0.013)$ & $(0.018)$ & $(0.022)$ & $(0.026)$ & $(0.030)$ & $(0.036)$ \\
\hline \multirow{2}{*}{ Accidental drowning and submersion } & $-0.109 * *$ & -0.055 & $-0.087 *$ & -0.004 & -0.006 & -0.008 & $-0.105^{*}$ & -0.049 & -0.079 \\
\hline & $(0.045)$ & $(0.048)$ & $(0.052)$ & $(0.035)$ & $(0.024)$ & $(0.032)$ & $(0.057)$ & $(0.054)$ & $(0.061)$ \\
\hline \multirow[t]{2}{*}{ Accidental exposure to smoke, fire and flames } & 0.057 & 0.025 & 0.035 & -0.019 & 0.001 & 0.003 & 0.076 & 0.024 & 0.032 \\
\hline & $(0.072)$ & $(0.038)$ & $(0.021)$ & $(0.036)$ & $(0.018)$ & $(0.017)$ & $(0.081)$ & $(0.042)$ & $(0.028)$ \\
\hline \multirow[t]{2}{*}{ Accidental poisoning and exposure to noxious substances } & -0.009 & 0.003 & 0.004 & -0.002 & 0.008 & 0.045 & -0.007 & -0.005 & -0.041 \\
\hline & $(0.011)$ & $(0.011)$ & $(0.018)$ & $(0.009)$ & $(0.010)$ & $(0.040)$ & $(0.014)$ & $(0.015)$ & $(0.044)$ \\
\hline \multirow[t]{2}{*}{ Other and unspecified nontransport accidents } & -0.004 & 0.008 & 0.048 & -0.008 & 0.010 & 0.018 & 0.004 & -0.003 & 0.030 \\
\hline & $(0.035)$ & $(0.026)$ & $(0.030)$ & $(0.032)$ & $(0.028)$ & $(0.034)$ & $(0.047)$ & $(0.039)$ & $(0.046)$ \\
\hline \multirow[t]{2}{*}{ Intentional self-harm (suicide) } & 0.009 & 0.027 & -0.052 & -0.002 & 0.005 & -0.042 & 0.010 & 0.022 & -0.010 \\
\hline & $(0.006)$ & $(0.025)$ & $(0.060)$ & $(0.003)$ & $(0.032)$ & $(0.084)$ & $(0.007)$ & $(0.041)$ & $(0.103)$ \\
\hline \multirow[t]{2}{*}{ Assault (homicide) } & -0.017 & -0.047 & 0.026 & -0.012 & -0.004 & 0.019 & -0.005 & -0.044 & 0.007 \\
\hline & $(0.047)$ & $(0.052)$ & $(0.160)$ & $(0.024)$ & $(0.028)$ & $(0.058)$ & $(0.053)$ & $(0.060)$ & $(0.170)$ \\
\hline \multirow[t]{2}{*}{ Legal intervention } & 0.000 & -0.002 & -0.004 & 0.000 & 0.000 & -0.002 & 0.000 & -0.002 & -0.003 \\
\hline & $(0.000)$ & $(0.006)$ & $(0.013)$ & $(0.000)$ & $(0.000)$ & $(0.007)$ & $(0.000)$ & $(0.006)$ & $(0.015)$ \\
\hline \multirow[t]{2}{*}{ Events of undetermined intent } & -0.004 & -0.015 & -0.013 & -0.007 & -0.001 & -0.003 & 0.003 & -0.014 & -0.010 \\
\hline & $(0.019)$ & $(0.013)$ & $(0.019)$ & $(0.007)$ & $(0.011)$ & $(0.022)$ & $(0.020)$ & $(0.017)$ & $(0.029)$ \\
\hline \multirow[t]{2}{*}{ Operations of war and their sequelae } & 0.000 & 0.000 & 0.000 & 0.000 & 0.000 & 0.000 & 0.000 & 0.000 & 0.000 \\
\hline & $(0.000)$ & $(0.000)$ & $(0.000)$ & $(0.000)$ & $(0.000)$ & $(0.000)$ & $(0.000)$ & $(0.000)$ & $(0.000)$ \\
\hline \multirow[t]{2}{*}{ Complications of medical and surgical care } & -0.017 & 0.007 & 0.009 & 0.004 & 0.005 & -0.002 & -0.021 & 0.002 & 0.010 \\
\hline & $(0.011)$ & $(0.010)$ & $(0.006)$ & $(0.010)$ & $(0.008)$ & $(0.010)$ & $(0.015)$ & $(0.013)$ & $(0.011)$ \\
\hline
\end{tabular}

Notes: Mortality rates for each age group are calculated as the sum of the total number of deaths divided by the sum of the population at risk for those ages. Counts of death are from the National Vital Statistics System Multiple Cause of Death files for the years 1980 to 2007. The population at risk for each age is calculated as the population at birth minus the number of deaths for all preceding ages. Population counts at birth are from the NVSS Birth Date files for the years 1980 to 2007 . Standard errors are calculated based on the binomial distribution, $* * *$ p $<0.01$, ** $\mathrm{p}<0.05, * \mathrm{p}<0.1$. 
Figure 1. Average Years of Childhood Eligibility for Medicaid/SCHIP by Birth Cohort and Family Income (\%FPL)

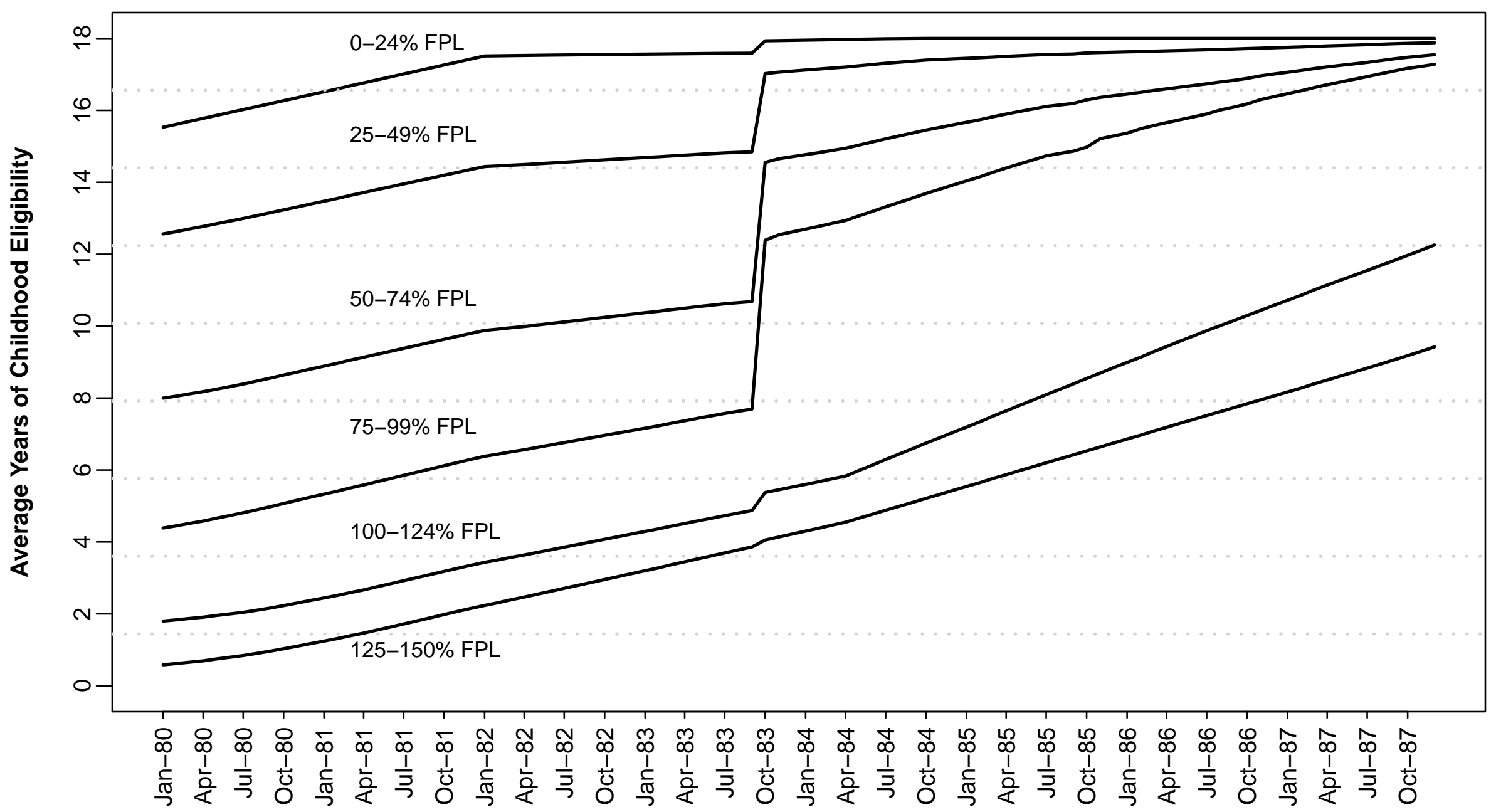

\section{Birth Cohort}

Notes: Weighted average calculated using the characteristics and state of residence of a sample of children of ages 0-17 in the 1981-1988 March CPS. See text for more information. Family income is indexed using the CPI-U and assumed to be constant over the child's lifetime. 
Figure 2. Average Difference in Childhood Eligibility for October vs. September 1983 Birth, by Family Income

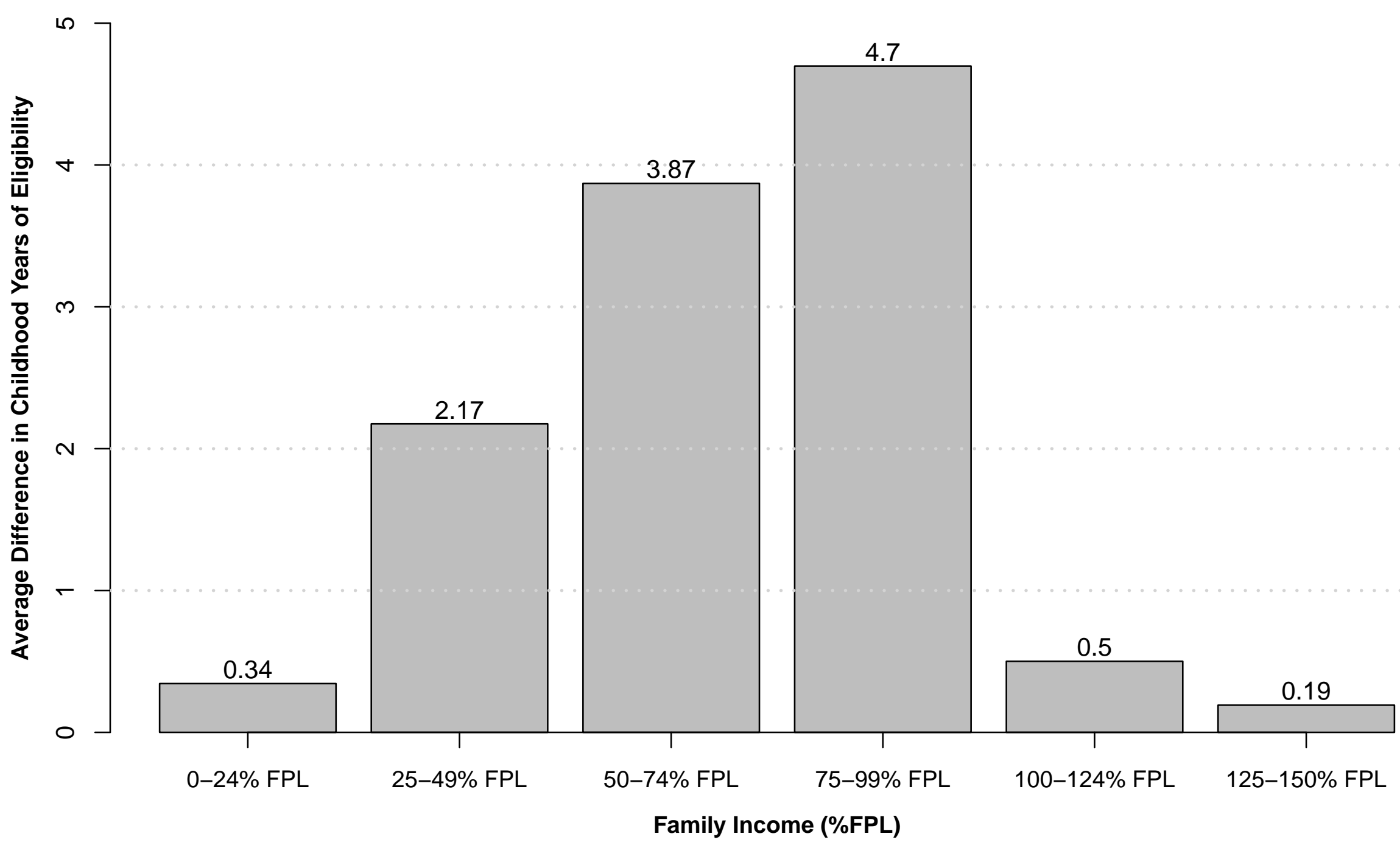

Notes: Weighted average calculated using the characteristics and state of residence of a sample of children of ages 0-17 in the 1981-1988 March CPS. See text for more information. Family income is indexed using the CPI-U and assumed to be constant over the child's lifetime. 
Figure 3. Average Public Eligibility for Each Age of Childhood by Birth Month Cohort, All Races

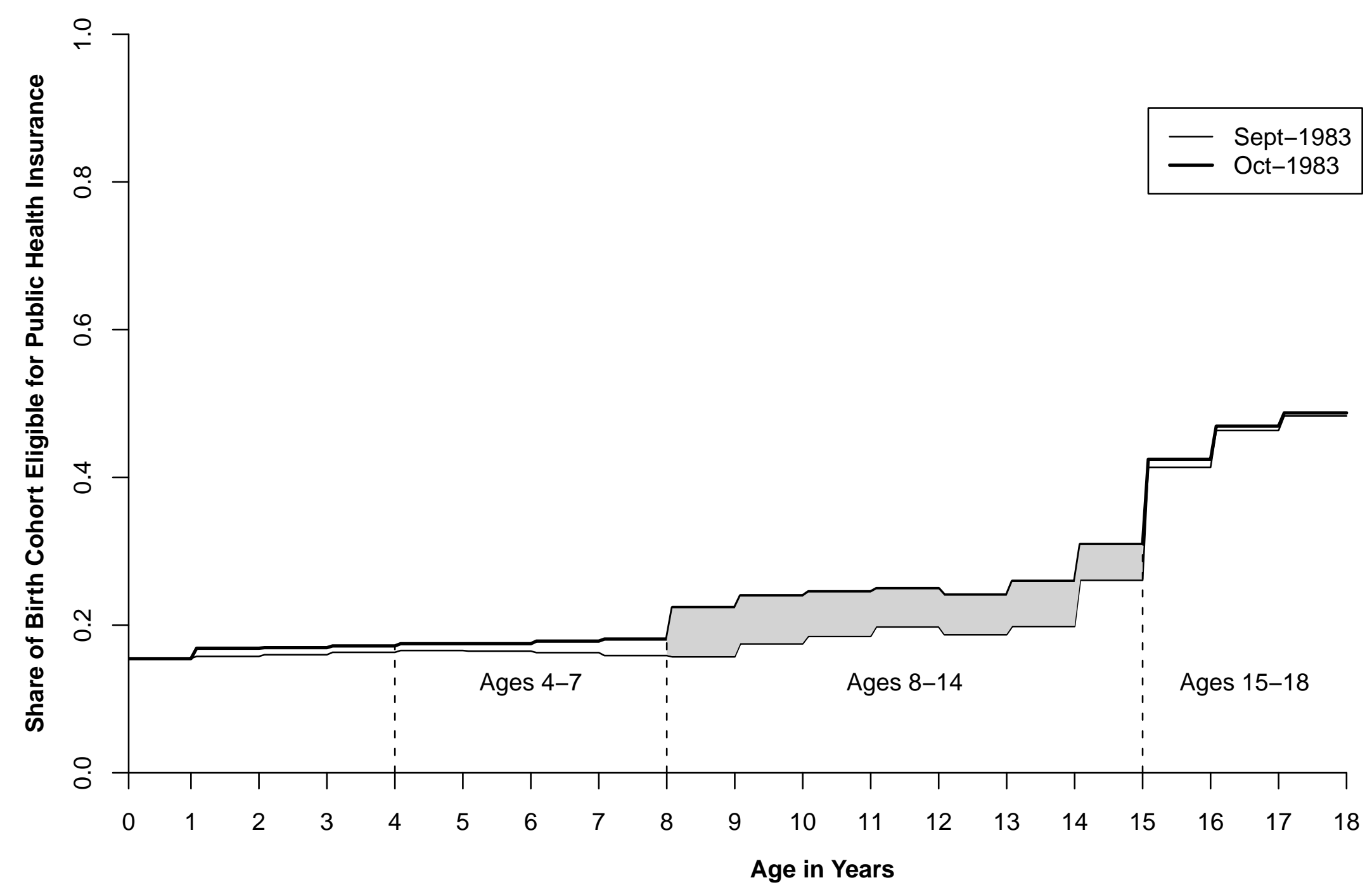

Notes: Weighted average calculated using the characteristics and state of residence of a sample of children of ages $0-17$ in the 1981-1988 March CPS. See text for more information. Family income is indexed using the CPI-U and assumed to be constant over the child's lifetime. 
Figure 5. Mortality Rates by Underlying Cause for Children Ages 1-19, 1983

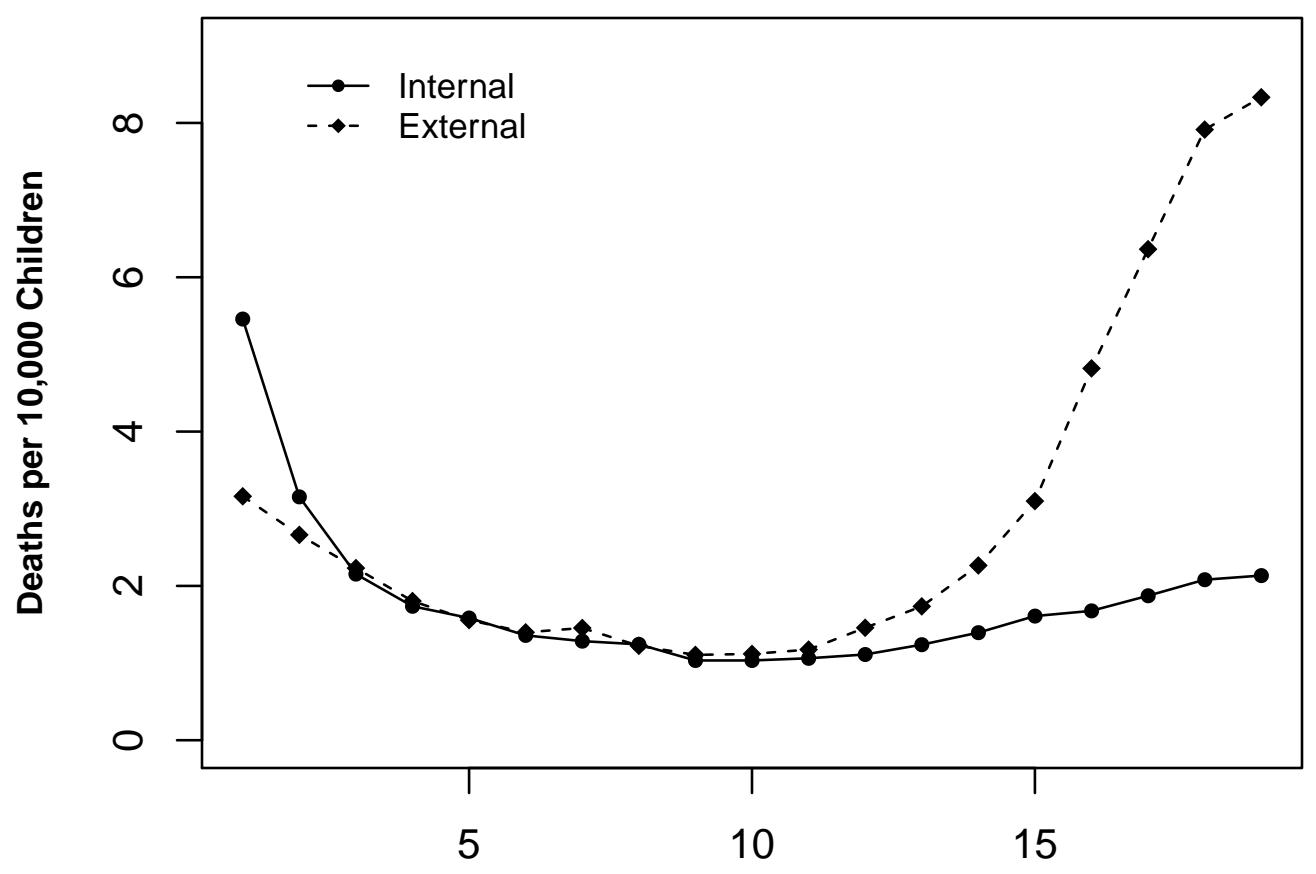

Age in Years

Sources: 1983 NVSS Multiple Cause of Death and Census Bureau population estimates. 
Figure 6: Child Mortality from All Causes
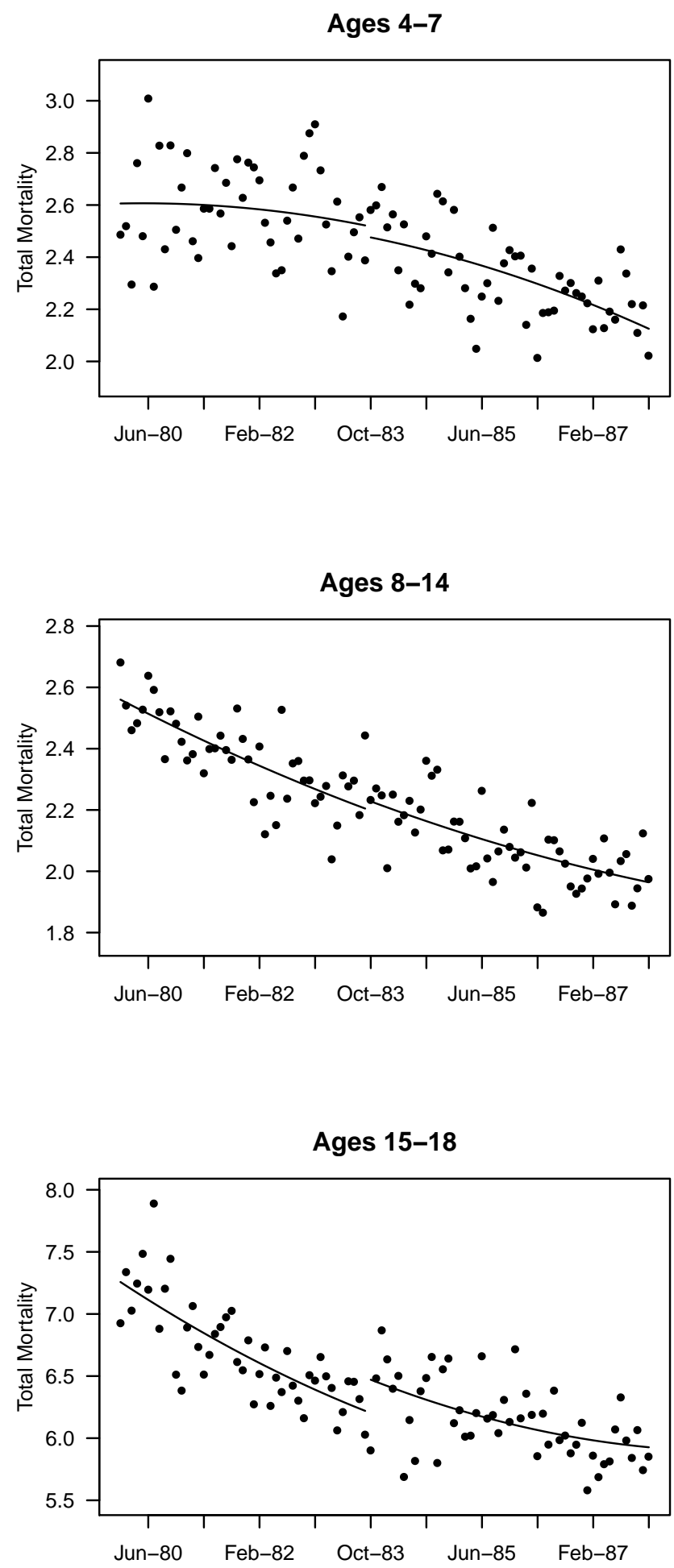

Mortality rates by cohort (per 10,000 children) were constructed using Multiple Cause of Death Data files for the years 19802006 and Birth Data files for 1980-1987. Points represent means of the age-specific mortality rates for each birth cohort, as described in the text. The lines are fitted values from a regression that includes a quadratic in birth cohort and a dummy variable for children born after September 30, 1983. 
Figure 7: Child Mortality by Underlying Cause
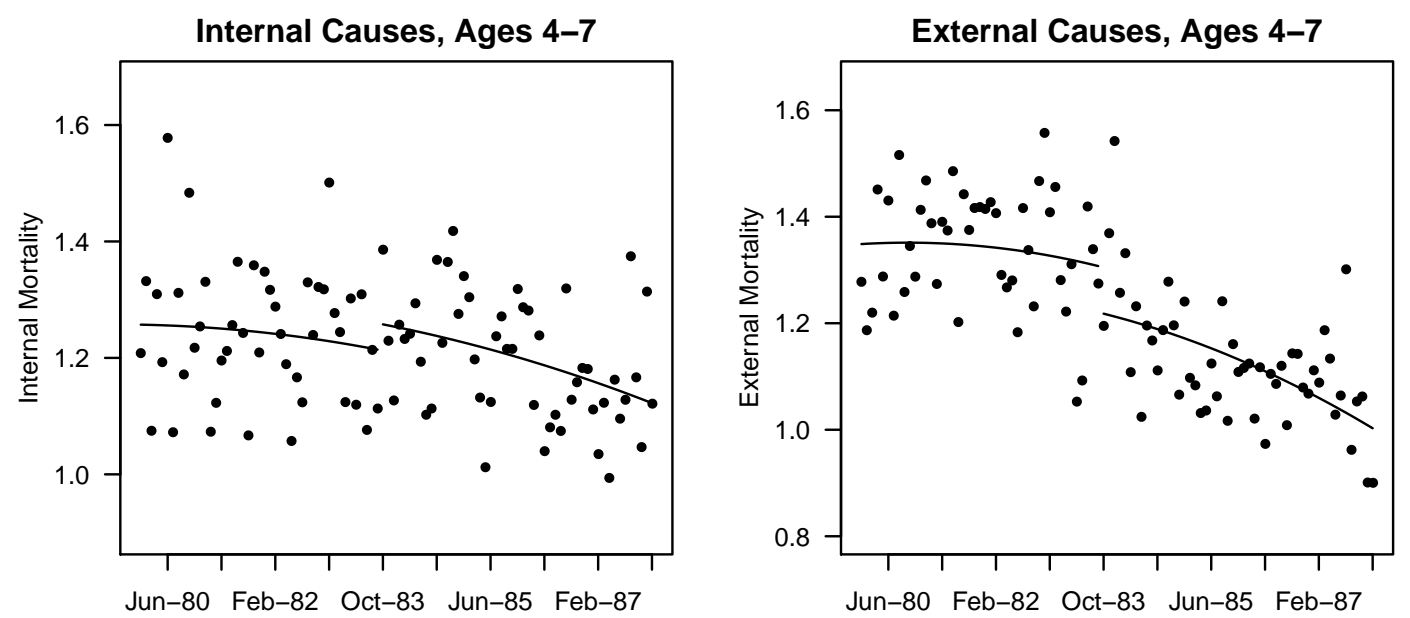

Jun-80 Feb-82 Oct-83 Jun-85 Feb-87
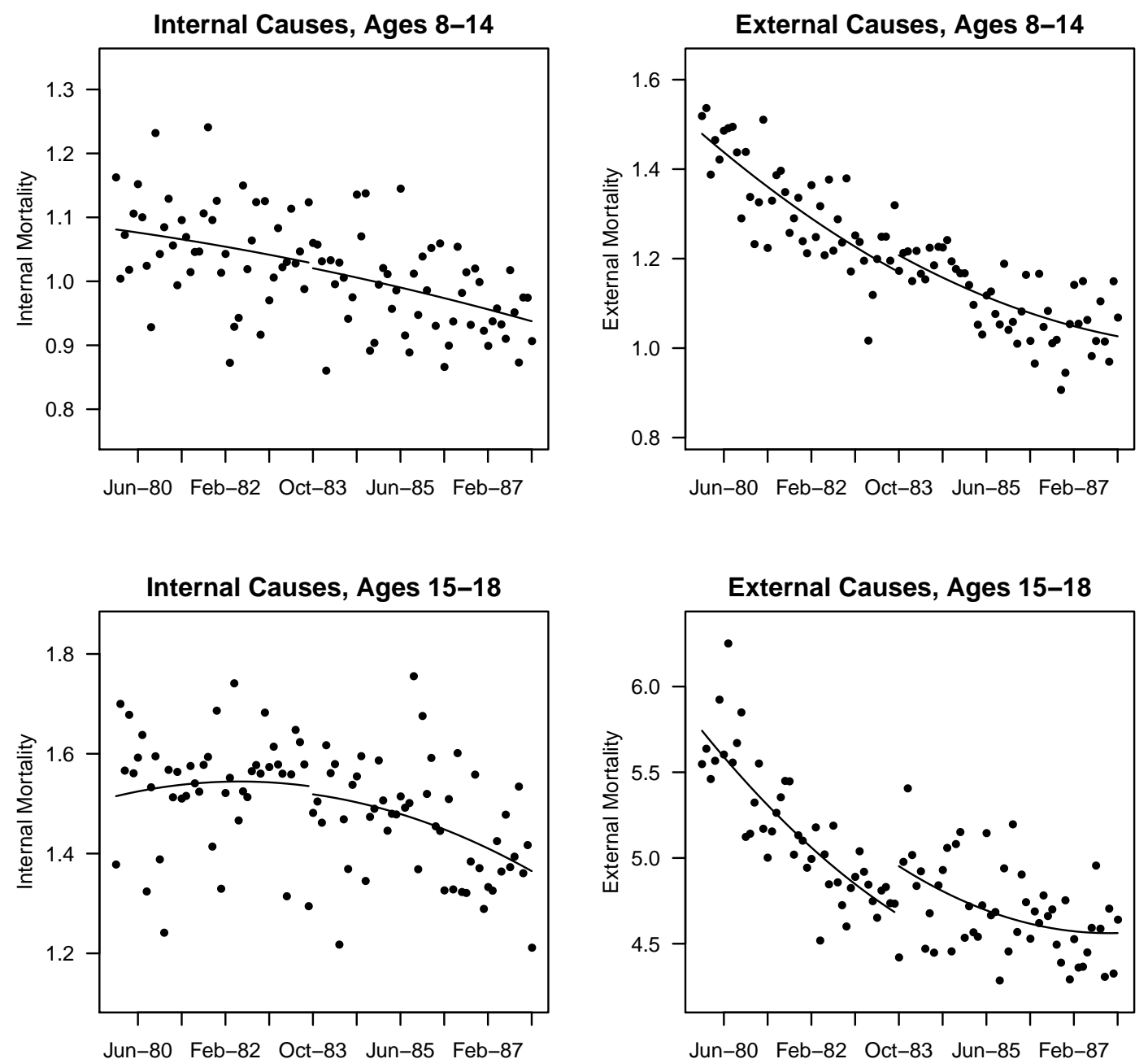

Mortality rates by cohort (per 10,000 children) were constructed using Multiple Cause of Death Data files for the years 19802006 and Birth Data files for 1980-1987. Points represent means of the age-specific mortality rates for each birth cohort, as described in the text. The lines are fitted values from a regression that includes a quadratic in birth cohort and a dummy variable for children born after September 30, 1983. 
Figure 8: Child Mortality from All Causes by Child Race

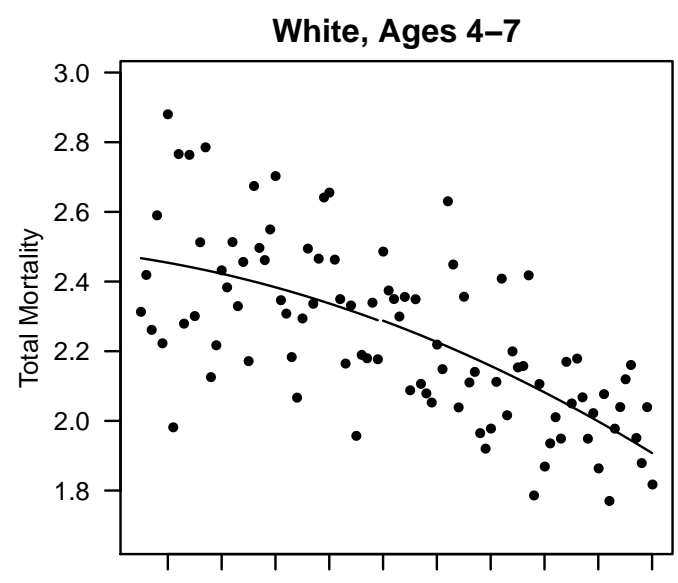

Jun-80 Feb-82 Oct-83 Jun-85 Feb-87

White, Ages 8-14

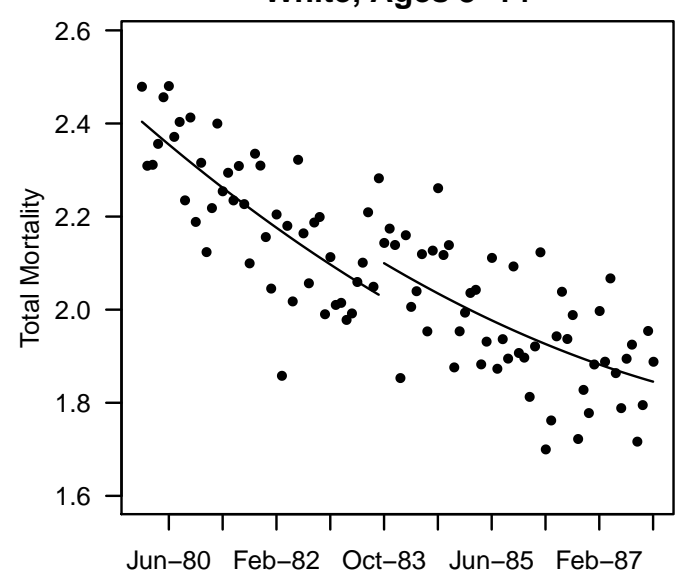

White, Ages 15-18

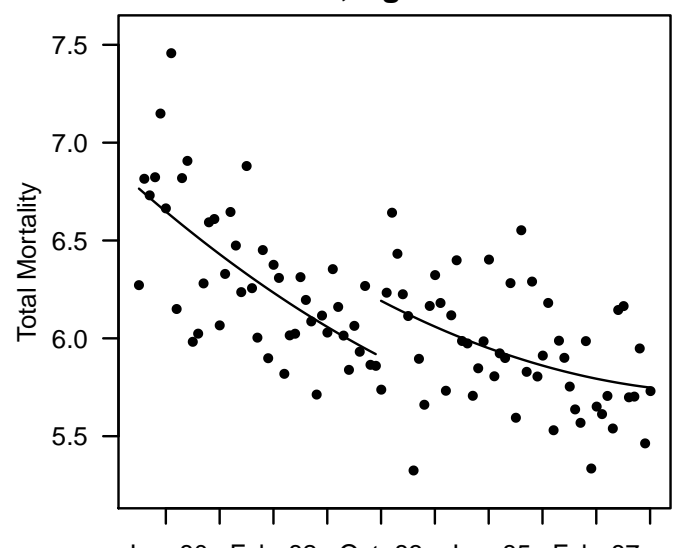

Jun-80 Feb-82 Oct-83 Jun-85 Feb-87

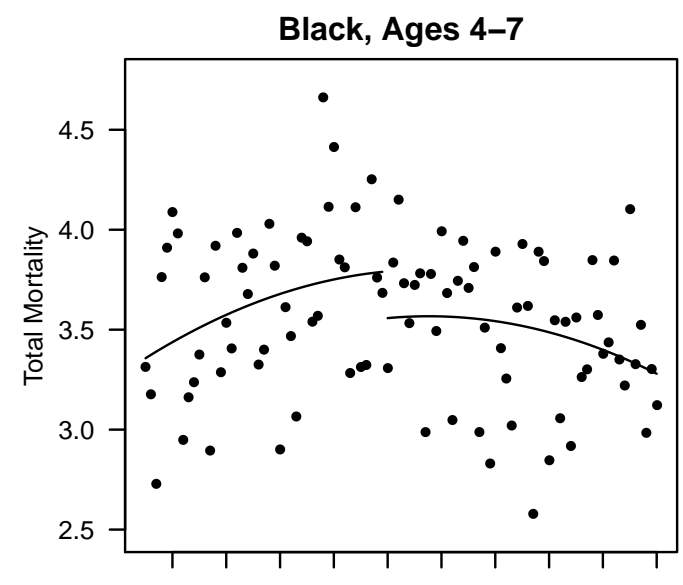

Jun-80 Feb-82 Oct-83 Jun-85 Feb-87
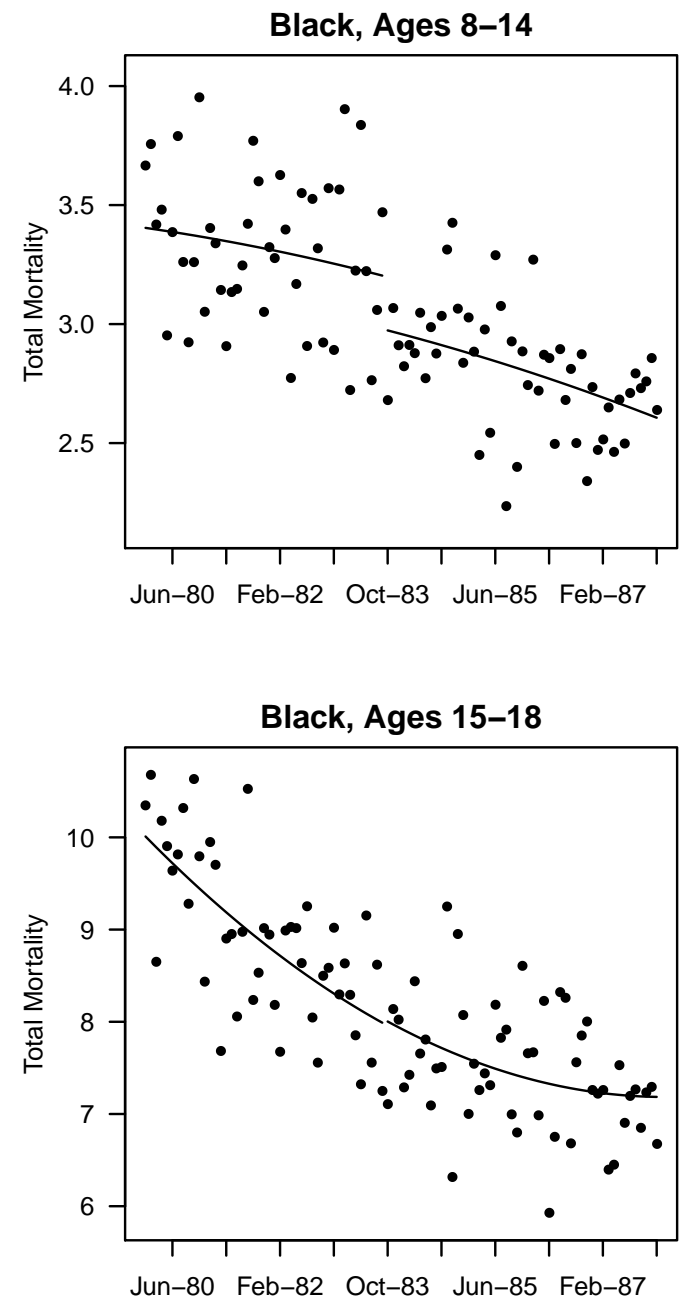

Mortality rates by cohort (per 10,000 children) were constructed using Multiple Cause of Death Data files for the years 19802006 and Birth Data files for 1980-1987. Points represent means of the age-specific mortality rates for each birth cohort, as described in the text. The lines are fitted values from a regression that includes a quadratic in birth cohort and a dummy variable for children born after September 30, 1983. 
Figure 9: Child Mortality from Internal Causes by Child Race

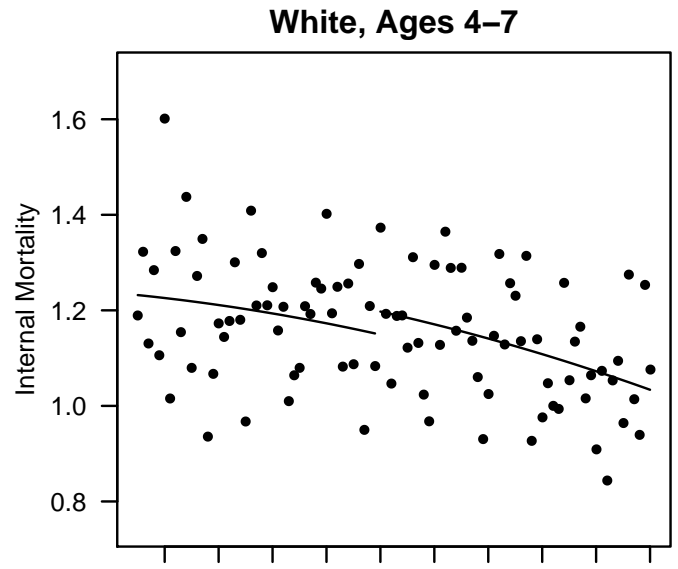

Jun-80 Feb-82 Oct-83 Jun-85 Feb-87

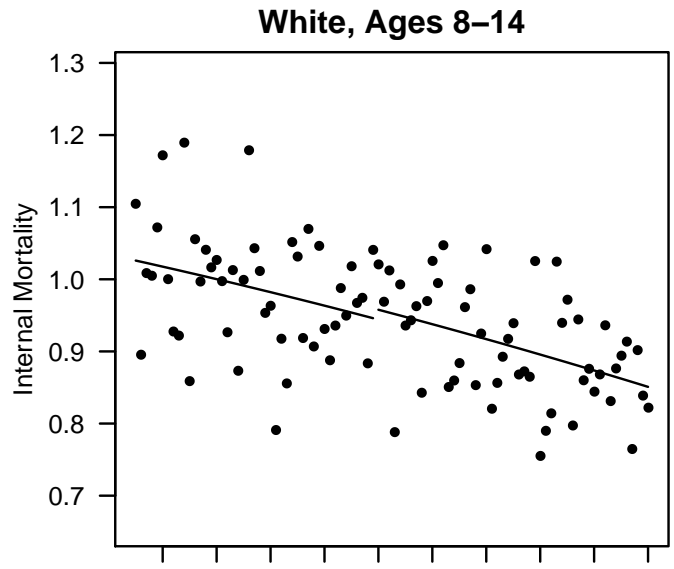

Jun-80 Feb-82 Oct-83 Jun-85 Feb-87

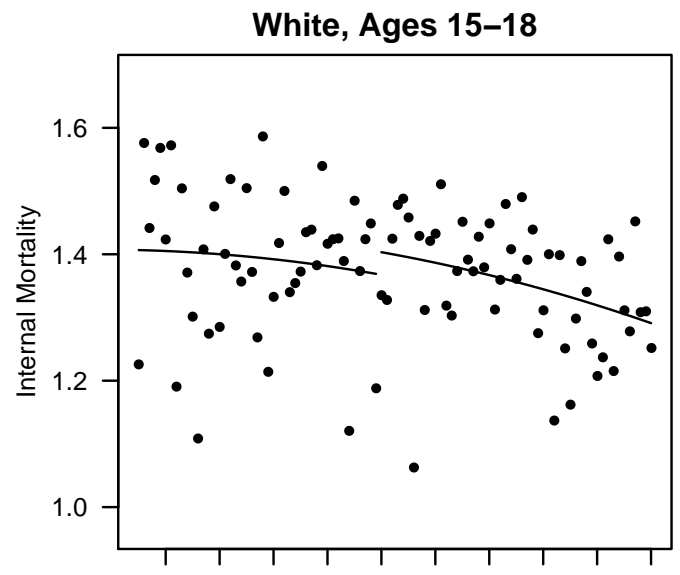

Jun-80 Feb-82 Oct-83 Jun-85 Feb-87

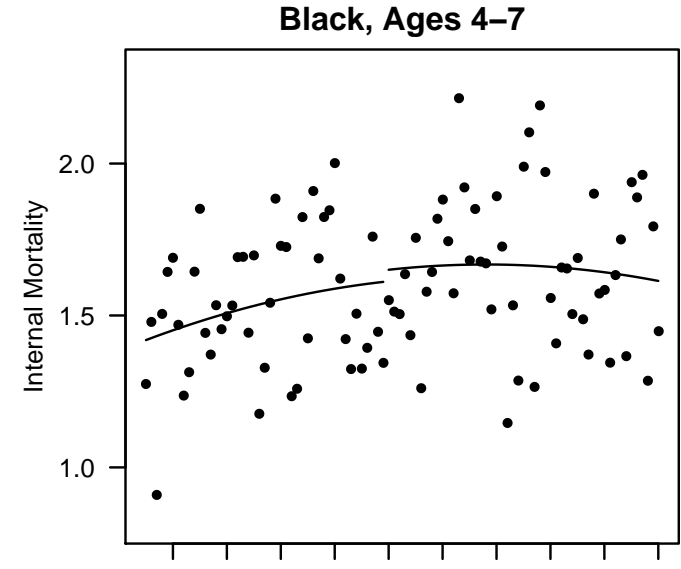

Jun-80 Feb-82 Oct-83 Jun-85 Feb-87
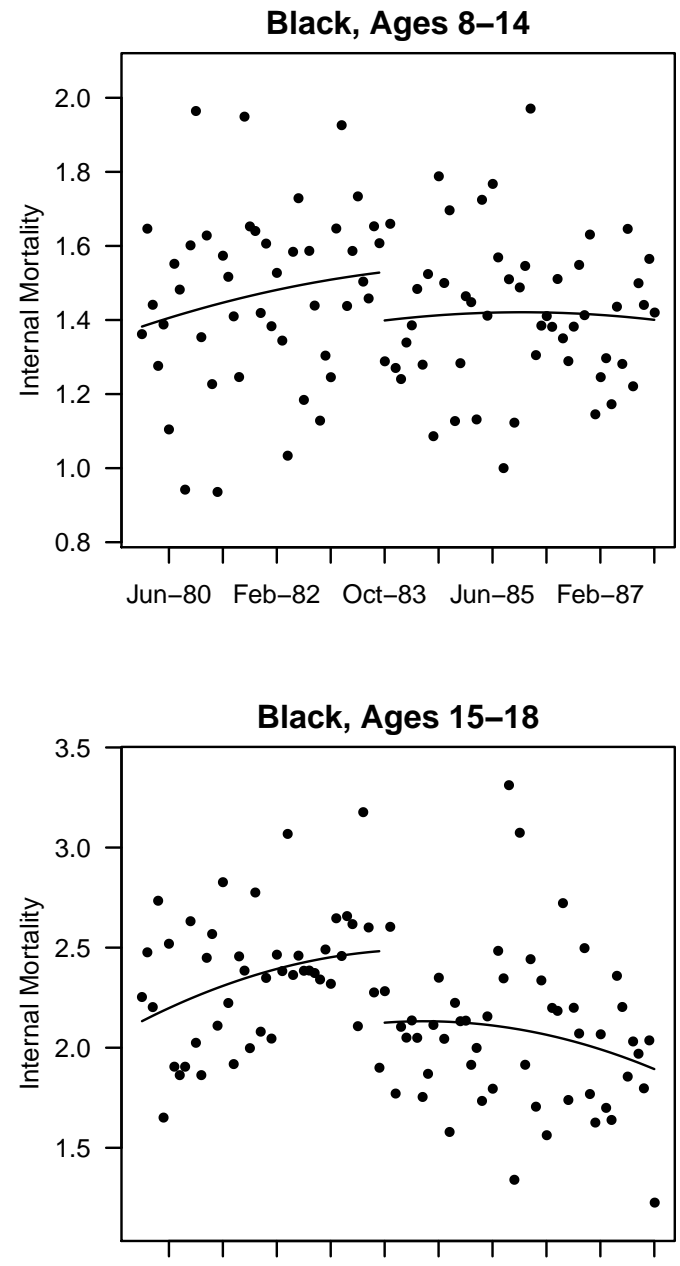

Jun-80 Feb-82 Oct-83 Jun-85 Feb-87

Mortality rates by cohort (per 10,000 children) were constructed using Multiple Cause of Death Data files for the years 19802006 and Birth Data files for 1980-1987. Points represent means of the age-specific mortality rates for each birth cohort, as described in the text. The lines are fitted values from a regression that includes a quadratic in birth cohort and a dummy variable for children born after September 30, 1983. 
Figure 10: Child Mortality from External Causes by Child Race

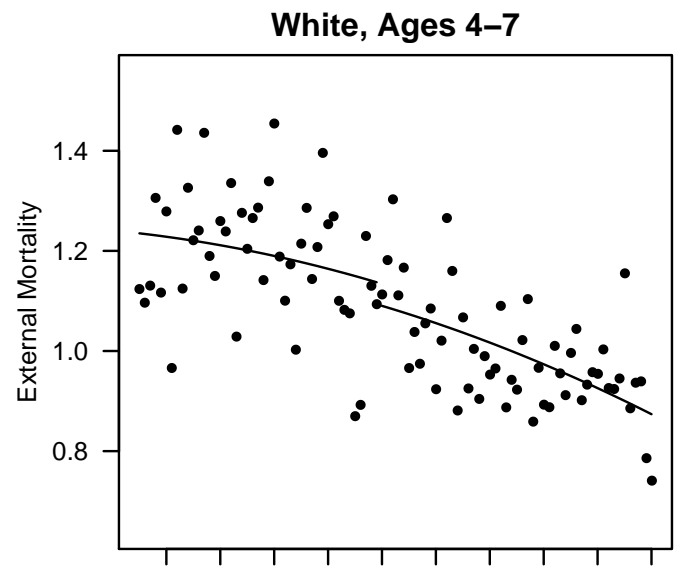

Jun-80 Feb-82 Oct-83 Jun-85 Feb-87

White, Ages 8-14

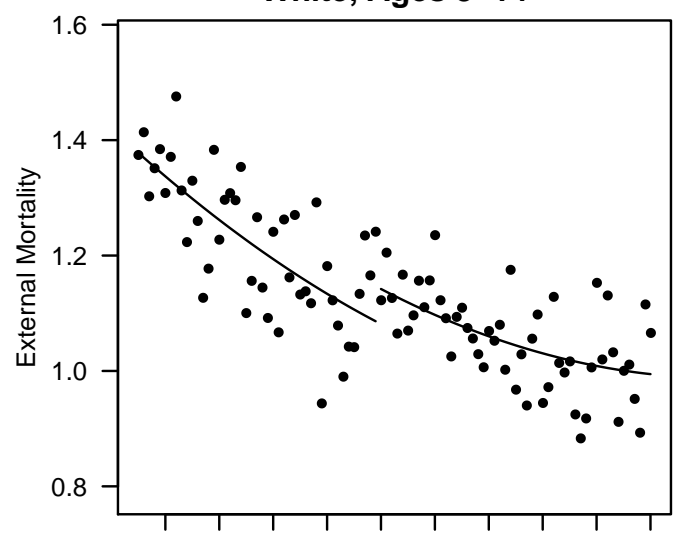

Jun-80 Feb-82 Oct-83 Jun-85 Feb-87

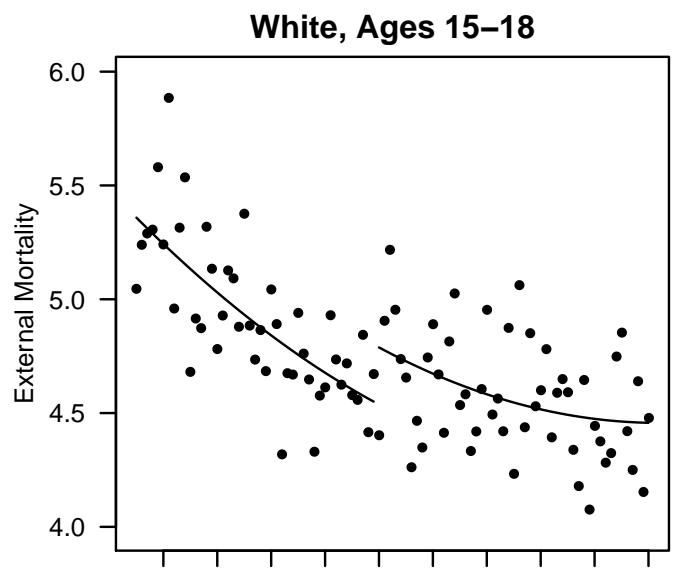

Jun-80 Feb-82 Oct-83 Jun-85 Feb-87
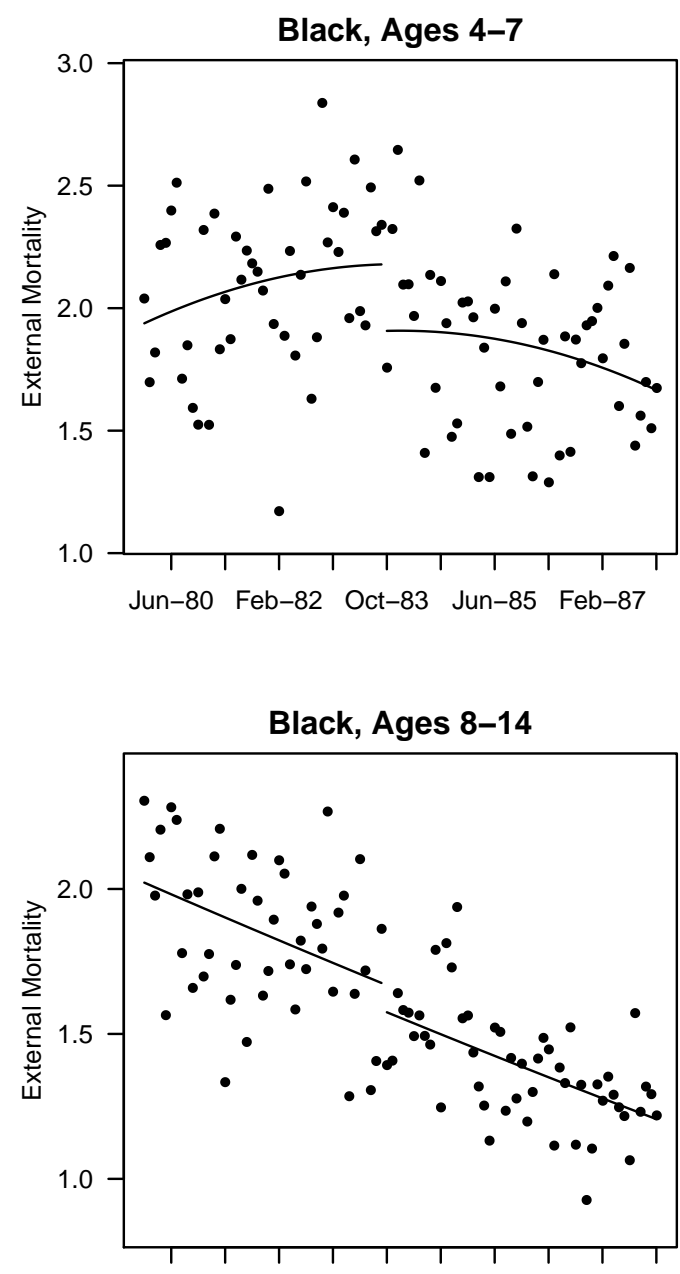

Jun-80 Feb-82 Oct-83 Jun-85 Feb-87

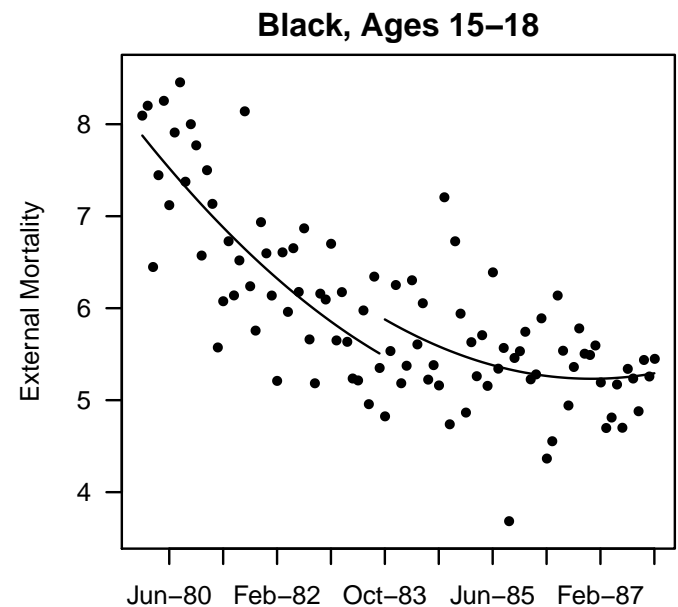

Mortality rates by cohort (per 10,000 children) were constructed using Multiple Cause of Death Data files for the years 19802006 and Birth Data files for 1980-1987. Points represent means of the age-specific mortality rates for each birth cohort, as described in the text. The lines are fitted values from a regression that includes a quadratic in birth cohort and a dummy variable for children born after September 30, 1983. 
Appendix Table 1. Difference in Years of Eligibility by Type of Expansion, Oct. vs. Sept. 1983

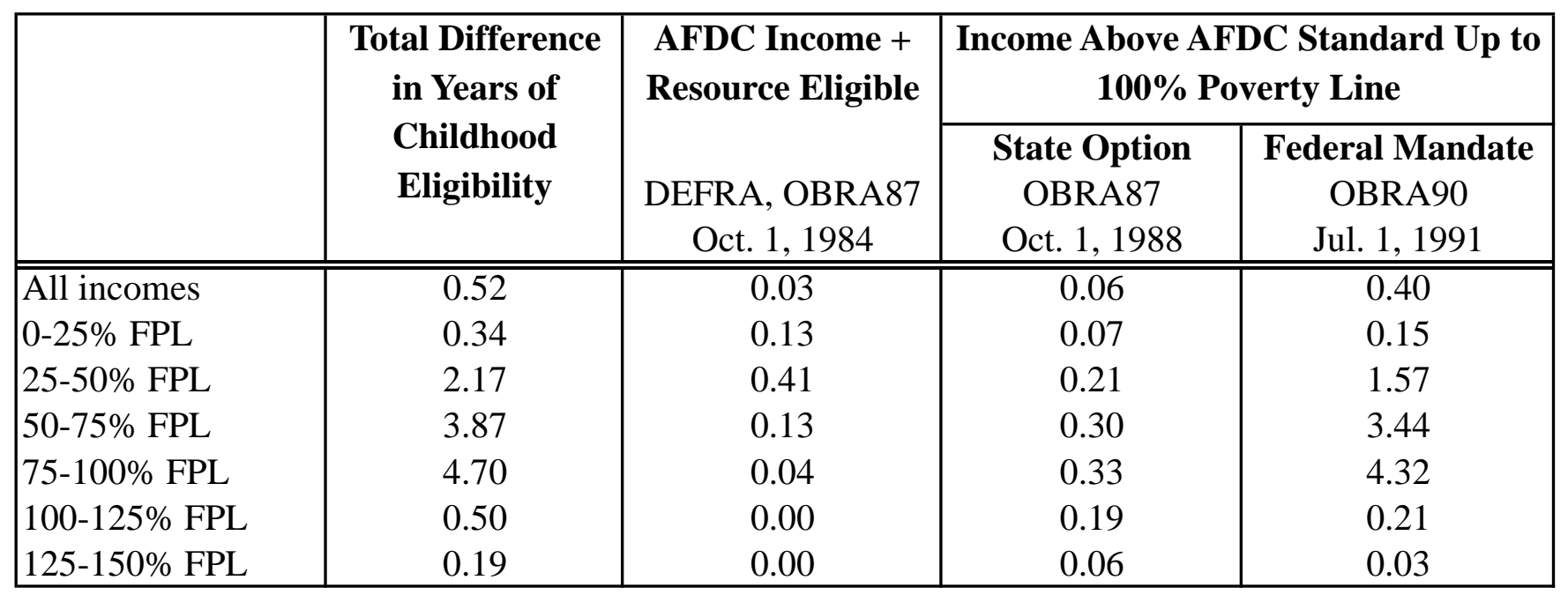

Notes: Weighted average calculated using the characteristics and state of residence of a sample of children of ages 0-17 in the 1981-1988 March CPS. See text for more information. Family income is indexed using the $\mathrm{CPI}-\mathrm{U}$ and assumed to be constant over the child's lifetime. Coverage under federally mandated rules is considered to supplant coverage under state optional rules or programs. Differences in years of eligibility under AFDC- and poverty-related expansions may not always equal total difference in years of childhood eligibility since optional state expansions under SCHIP are not included in the table. 


\section{Appendix Table 2. State Groupings for Eligibiity Gain by Race}

\begin{tabular}{lll}
\hline \hline & High eligibility gain & Low eligibility gain \\
\hline All children & AL, AR, AZ, CO, CT, DC, FL, IA, & AK, CA, DE, GA, HI, KS, MA, ME, \\
& ID, IL, IN, KY, LA, MD, MT, MS, & MI, MO, MN, NC, ND, NY, OR, PA, \\
& NE, NH, NJ, NM, NV, OH, OK, RI, & TN, UT, VA, VT, WA \\
& SC, SD, TX, WI, WV, WY & \\
& & \\
Black children & AL, AR, AZ, CO, CT, DC, FL, IA, & AK, CA, DE, GA, HI, KS, MA, ME, \\
& ID, IL, IN, KY, LA, MD, MS, MT, & MI, MN, MO, NC, ND, NJ, NH, \\
& NE, NV, OH, OK, SC, TX, WY & NM, NY, OR, PA, RI, SD, TN, UT, \\
& & VA, VT, WA, WI, WV \\
White children & AL, AR, AZ, CO, CT, DC, FL, IA, & AK, CA, DE, GA, HI, KS, MA, ME, \\
& ID, IL, IN, KY, LA, MD, MS, MT, & MI, MO, MN, NC, ND, NY, PA, TN, \\
& NE, NH, NJ, NM, NV, OH, OK, & UT, VA, VT, WA \\
& OR, RI, SC, SD, TX, WI, WV, WY & \\
\hline
\end{tabular}

Notes: For each race category, states are classified as having a high eligibility gain by first ranking state-level estimates of the difference in years of eligibility for a child of that race born in October versus September 1983 and then selecting the number of states with the largest average gain in eligibility that comprises $50 \%$ of the national population of children of that race. 
Appendix Table 3. Change in Annual Mortality Rate for Children Born after September 30, 1983 by Age and Race, Three Year Window (Oct. 1980-Sept.1986)

\begin{tabular}{|c|c|c|c|c|c|c|c|c|c|}
\hline & \multicolumn{3}{|c|}{ Ages 4-7 } & \multicolumn{3}{|c|}{ Ages 8-14 } & \multicolumn{3}{|c|}{ Ages 15-18 } \\
\hline & $\begin{array}{c}\text { All } \\
\text { causes } \\
(1)\end{array}$ & $\begin{array}{c}\text { Internal } \\
\text { causes } \\
(2)\end{array}$ & $\begin{array}{c}\text { External } \\
\text { causes } \\
(3)\end{array}$ & $\begin{array}{c}\text { All } \\
\text { causes } \\
(4) \\
\end{array}$ & $\begin{array}{c}\text { Internal } \\
\text { causes } \\
(5)\end{array}$ & $\begin{array}{c}\text { External } \\
\text { causes } \\
(6)\end{array}$ & $\begin{array}{c}\text { All } \\
\text { causes } \\
(7) \\
\end{array}$ & $\begin{array}{c}\text { Internal } \\
\text { causes } \\
(8)\end{array}$ & $\begin{array}{c}\text { External } \\
\text { causes } \\
(9)\end{array}$ \\
\hline \multicolumn{10}{|l|}{ All children } \\
\hline Linear & $\begin{array}{c}-0.004 \\
(0.058)\end{array}$ & $\begin{array}{c}0.002 \\
(0.048)\end{array}$ & $\begin{array}{l}-0.005 \\
(0.057)\end{array}$ & $\begin{array}{c}0.083 \\
(0.050)\end{array}$ & $\begin{array}{c}0.037 \\
(0.039)\end{array}$ & $\begin{array}{c}0.045 \\
(0.039)\end{array}$ & $\begin{array}{c}0.068 \\
(0.123)\end{array}$ & $\begin{array}{c}-0.057 \\
(0.052)\end{array}$ & $\begin{array}{c}0.125 \\
(0.110)\end{array}$ \\
\hline Linear spline & $\begin{array}{l}-0.007 \\
(0.059)\end{array}$ & $\begin{array}{l}-0.001 \\
(0.048)\end{array}$ & $\begin{array}{l}-0.006 \\
(0.058)\end{array}$ & $\begin{array}{c}0.100 * * \\
(0.047)\end{array}$ & $\begin{array}{c}0.036 \\
(0.040)\end{array}$ & $\begin{array}{c}0.063 \\
(0.038)\end{array}$ & $\begin{array}{c}0.067 \\
(0.123)\end{array}$ & $\begin{array}{l}-0.060 \\
(0.053)\end{array}$ & $\begin{array}{c}0.126 \\
(0.110)\end{array}$ \\
\hline Quadratic & $\begin{array}{c}-0.004 \\
(0.058)\end{array}$ & $\begin{array}{c}0.002 \\
(0.048)\end{array}$ & $\begin{array}{l}-0.005 \\
(0.058)\end{array}$ & $\begin{array}{l}0.091 * \\
(0.047)\end{array}$ & $\begin{array}{c}0.037 \\
(0.040)\end{array}$ & $\begin{array}{c}0.054 \\
(0.037)\end{array}$ & $\begin{array}{c}0.068 \\
(0.123)\end{array}$ & $\begin{array}{c}-0.057 \\
(0.052)\end{array}$ & $\begin{array}{c}0.125 \\
(0.111)\end{array}$ \\
\hline Quadratic spline & $\begin{array}{c}0.040 \\
(0.081)\end{array}$ & $\begin{array}{l}-0.039 \\
(0.075)\end{array}$ & $\begin{array}{c}0.080 \\
(0.100)\end{array}$ & $\begin{array}{l}-0.034 \\
(0.064)\end{array}$ & $\begin{array}{c}-0.024 \\
(0.044)\end{array}$ & $\begin{array}{l}-0.010 \\
(0.053)\end{array}$ & $\begin{array}{c}0.098 \\
(0.224)\end{array}$ & $\begin{array}{c}-0.013 \\
(0.088)\end{array}$ & $\begin{array}{c}0.111 \\
(0.204)\end{array}$ \\
\hline Baseline mean & 2.58 & 1.24 & 1.35 & 2.33 & 1.06 & 1.28 & 6.56 & 1.53 & 5.03 \\
\hline \multicolumn{10}{|l|}{ Black children } \\
\hline Linear & $\begin{array}{l}-0.109 \\
(0.176)\end{array}$ & $\begin{array}{c}0.028 \\
(0.114)\end{array}$ & $\begin{array}{l}-0.137 \\
(0.169)\end{array}$ & $\begin{array}{l}-0.187 \\
(0.152)\end{array}$ & $\begin{array}{l}-0.022 \\
(0.117)\end{array}$ & $\begin{array}{l}-0.165 \\
(0.124)\end{array}$ & $\begin{array}{l}-0.387 \\
(0.329)\end{array}$ & $\begin{array}{c}-0.400^{* *} \\
(0.157)\end{array}$ & $\begin{array}{c}0.013 \\
(0.313)\end{array}$ \\
\hline Linear spline & $\begin{array}{l}-0.126 \\
(0.172)\end{array}$ & $\begin{array}{c}0.031 \\
(0.112)\end{array}$ & $\begin{array}{l}-0.156 \\
(0.153)\end{array}$ & $\begin{array}{l}-0.181 \\
(0.155)\end{array}$ & $\begin{array}{l}-0.038 \\
(0.119)\end{array}$ & $\begin{array}{l}-0.144 \\
(0.125)\end{array}$ & $\begin{array}{l}-0.363 \\
(0.319)\end{array}$ & $\begin{array}{c}-0.397 * * \\
(0.159)\end{array}$ & $\begin{array}{c}0.034 \\
(0.299)\end{array}$ \\
\hline Quadratic & $\begin{array}{l}-0.109 \\
(0.168)\end{array}$ & $\begin{array}{c}0.028 \\
(0.114)\end{array}$ & $\begin{array}{l}-0.137 \\
(0.155)\end{array}$ & $\begin{array}{l}-0.189 \\
(0.154)\end{array}$ & $\begin{array}{l}-0.031 \\
(0.117)\end{array}$ & $\begin{array}{c}-0.158 \\
(0.124)\end{array}$ & $\begin{array}{l}-0.387 \\
(0.321)\end{array}$ & $\begin{array}{c}-0.400 * * \\
(0.158)\end{array}$ & $\begin{array}{c}0.013 \\
(0.305)\end{array}$ \\
\hline Quadratic spline & $\begin{array}{l}-0.199 \\
(0.240)\end{array}$ & $\begin{array}{c}-0.146 \\
(0.170)\end{array}$ & $\begin{array}{l}-0.054 \\
(0.241)\end{array}$ & $\begin{array}{c}-0.413 * * \\
(0.182)\end{array}$ & $\begin{array}{l}-0.224 \\
(0.143)\end{array}$ & $\begin{array}{l}-0.188 \\
(0.169)\end{array}$ & $\begin{array}{l}-0.513 \\
(0.457)\end{array}$ & $\begin{array}{l}-0.173 \\
(0.268)\end{array}$ & $\begin{array}{l}-0.340 \\
(0.398)\end{array}$ \\
\hline Baseline mean & 3.67 & 1.57 & 2.10 & 3.29 & 1.49 & 1.80 & 8.66 & 2.39 & 6.27 \\
\hline \multicolumn{10}{|l|}{ White children } \\
\hline Linear & $\begin{array}{c}0.011 \\
(0.066)\end{array}$ & $\begin{array}{l}-0.019 \\
(0.054)\end{array}$ & $\begin{array}{c}0.030 \\
(0.055)\end{array}$ & $\begin{array}{c}0.130^{* *} \\
(0.050)\end{array}$ & $\begin{array}{c}0.051 \\
(0.036)\end{array}$ & $\begin{array}{l}0.080^{*} \\
(0.045)\end{array}$ & $\begin{array}{c}0.147 \\
(0.140)\end{array}$ & $\begin{array}{c}0.009 \\
(0.053)\end{array}$ & $\begin{array}{c}0.138 \\
(0.124)\end{array}$ \\
\hline Linear spline & $\begin{array}{c}0.010 \\
(0.067)\end{array}$ & $\begin{array}{l}-0.022 \\
(0.054)\end{array}$ & $\begin{array}{c}0.032 \\
(0.056)\end{array}$ & $\begin{array}{c}0.148 * * * \\
(0.051)\end{array}$ & $\begin{array}{c}0.051 \\
(0.038)\end{array}$ & $\begin{array}{c}0.097 * * \\
(0.047)\end{array}$ & $\begin{array}{c}0.141 \\
(0.138)\end{array}$ & $\begin{array}{c}0.005 \\
(0.054)\end{array}$ & $\begin{array}{c}0.136 \\
(0.123)\end{array}$ \\
\hline Quadratic & $\begin{array}{c}0.011 \\
(0.067)\end{array}$ & $\begin{array}{c}-0.019 \\
(0.054)\end{array}$ & $\begin{array}{c}0.030 \\
(0.055)\end{array}$ & $\begin{array}{c}0.140 * * * \\
(0.049)\end{array}$ & $\begin{array}{c}0.051 \\
(0.037)\end{array}$ & $\begin{array}{l}0.089 * \\
(0.045)\end{array}$ & $\begin{array}{c}0.147 \\
(0.138)\end{array}$ & $\begin{array}{c}0.009 \\
(0.052)\end{array}$ & $\begin{array}{c}0.138 \\
(0.124)\end{array}$ \\
\hline Quadratic spline & $\begin{array}{c}0.060 \\
(0.094)\end{array}$ & $\begin{array}{c}-0.044 \\
(0.083)\end{array}$ & $\begin{array}{c}0.104 \\
(0.093)\end{array}$ & $\begin{array}{c}0.034 \\
(0.076)\end{array}$ & $\begin{array}{c}0.010 \\
(0.046)\end{array}$ & $\begin{array}{c}0.023 \\
(0.068)\end{array}$ & $\begin{array}{c}0.210 \\
(0.232)\end{array}$ & $\begin{array}{c}0.033 \\
(0.074)\end{array}$ & $\begin{array}{c}0.177 \\
(0.214)\end{array}$ \\
\hline Baseline mean & 2.38 & 1.19 & 1.20 & 2.16 & 0.98 & 1.18 & 6.19 & 1.38 & 4.82 \\
\hline$N$ & & 144 & & & 216 & & & 144 & \\
\hline
\end{tabular}

Notes: Coefficients from OLS regressions with the specified function in birth cohort, which also includes age, month, and year dummies. Standard errors reported in parentheses are robust and clustered by birth month cohort, $* * * \mathrm{p}<0.01, * * \mathrm{p}<0.05, * \mathrm{p}<0.1$ 
Appendix Table 4. Change in Annual Mortality Rate for Children Born after September 30, 1983 by Age and Race, Two Year Window (Oct. 1981-Sept.1985)

\begin{tabular}{|c|c|c|c|c|c|c|c|c|c|}
\hline & \multicolumn{3}{|c|}{ Ages 4-7 } & \multicolumn{3}{|c|}{ Ages 8-14 } & \multicolumn{3}{|c|}{ Ages 15-18 } \\
\hline & $\begin{array}{c}\text { All } \\
\text { causes } \\
(1)\end{array}$ & $\begin{array}{c}\text { Internal } \\
\text { causes } \\
(2)\end{array}$ & $\begin{array}{c}\text { External } \\
\text { causes } \\
(3)\end{array}$ & $\begin{array}{c}\text { All } \\
\text { causes } \\
(4)\end{array}$ & $\begin{array}{c}\text { Internal } \\
\text { causes } \\
(5)\end{array}$ & $\begin{array}{c}\text { External } \\
\text { causes } \\
(6)\end{array}$ & $\begin{array}{c}\text { All } \\
\text { causes } \\
(7) \\
\end{array}$ & $\begin{array}{c}\text { Internal } \\
\text { causes } \\
(8)\end{array}$ & $\begin{array}{c}\text { External } \\
\text { causes } \\
(9)\end{array}$ \\
\hline \multicolumn{10}{|l|}{ All children } \\
\hline Linear & $\begin{array}{c}-0.098 \\
(0.071)\end{array}$ & $\begin{array}{l}-0.103 \\
(0.072)\end{array}$ & $\begin{array}{c}0.005 \\
(0.085)\end{array}$ & $\begin{array}{c}0.070 \\
(0.058)\end{array}$ & $\begin{array}{c}0.049 \\
(0.051)\end{array}$ & $\begin{array}{c}0.021 \\
(0.049)\end{array}$ & $\begin{array}{c}0.046 \\
(0.143)\end{array}$ & $\begin{array}{c}-0.056 \\
(0.069)\end{array}$ & $\begin{array}{c}0.102 \\
(0.148)\end{array}$ \\
\hline Linear spline & $\begin{array}{l}-0.100 \\
(0.070)\end{array}$ & $\begin{array}{l}-0.103 \\
(0.072)\end{array}$ & $\begin{array}{c}0.003 \\
(0.084)\end{array}$ & $\begin{array}{c}0.073 \\
(0.056)\end{array}$ & $\begin{array}{c}0.048 \\
(0.053)\end{array}$ & $\begin{array}{c}0.025 \\
(0.050)\end{array}$ & $\begin{array}{c}0.046 \\
(0.144)\end{array}$ & $\begin{array}{l}-0.054 \\
(0.071)\end{array}$ & $\begin{array}{c}0.100 \\
(0.147)\end{array}$ \\
\hline Quadratic & $\begin{array}{l}-0.090 \\
(0.069)\end{array}$ & $\begin{array}{l}-0.101 \\
(0.073)\end{array}$ & $\begin{array}{c}0.011 \\
(0.087)\end{array}$ & $\begin{array}{c}0.070 \\
(0.059)\end{array}$ & $\begin{array}{c}0.052 \\
(0.052)\end{array}$ & $\begin{array}{c}0.018 \\
(0.047)\end{array}$ & $\begin{array}{c}0.048 \\
(0.147)\end{array}$ & $\begin{array}{l}-0.060 \\
(0.067)\end{array}$ & $\begin{array}{c}0.109 \\
(0.151)\end{array}$ \\
\hline Quadratic spline & $\begin{array}{l}-0.059 \\
(0.093)\end{array}$ & $\begin{array}{l}-0.058 \\
(0.087)\end{array}$ & $\begin{array}{l}-0.001 \\
(0.121)\end{array}$ & $\begin{array}{c}0.007 \\
(0.084)\end{array}$ & $\begin{array}{c}0.048 \\
(0.059)\end{array}$ & $\begin{array}{l}-0.040 \\
(0.052)\end{array}$ & $\begin{array}{c}0.251 \\
(0.192)\end{array}$ & $\begin{array}{c}0.113 \\
(0.128)\end{array}$ & $\begin{array}{c}0.138 \\
(0.180)\end{array}$ \\
\hline Baseline mean & 2.57 & 1.24 & 1.33 & 2.29 & 1.05 & 1.25 & 6.43 & 1.55 & 4.88 \\
\hline \multicolumn{10}{|l|}{ Black children } \\
\hline Linear & $\begin{array}{c}-0.446^{*} \\
(0.266)\end{array}$ & $\begin{array}{c}-0.313 * * \\
(0.135)\end{array}$ & $\begin{array}{l}-0.133 \\
(0.249)\end{array}$ & $\begin{array}{c}-0.367^{*} \\
(0.198)\end{array}$ & $\begin{array}{c}-0.082 \\
(0.151)\end{array}$ & $\begin{array}{c}-0.285^{*} \\
(0.158)\end{array}$ & $\begin{array}{l}-0.658^{*} \\
(0.381)\end{array}$ & $\begin{array}{l}-0.247 \\
(0.223)\end{array}$ & $\begin{array}{l}-0.411 \\
(0.369)\end{array}$ \\
\hline Linear spline & $\begin{array}{c}-0.470^{*} \\
(0.236)\end{array}$ & $\begin{array}{c}-0.313^{* *} \\
(0.134)\end{array}$ & $\begin{array}{l}-0.156 \\
(0.241)\end{array}$ & $\begin{array}{c}-0.349 * \\
(0.190)\end{array}$ & $\begin{array}{c}-0.084 \\
(0.152)\end{array}$ & $\begin{array}{l}-0.266^{*} \\
(0.149)\end{array}$ & $\begin{array}{l}-0.635 \\
(0.408)\end{array}$ & $\begin{array}{l}-0.238 \\
(0.231)\end{array}$ & $\begin{array}{l}-0.397 \\
(0.383)\end{array}$ \\
\hline Quadratic & $\begin{array}{c}-0.372 \\
(0.225)\end{array}$ & $\begin{array}{c}-0.308 * * \\
(0.137)\end{array}$ & $\begin{array}{l}-0.064 \\
(0.240)\end{array}$ & $\begin{array}{c}-0.382^{*} \\
(0.191)\end{array}$ & $\begin{array}{l}-0.077 \\
(0.155)\end{array}$ & $\begin{array}{c}-0.305 * * \\
(0.150)\end{array}$ & $\begin{array}{l}-0.717^{*} \\
(0.400)\end{array}$ & $\begin{array}{l}-0.277 \\
(0.225)\end{array}$ & $\begin{array}{c}-0.441 \\
(0.380)\end{array}$ \\
\hline Quadratic spline & $\begin{array}{l}-0.181 \\
(0.289)\end{array}$ & $\begin{array}{l}-0.143 \\
(0.188)\end{array}$ & $\begin{array}{l}-0.038 \\
(0.327)\end{array}$ & $\begin{array}{c}-0.274 \\
(0.230)\end{array}$ & $\begin{array}{c}-0.014 \\
(0.174)\end{array}$ & $\begin{array}{l}-0.260 \\
(0.195)\end{array}$ & $\begin{array}{c}0.061 \\
(0.641)\end{array}$ & $\begin{array}{c}0.137 \\
(0.370)\end{array}$ & $\begin{array}{l}-0.076 \\
(0.624)\end{array}$ \\
\hline Baseline mean & 3.72 & 1.56 & 2.15 & 3.28 & 1.49 & 1.79 & 8.42 & 2.45 & 5.97 \\
\hline \multicolumn{10}{|l|}{ White children } \\
\hline Linear & $\begin{array}{l}-0.047 \\
(0.087)\end{array}$ & $\begin{array}{l}-0.072 \\
(0.076)\end{array}$ & $\begin{array}{c}0.025 \\
(0.080)\end{array}$ & $\begin{array}{c}0.144 * * \\
(0.063)\end{array}$ & $\begin{array}{c}0.076 \\
(0.047)\end{array}$ & $\begin{array}{c}0.069 \\
(0.067)\end{array}$ & $\begin{array}{c}0.187 \\
(0.154)\end{array}$ & $\begin{array}{l}-0.001 \\
(0.061)\end{array}$ & $\begin{array}{c}0.188 \\
(0.154)\end{array}$ \\
\hline Linear spline & $\begin{array}{l}-0.046 \\
(0.088)\end{array}$ & $\begin{array}{l}-0.072 \\
(0.077)\end{array}$ & $\begin{array}{c}0.026 \\
(0.081)\end{array}$ & $\begin{array}{c}0.142 * * \\
(0.065)\end{array}$ & $\begin{array}{c}0.074 \\
(0.049)\end{array}$ & $\begin{array}{c}0.067 \\
(0.069)\end{array}$ & $\begin{array}{c}0.182 \\
(0.152)\end{array}$ & $\begin{array}{c}-0.001 \\
(0.063)\end{array}$ & $\begin{array}{c}0.184 \\
(0.152)\end{array}$ \\
\hline Quadratic & $\begin{array}{l}-0.050 \\
(0.087)\end{array}$ & $\begin{array}{l}-0.071 \\
(0.077)\end{array}$ & $\begin{array}{c}0.021 \\
(0.083)\end{array}$ & $\begin{array}{c}0.148 * * \\
(0.065)\end{array}$ & $\begin{array}{c}0.079 \\
(0.047)\end{array}$ & $\begin{array}{c}0.070 \\
(0.065)\end{array}$ & $\begin{array}{c}0.202 \\
(0.154)\end{array}$ & $\begin{array}{c}0.001 \\
(0.060)\end{array}$ & $\begin{array}{c}0.202 \\
(0.153)\end{array}$ \\
\hline Quadratic spline & $\begin{array}{l}-0.069 \\
(0.109)\end{array}$ & $\begin{array}{l}-0.064 \\
(0.094)\end{array}$ & $\begin{array}{l}-0.005 \\
(0.117)\end{array}$ & $\begin{array}{c}0.047 \\
(0.085)\end{array}$ & $\begin{array}{c}0.047 \\
(0.056)\end{array}$ & $\begin{array}{l}-0.001 \\
(0.071)\end{array}$ & $\begin{array}{l}0.335^{*} \\
(0.184)\end{array}$ & $\begin{array}{c}0.141 \\
(0.100)\end{array}$ & $\begin{array}{c}0.194 \\
(0.199)\end{array}$ \\
\hline Baseline mean & 2.37 & 1.19 & 1.18 & 2.12 & 0.97 & 1.15 & 6.08 & 1.39 & 4.70 \\
\hline$\underline{\mathbf{N}}$ & & 96 & & & 144 & & & 96 & \\
\hline
\end{tabular}

Notes: Coefficients from OLS regressions with the specified function in birth cohort, which also includes age, month, and year dummies. Standard errors reported in parentheses are robust and clustered by birth month cohort, $* * * \mathrm{p}<0.01, * * \mathrm{p}<0.05, * \mathrm{p}<0.1$ 
Appendix Table 5. Comparison of Annual Rates of Internal-Cause Death for Children Born One Year Before and After Cutoff at Ages 19-22 by Race

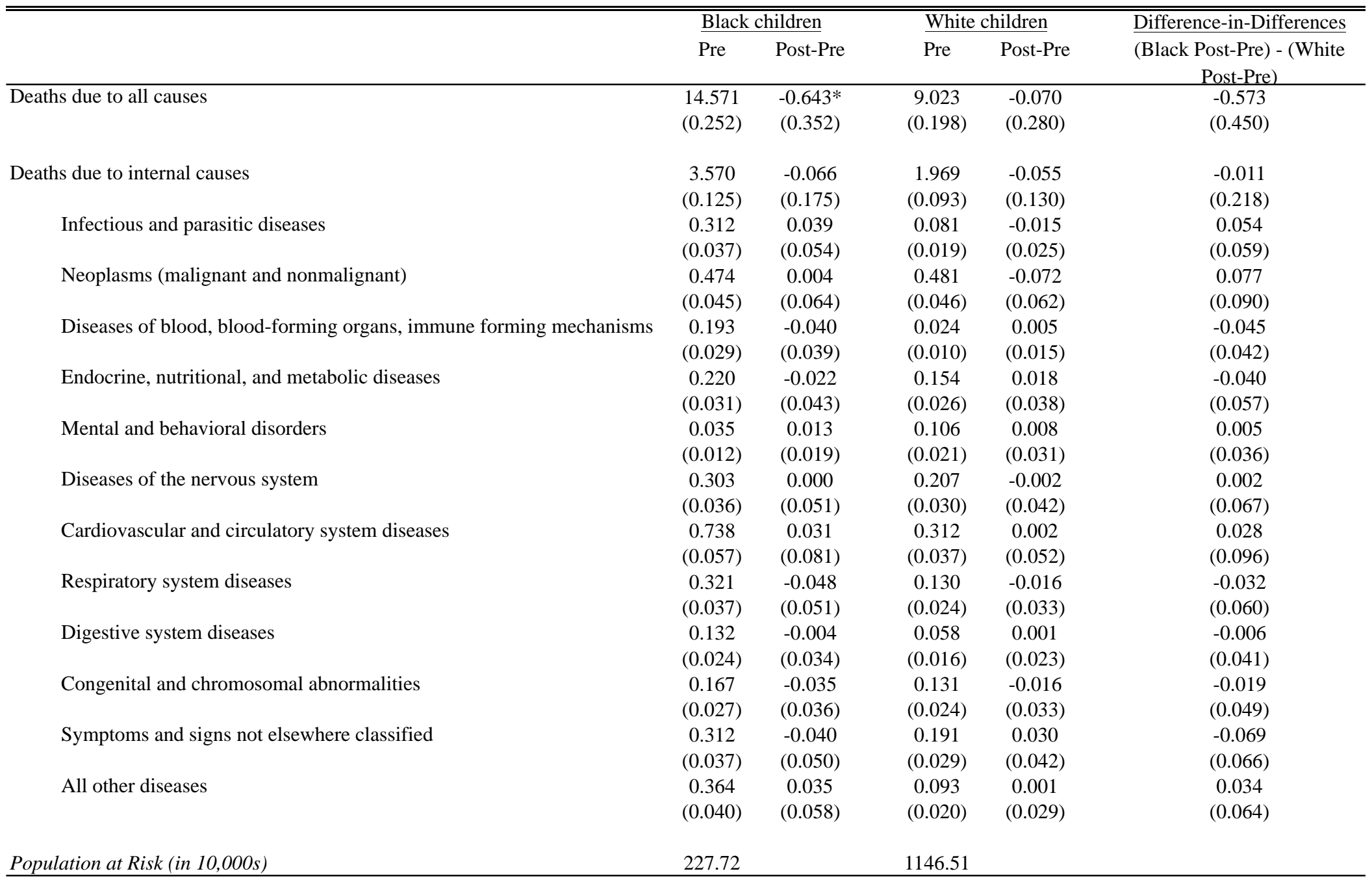

Notes: Mortality rates for each age group are calculated as the sum of the total number of deaths divided by the sum of the population at risk for those ages. Counts of death are from the National Vital Statistics System Multiple Cause of Death files for the years 1980 to 2007. The population at risk for each age is calculated as the population at birth minus the number of deaths for all preceding ages. Population counts at birth are from the NVSS Birth Date files for the years 1980 to 2007. Standard errors are calculated based on the binomial distribution, asterisks on differences indicate $* * * \mathrm{p}<0.01, * * \mathrm{p}<0.05, * \mathrm{p}<0.1$. 
Appendix Table 6. Comparison of Annual Rates of External-Cause Death for Children Born One Year Before and After Cutoff at Ages 19-22 by Race

\begin{tabular}{|c|c|c|c|c|c|}
\hline & \multicolumn{2}{|c|}{ Black children } & \multicolumn{2}{|c|}{ White children } & \multirow{2}{*}{$\begin{array}{c}\text { Difference-in-Differences } \\
\text { (Black Post-Pre) - (White Post- } \\
\text { Pre) }\end{array}$} \\
\hline & Pre & Post-Pre & Pre & Post-Pre & \\
\hline$\overline{\text { Deaths due to all causes }}$ & $\begin{array}{l}14.571 \\
(0.252)\end{array}$ & $\begin{array}{l}-0.643^{*} \\
(0.352)\end{array}$ & $\begin{array}{l}9.023 \\
(0.198)\end{array}$ & $\begin{array}{l}-0.070 \\
(0.280)\end{array}$ & $\begin{array}{l}-0.573 \\
(0.450)\end{array}$ \\
\hline Deaths due to external causes & $\begin{array}{l}10.424 \\
(0.213)\end{array}$ & $\begin{array}{l}-0.577^{*} \\
(0.305)\end{array}$ & $\begin{array}{c}7.054 \\
(0.175)\end{array}$ & $\begin{array}{l}-0.015 \\
(0.248)\end{array}$ & $\begin{array}{l}-0.561 \\
(0.393)\end{array}$ \\
\hline Accidents (unintentional injuries) & $\begin{array}{c}2.977 \\
(0.114)\end{array}$ & $\begin{array}{c}-0.483^{* * * *} \\
(0.167)\end{array}$ & $\begin{array}{c}4.847 \\
(0.145)\end{array}$ & $\begin{array}{l}-0.036 \\
(0.205)\end{array}$ & $\begin{array}{c}-0.447^{*} \\
(0.265)\end{array}$ \\
\hline Nontransport accidents & $\begin{array}{c}0.676 \\
(0.054)\end{array}$ & $\begin{array}{c}-0.202 * * \\
(0.082)\end{array}$ & $\begin{array}{l}1.369 \\
(0.077)\end{array}$ & $\begin{array}{c}0.109 \\
(0.111)\end{array}$ & $\begin{array}{c}-0.311 * * \\
(0.138)\end{array}$ \\
\hline Falls & $\begin{array}{c}0.018 \\
(0.009)\end{array}$ & $\begin{array}{l}-0.013 \\
(0.015)\end{array}$ & $\begin{array}{c}0.072 \\
(0.018)\end{array}$ & $\begin{array}{c}0.014 \\
(0.026)\end{array}$ & $\begin{array}{l}-0.027 \\
(0.030)\end{array}$ \\
\hline Accidental discharge of firearms & $\begin{array}{c}0.088 \\
(0.020)\end{array}$ & $\begin{array}{c}-0.070 * * \\
(0.033)\end{array}$ & $\begin{array}{c}0.049 \\
(0.015)\end{array}$ & $\begin{array}{c}0.002 \\
(0.021)\end{array}$ & $\begin{array}{l}-0.072^{*} \\
(0.039)\end{array}$ \\
\hline Accidental poisoning and exposure to noxious substances & $\begin{array}{c}0.198 \\
(0.029)\end{array}$ & $\begin{array}{l}-0.062 \\
(0.045)\end{array}$ & $\begin{array}{c}0.908 \\
(0.063)\end{array}$ & $\begin{array}{c}0.070 \\
(0.091)\end{array}$ & $\begin{array}{c}-0.132 \\
(0.101)\end{array}$ \\
\hline Other and unspecified nontransport accidents & $\begin{array}{c}0.145 \\
(0.025)\end{array}$ & $\begin{array}{l}-0.026 \\
(0.037)\end{array}$ & $\begin{array}{c}0.181 \\
(0.028)\end{array}$ & $\begin{array}{c}0.006 \\
(0.040)\end{array}$ & $\begin{array}{l}-0.032 \\
(0.055)\end{array}$ \\
\hline Intentional self-harm (suicide) & $\begin{array}{c}0.821 \\
(0.060)\end{array}$ & $\begin{array}{l}-0.136 \\
(0.088)\end{array}$ & $\begin{array}{l}1.292 \\
(0.075)\end{array}$ & $\begin{array}{c}0.065 \\
(0.107)\end{array}$ & $\begin{array}{l}-0.201 \\
(0.139)\end{array}$ \\
\hline Assault (homicide) & $\begin{array}{c}6.424 \\
(0.167)\end{array}$ & $\begin{array}{c}0.008 \\
(0.236)\end{array}$ & $\begin{array}{c}0.686 \\
(0.055)\end{array}$ & $\begin{array}{l}-0.035 \\
(0.076)\end{array}$ & $\begin{array}{c}0.043 \\
(0.248)\end{array}$ \\
\hline Legal intervention & $\begin{array}{c}0.061 \\
(0.016)\end{array}$ & $\begin{array}{l}-0.013 \\
(0.024)\end{array}$ & $\begin{array}{c}0.028 \\
(0.011)\end{array}$ & $\begin{array}{l}-0.010 \\
(0.014)\end{array}$ & $\begin{array}{l}-0.003 \\
(0.028)\end{array}$ \\
\hline Events of undetermined intent & $\begin{array}{c}0.119 \\
(0.023)\end{array}$ & $\begin{array}{c}0.040 \\
(0.029)\end{array}$ & $\begin{array}{c}0.191 \\
(0.029)\end{array}$ & $\begin{array}{c}0.002 \\
(0.041)\end{array}$ & $\begin{array}{c}0.038 \\
(0.050)\end{array}$ \\
\hline
\end{tabular}

Notes: Mortality rates for each age group are calculated as the sum of the total number of deaths divided by the sum of the population at risk for those ages. Counts of death are from the National Vital Statistics System Multiple Cause of Death files for the years 1980 to 2007. The population at risk for each age is calculated as the population at birth minus the number of deaths for all preceding ages. Population counts at birth are from the NVSS Birth Date files for the years 1980 to 2007. Standard errors are calculated based on the binomial distribution, asterisks on differences indicate *** $\mathrm{p}<0.01,{ }^{*} \mathrm{p}<0.05$, * $\mathrm{p}<0.1$. 
Appendix Figure 1: Child Mortality from All Causes by State Group

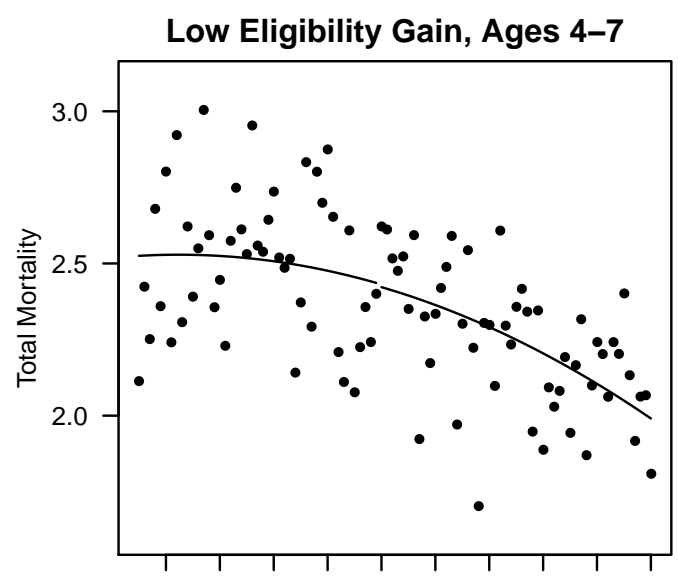

Jun-80 Feb-82 Oct-83 Jun-85 Feb-87

Low Eligibility Gain, Ages 8-14

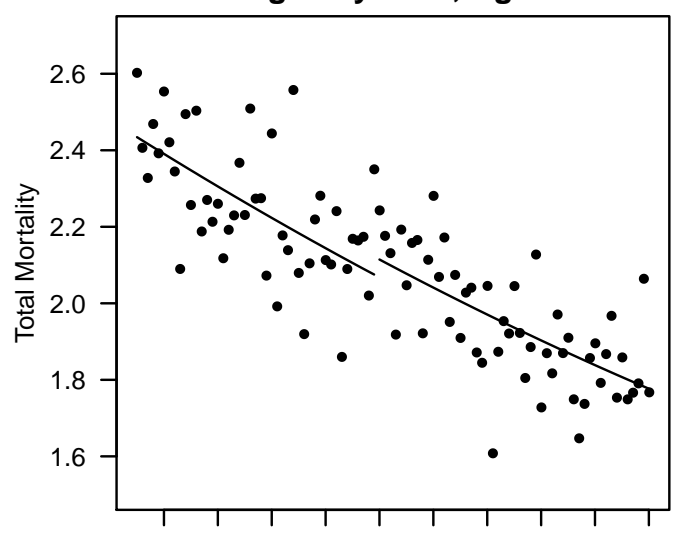

Jun-80 Feb-82 Oct-83 Jun-85 Feb-87

Low Eligibility Gain, Ages 15-18

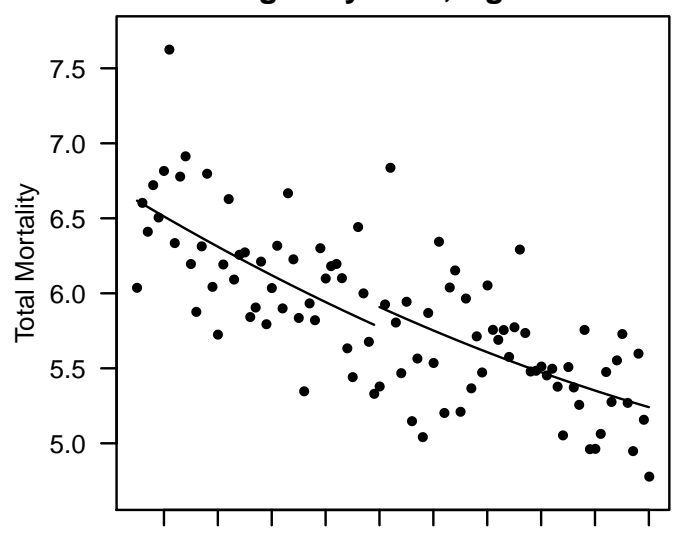

Jun-80 Feb-82 Oct-83 Jun-85 Feb-87

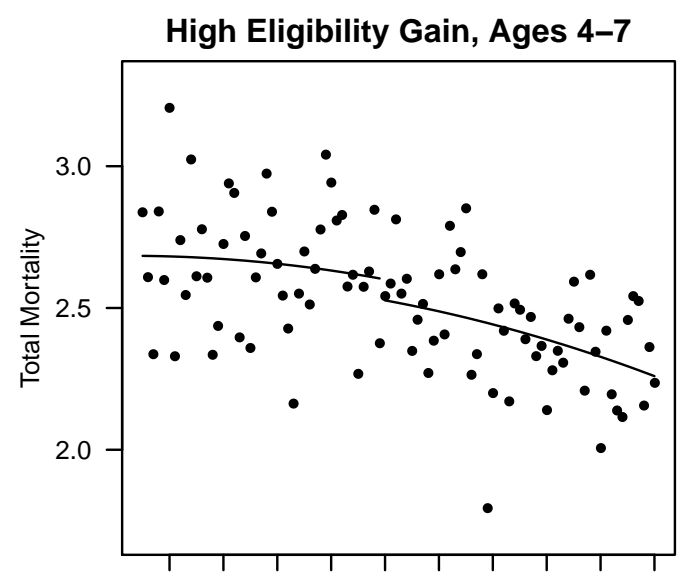

Jun-80 Feb-82 Oct-83 Jun-85 Feb-87

High Eligibility Gain, Ages 8-14

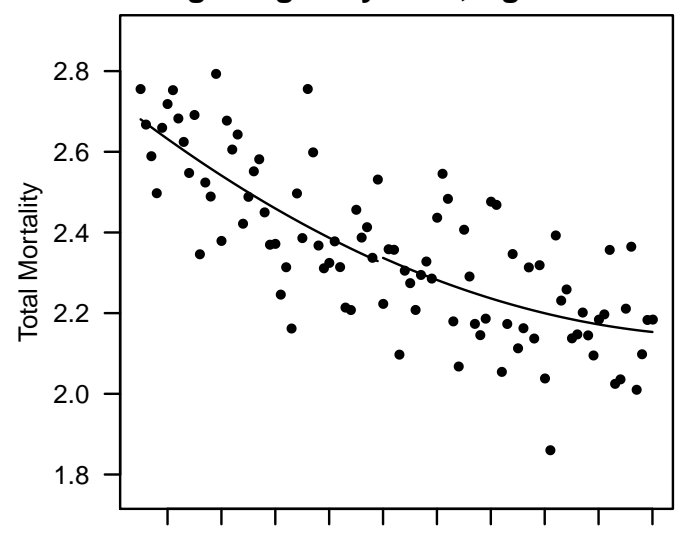

Jun-80 Feb-82 Oct-83 Jun-85 Feb-87

High Eligibility Gain, Ages 15-18

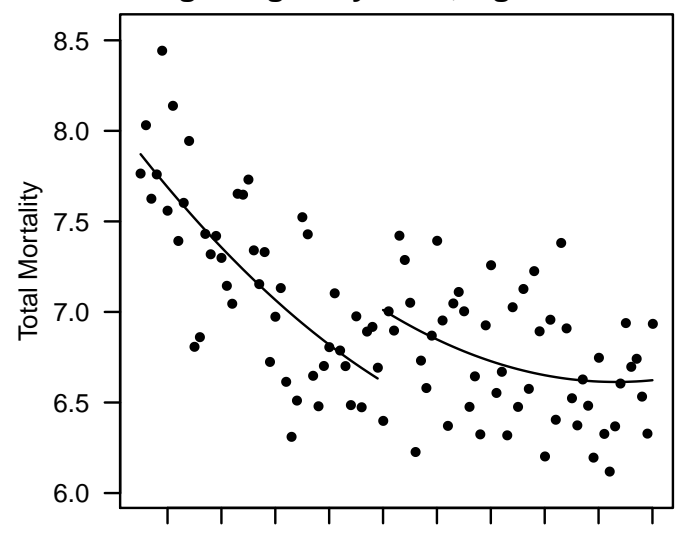

Jun-80 Feb-82 Oct-83 Jun-85 Feb-87

Mortality rates by cohort (per 10,000 children) were constructed using Multiple Cause of Death Data files for the years 19802006 and Birth Data files for 1980-1987. Points represent means of the age-specific mortality rates for each birth cohort, as described in the text. The lines are fitted values from a regression that includes a quadratic in birth cohort and a dummy variable for children born after September 30, 1983. 
Appendix Figure 2: Child Mortality from Internal Causes by State Group

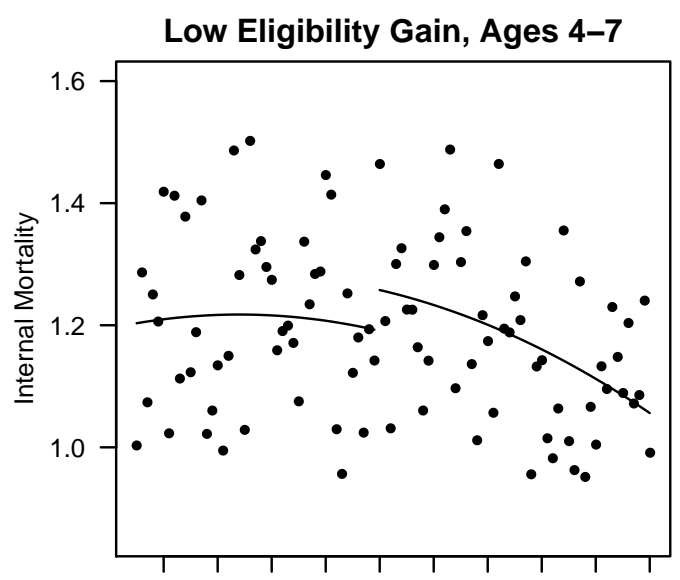

Jun-80 Feb-82 Oct-83 Jun-85 Feb-87
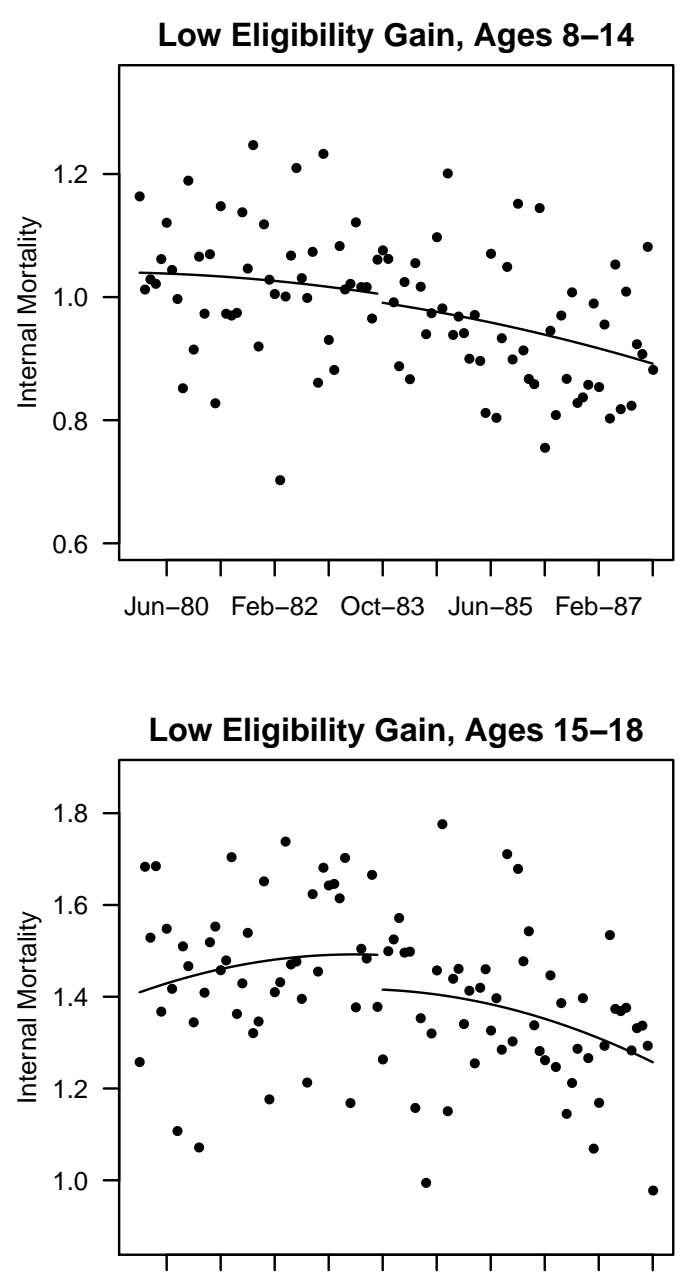

Jun-80 Feb-82 Oct-83 Jun-85 Feb-87

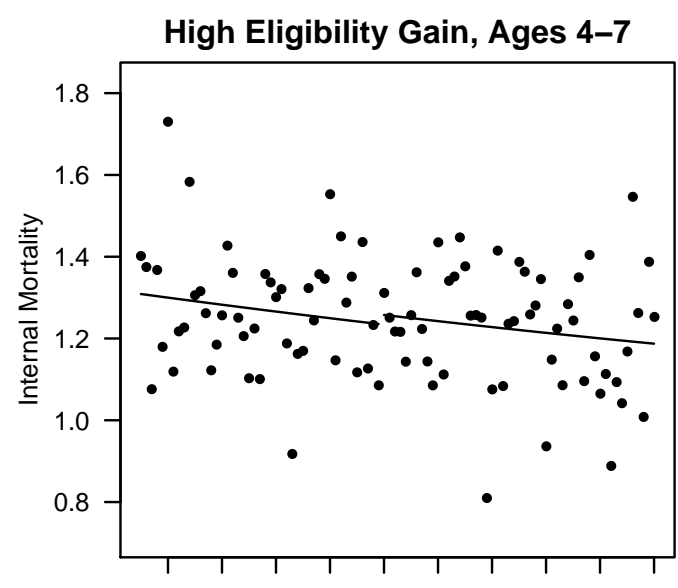

Jun-80 Feb-82 Oct-83 Jun-85 Feb-87

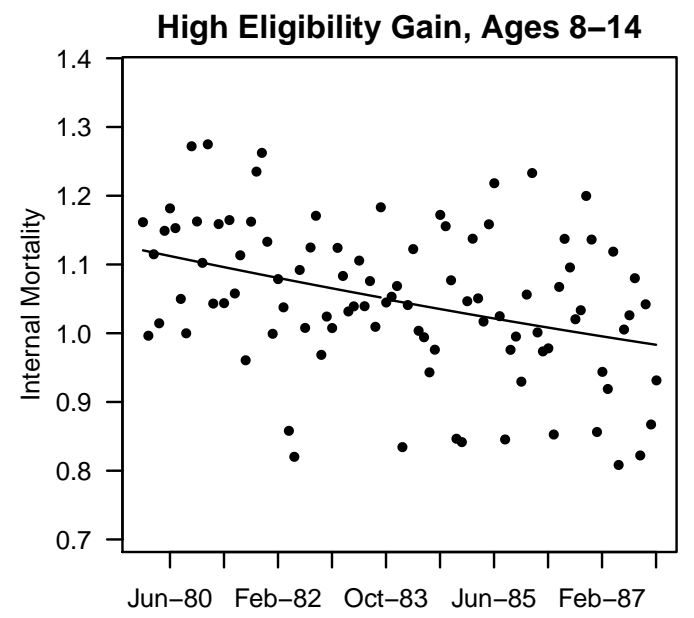

High Eligibility Gain, Ages 15-18

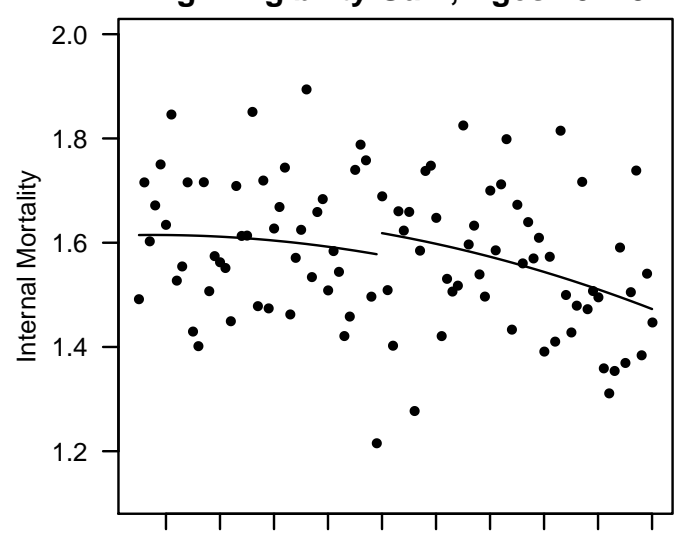

Jun-80 Feb-82 Oct-83 Jun-85 Feb-87

Mortality rates by cohort (per 10,000 children) were constructed using Multiple Cause of Death Data files for the years 19802006 and Birth Data files for 1980-1987. Points represent means of the age-specific mortality rates for each birth cohort, as described in the text. The lines are fitted values from a regression that includes a quadratic in birth cohort and a dummy variable for children born after September 30, 1983. 
Appendix Figure 3: Child Mortality from External Causes by State Group

Low Eligibility Gain, Ages 4-7

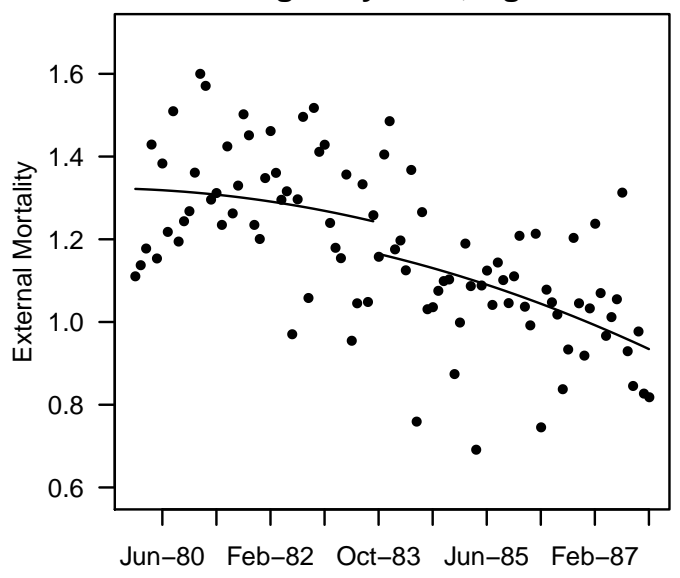

Low Eligibility Gain, Ages 8-14

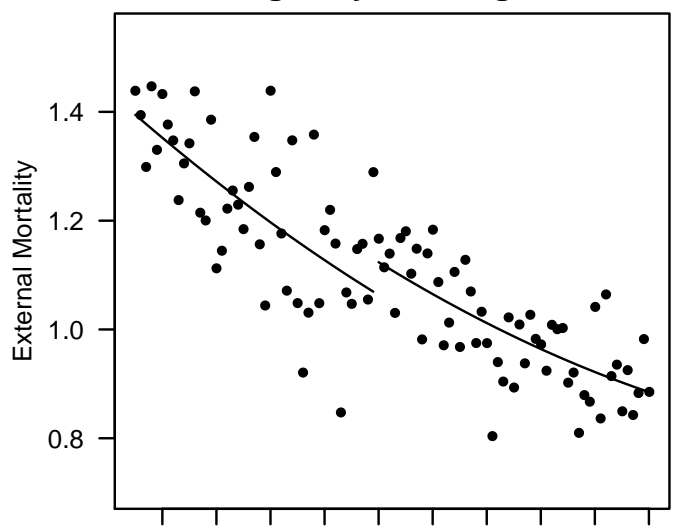

Jun-80 Feb-82 Oct-83 Jun-85 Feb-87

Low Eligibility Gain, Ages 15-18

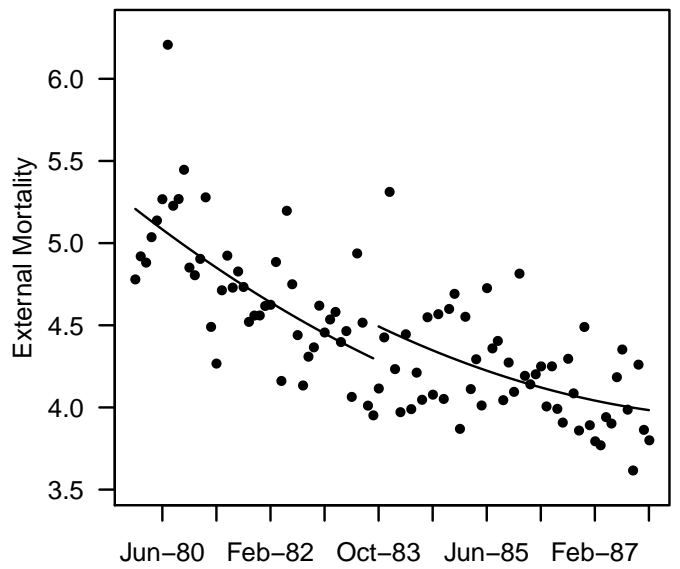

High Eligibility Gain, Ages 4-7

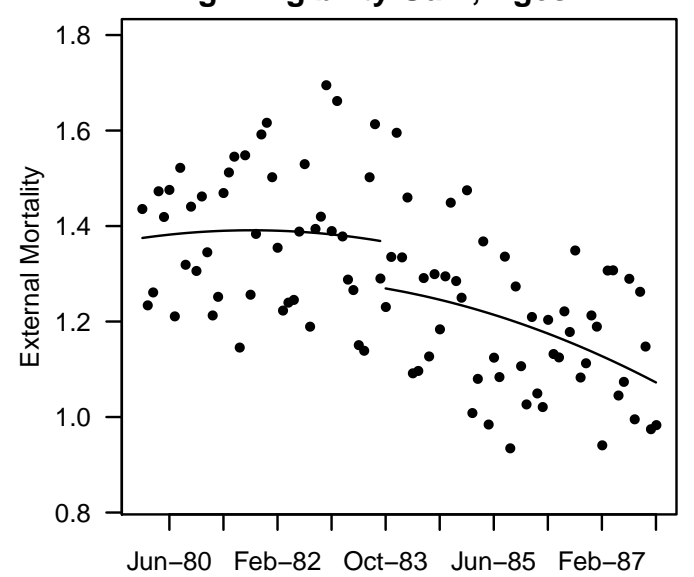

High Eligibility Gain, Ages 8-14

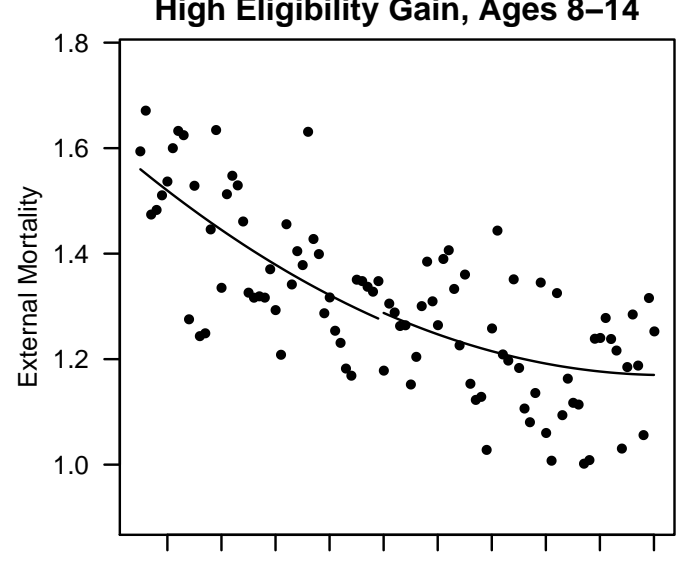

Jun-80 Feb-82 Oct-83 Jun-85 Feb-87

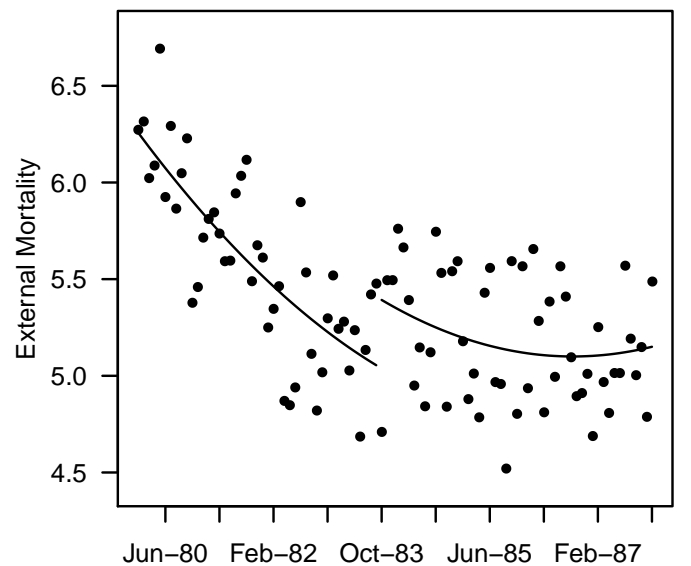

Mortality rates by cohort (per 10,000 children) were constructed using Multiple Cause of Death Data files for the years 19802006 and Birth Data files for 1980-1987. Points represent means of the age-specific mortality rates for each birth cohort, as described in the text. The lines are fitted values from a regression that includes a quadratic in birth cohort and a dummy variable for children born after September 30, 1983. 
Appendix Figure 4: Mortality from Internal Causes for Black Children by State Group

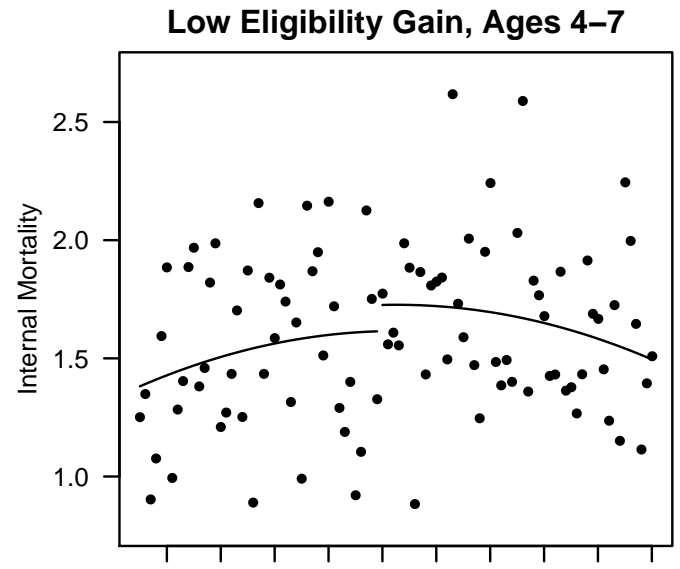

Jun-80 Feb-82 Oct-83 Jun-85 Feb-87

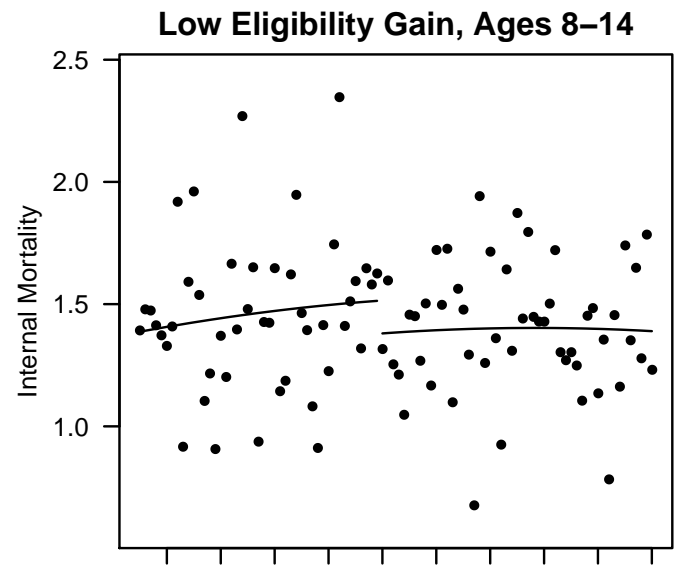

Jun-80 Feb-82 Oct-83 Jun-85 Feb-87

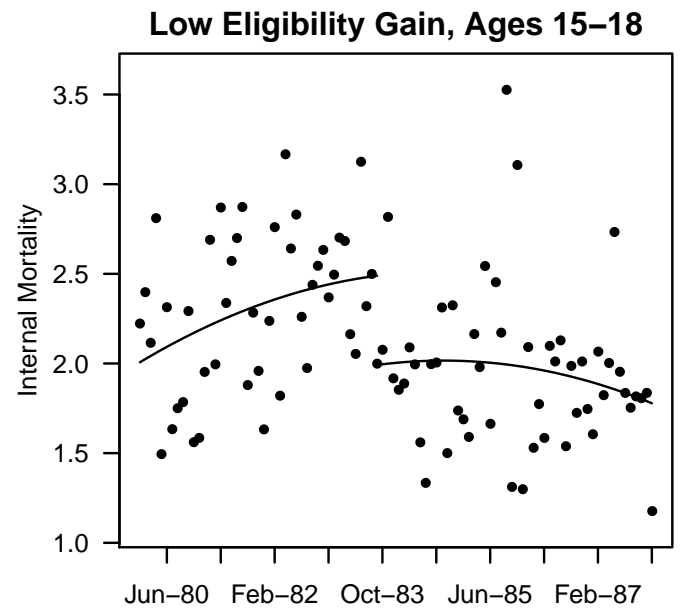

High Eligibility Gain, Ages 4-7

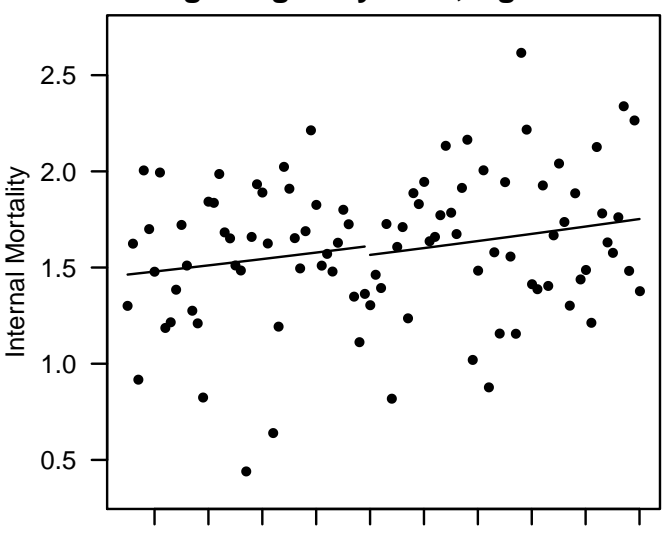

Jun-80 Feb-82 Oct-83 Jun-85 Feb-87

High Eligibility Gain, Ages 8-14

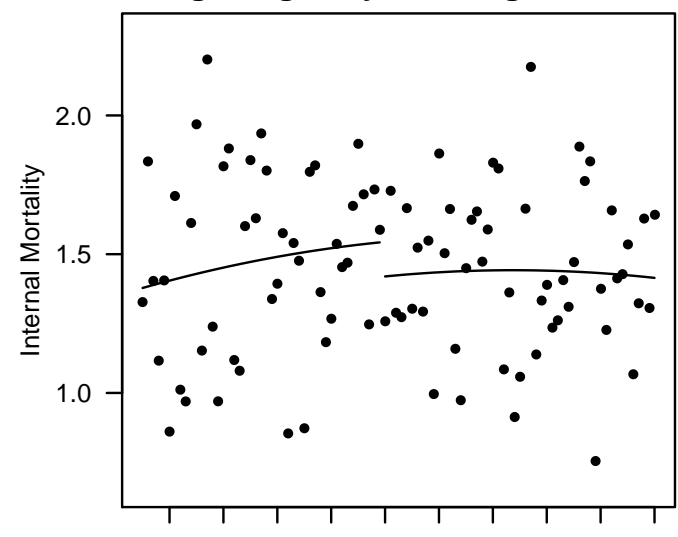

Jun-80 Feb-82 Oct-83 Jun-85 Feb-87

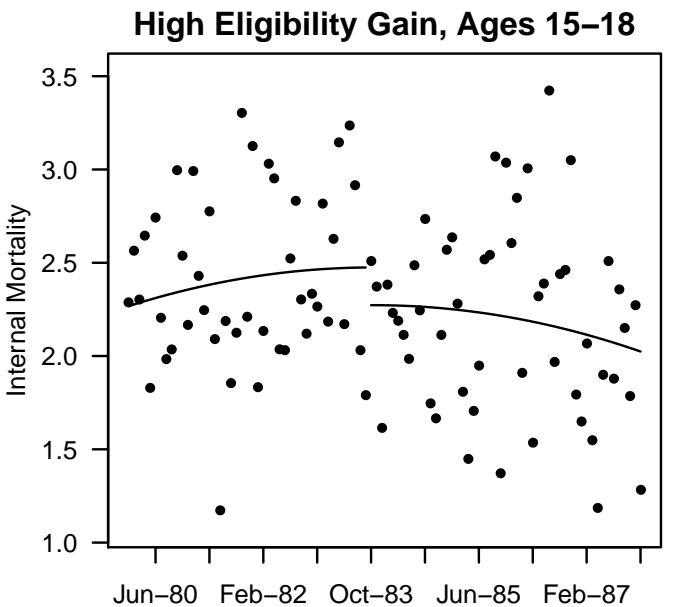

Mortality rates by cohort (per 10,000 children) were constructed using Multiple Cause of Death Data files for the years 19802006 and Birth Data files for 1980-1987. Points represent means of the age-specific mortality rates for each birth cohort, as described in the text. The lines are fitted values from a regression that includes a quadratic in birth cohort and a dummy variable for children born after September 30, 1983. 
Appendix Figure 5: Mortality from Internal Causes for White Children by State Group
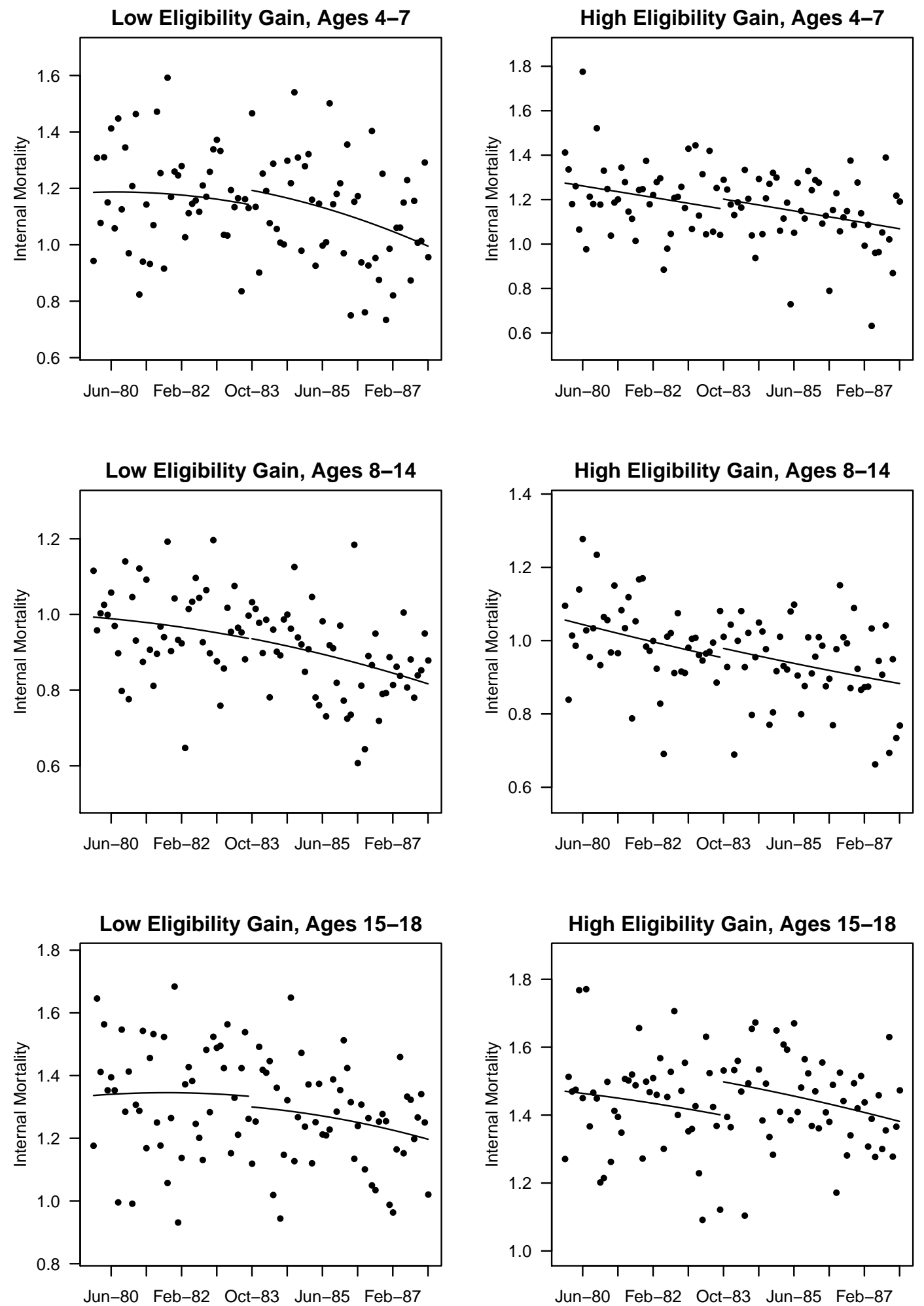

Mortality rates by cohort (per 10,000 children) were constructed using Multiple Cause of Death Data files for the years 19802006 and Birth Data files for 1980-1987. Points represent means of the age-specific mortality rates for each birth cohort, as described in the text. The lines are fitted values from a regression that includes a quadratic in birth cohort and a dummy variable for children born after September 30, 1983. 
Appendix Figure 6: Mortality from External Causes for Black Children by State Group

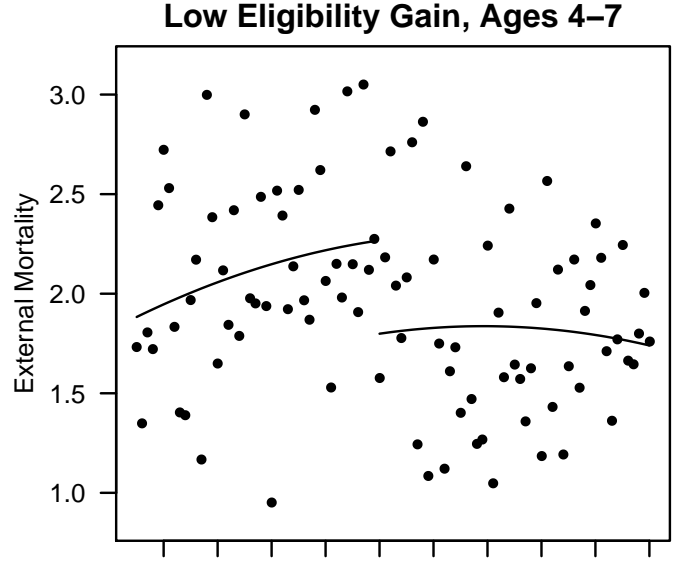

Jun-80 Feb-82 Oct-83 Jun-85 Feb-87

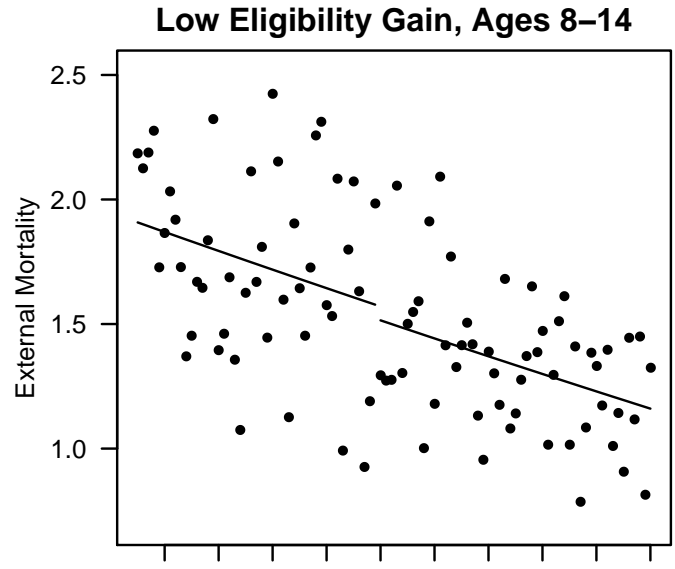

Jun-80 Feb-82 Oct-83 Jun-85 Feb-87

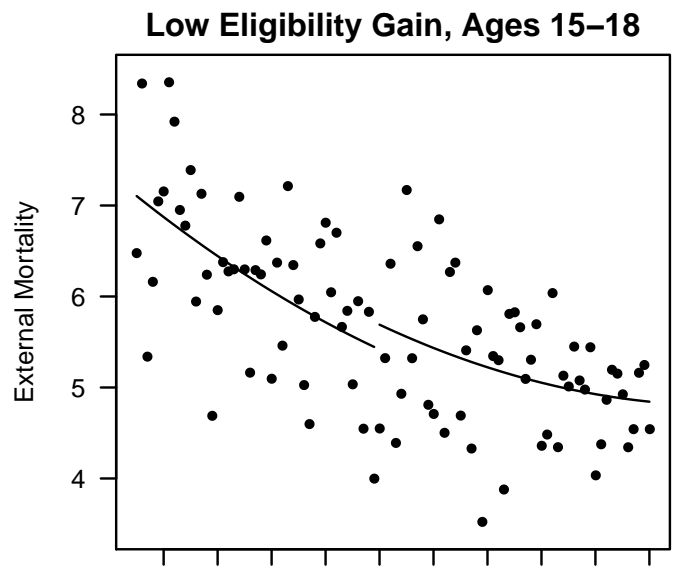

Jun-80 Feb-82 Oct-83 Jun-85 Feb-87
High Eligibility Gain, Ages 4-7

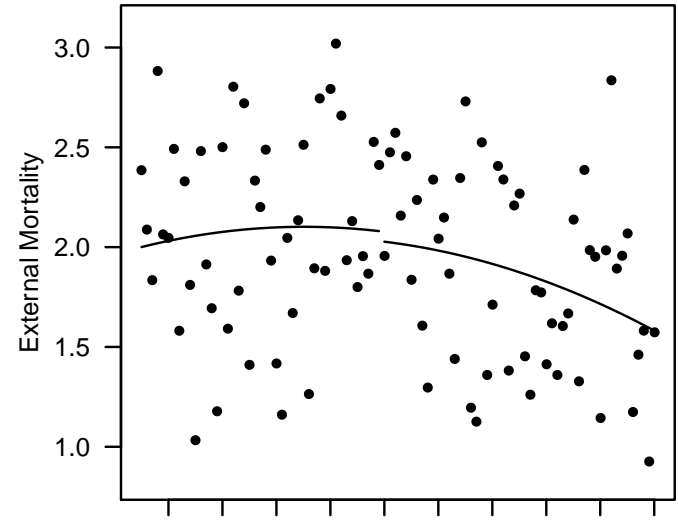

Jun-80 Feb-82 Oct-83 Jun-85 Feb-87

High Eligibility Gain, Ages 8-14

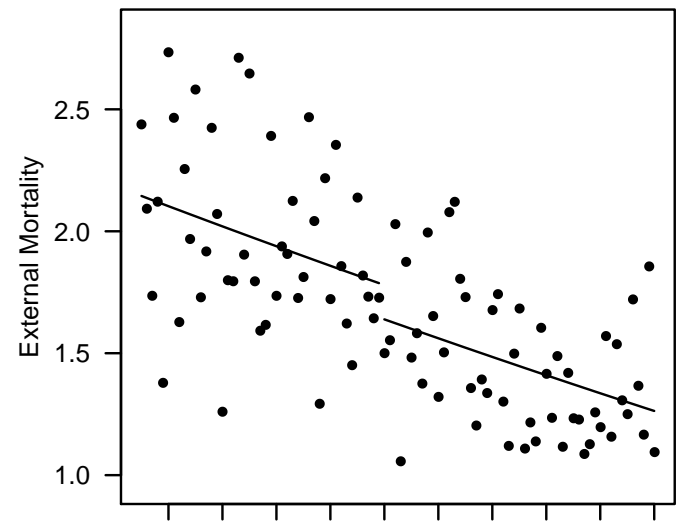

Jun-80 Feb-82 Oct-83 Jun-85 Feb-87

High Eligibility Gain, Ages 15-18

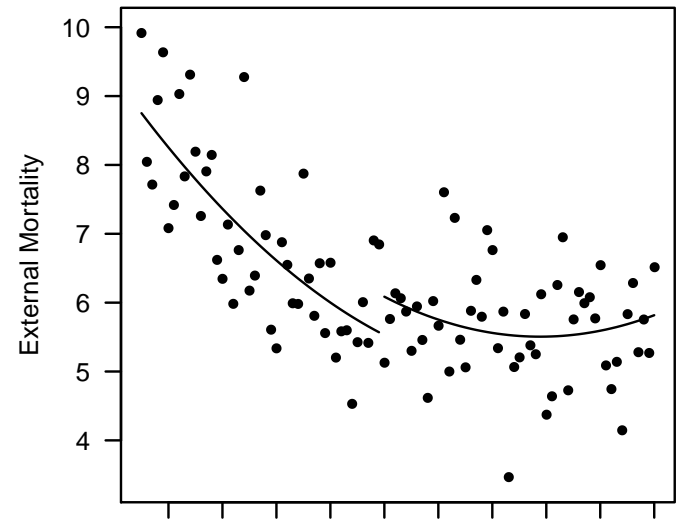

Jun-80 Feb-82 Oct-83 Jun-85 Feb-87

Mortality rates by cohort (per 10,000 children) were constructed using Multiple Cause of Death Data files for the years 19802006 and Birth Data files for 1980-1987. Points represent means of the age-specific mortality rates for each birth cohort, as described in the text. The lines are fitted values from a regression that includes a quadratic in birth cohort and a dummy variable for children born after September 30, 1983. 
Appendix Figure 7: Mortality from External Causes for White Children by State Group
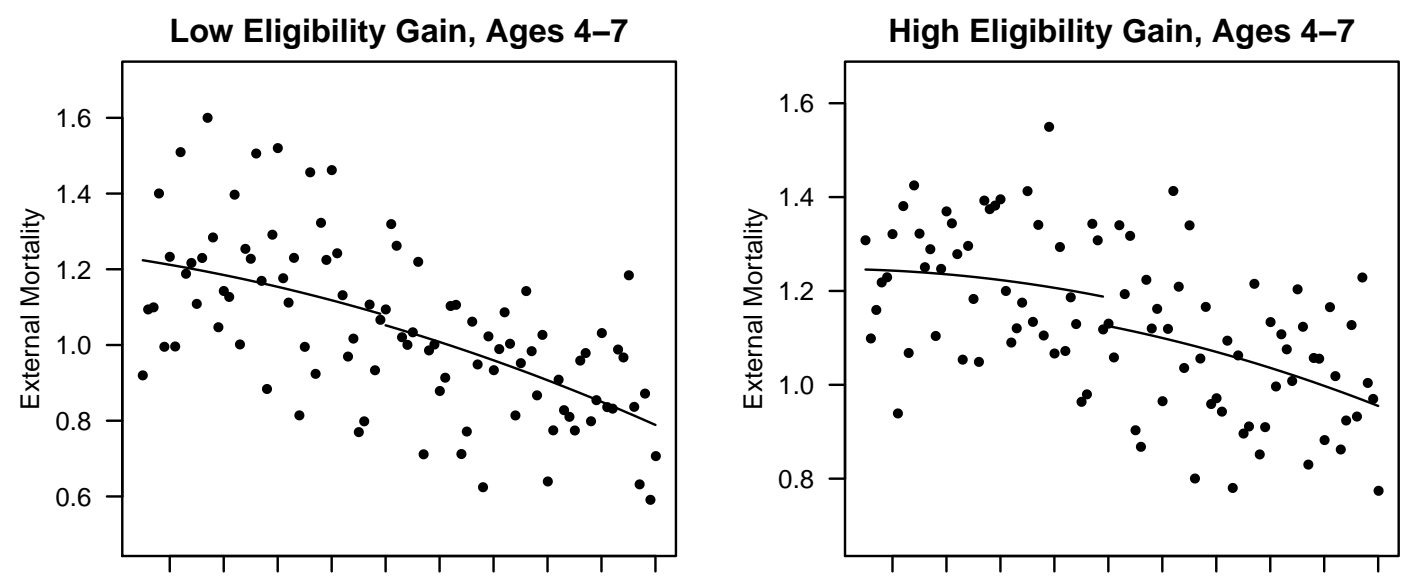

Jun-80 Feb-82 Oct-83 Jun-85 Feb-87

Jun-80 Feb-82 Oct-83 Jun-85 Feb-87
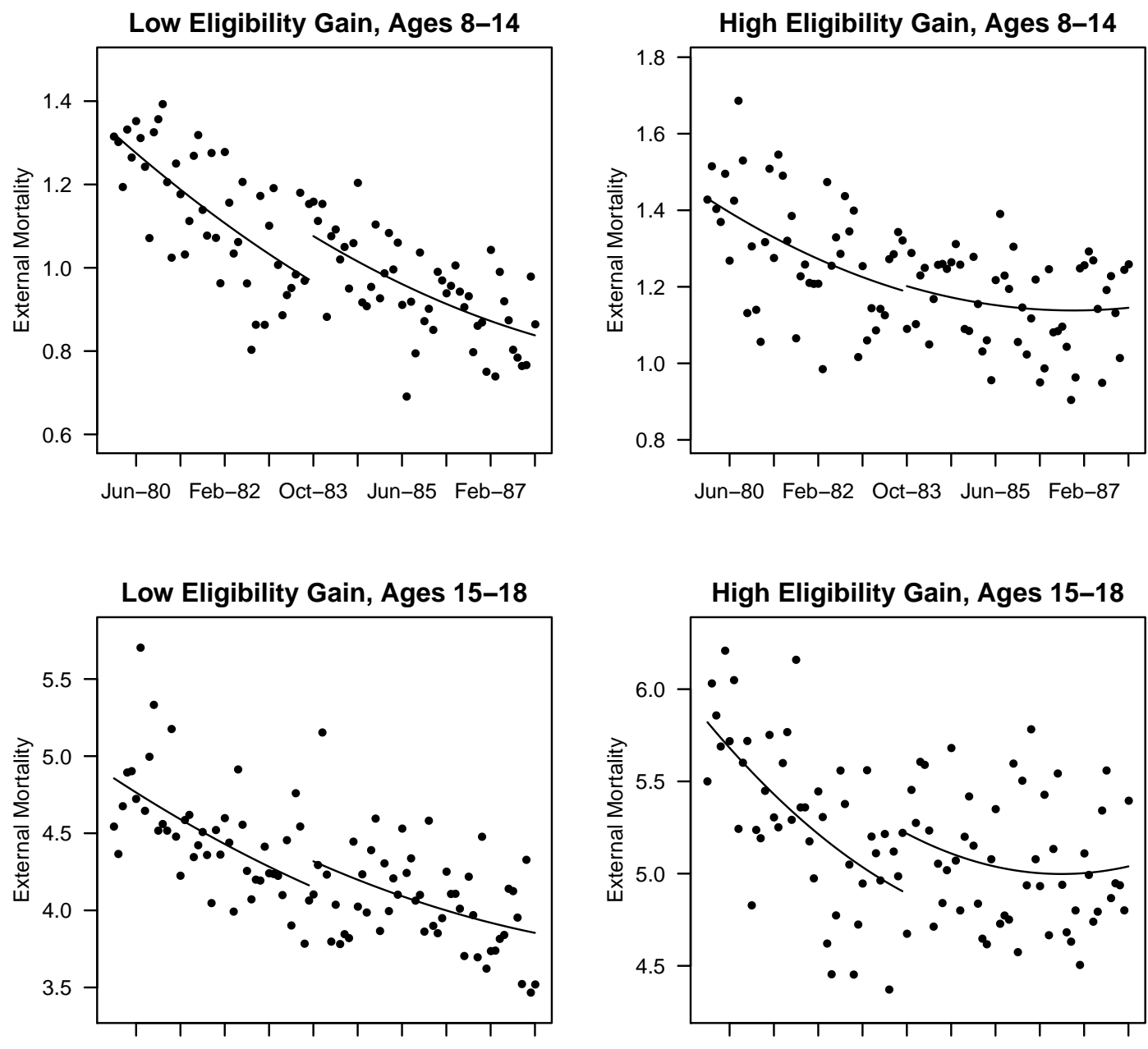

Jun-80 Feb-82 Oct-83 Jun-85 Feb-87

Jun-80 Feb-82 Oct-83 Jun-85 Feb-87

Mortality rates by cohort (per 10,000 children) were constructed using Multiple Cause of Death Data files for the years 19802006 and Birth Data files for 1980-1987. Points represent means of the age-specific mortality rates for each birth cohort, as described in the text. The lines are fitted values from a regression that includes a quadratic in birth cohort and a dummy variable for children born after September 30, 1983. 